\title{
Synthesis of acyl fluorides from carboxylic acids using a NaF-assisted deoxofluorination with XtalFluor-E
}

\author{
Marie Gonay, Chloé Batisse and Jean-François Paquin* \\ CGCC, PROTEO, Département de chimie, Université Laval, 1045 avenue de la \\ Médecine, Québec, \\ Québec, G1V 0A6, Canada \\ *Corresponding author: jean-francois.paquin@ chm.ulaval.ca
}

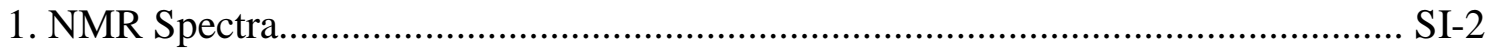




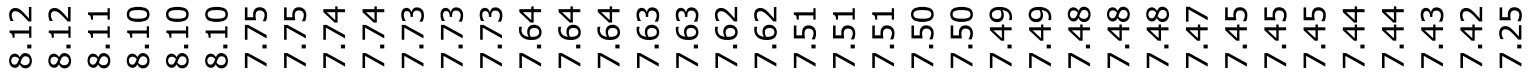

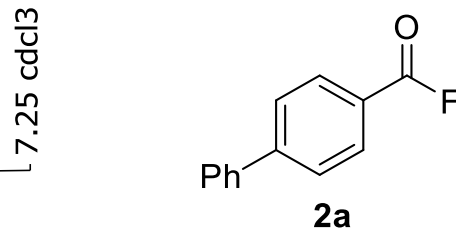

${ }^{1} \mathrm{H}$ NMR $\left(500 \mathrm{MHz}, \mathrm{CDCl}_{3}\right)$

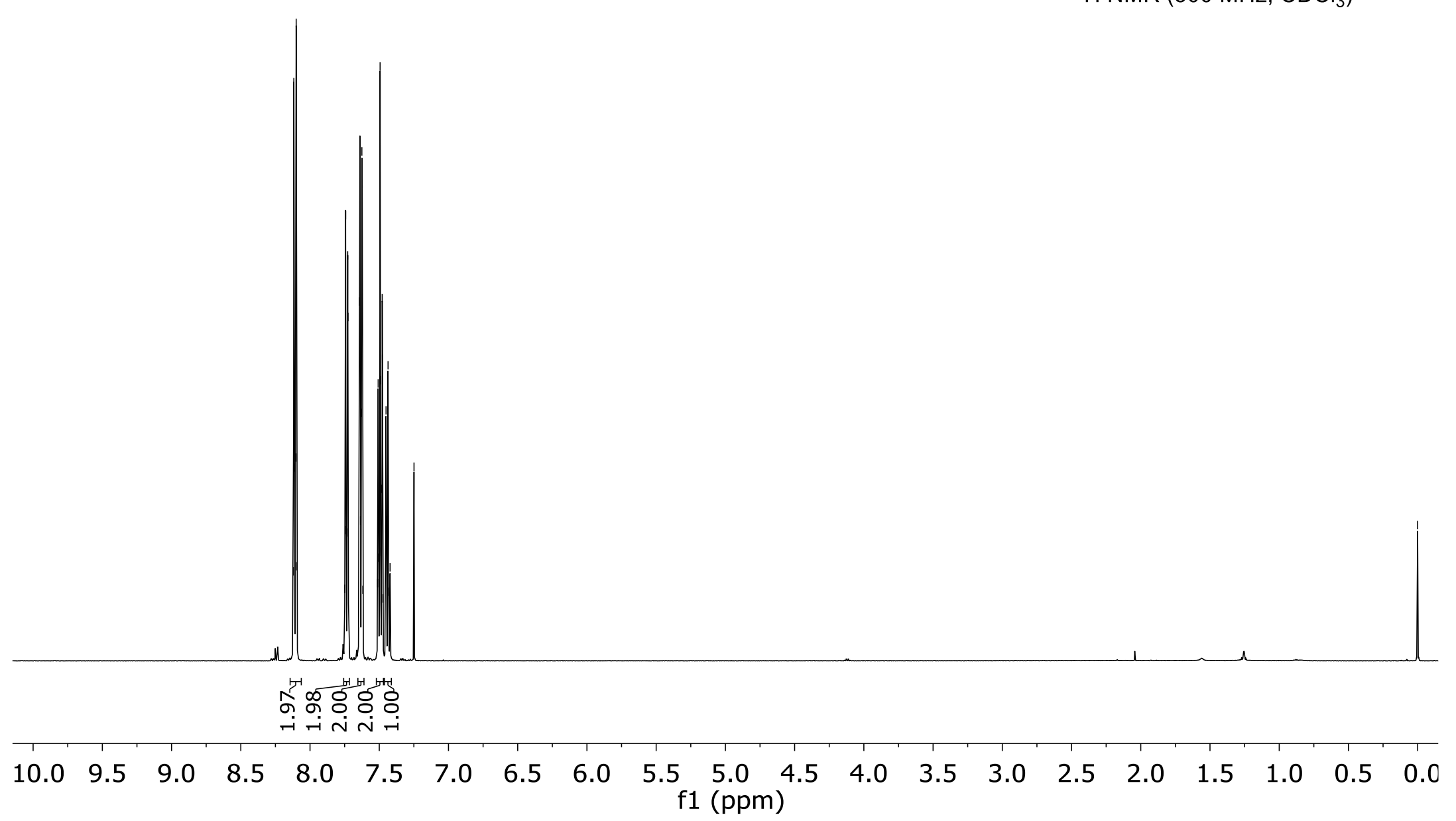


$\stackrel{-1}{\stackrel{-1}{\infty}} \underset{+}{+}$

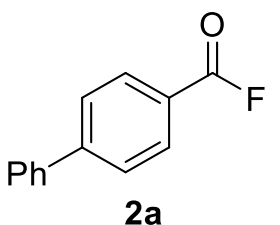

${ }^{19} \mathrm{~F}$ NMR $\left(470 \mathrm{MHz}, \mathrm{CDCl}_{3}\right)$

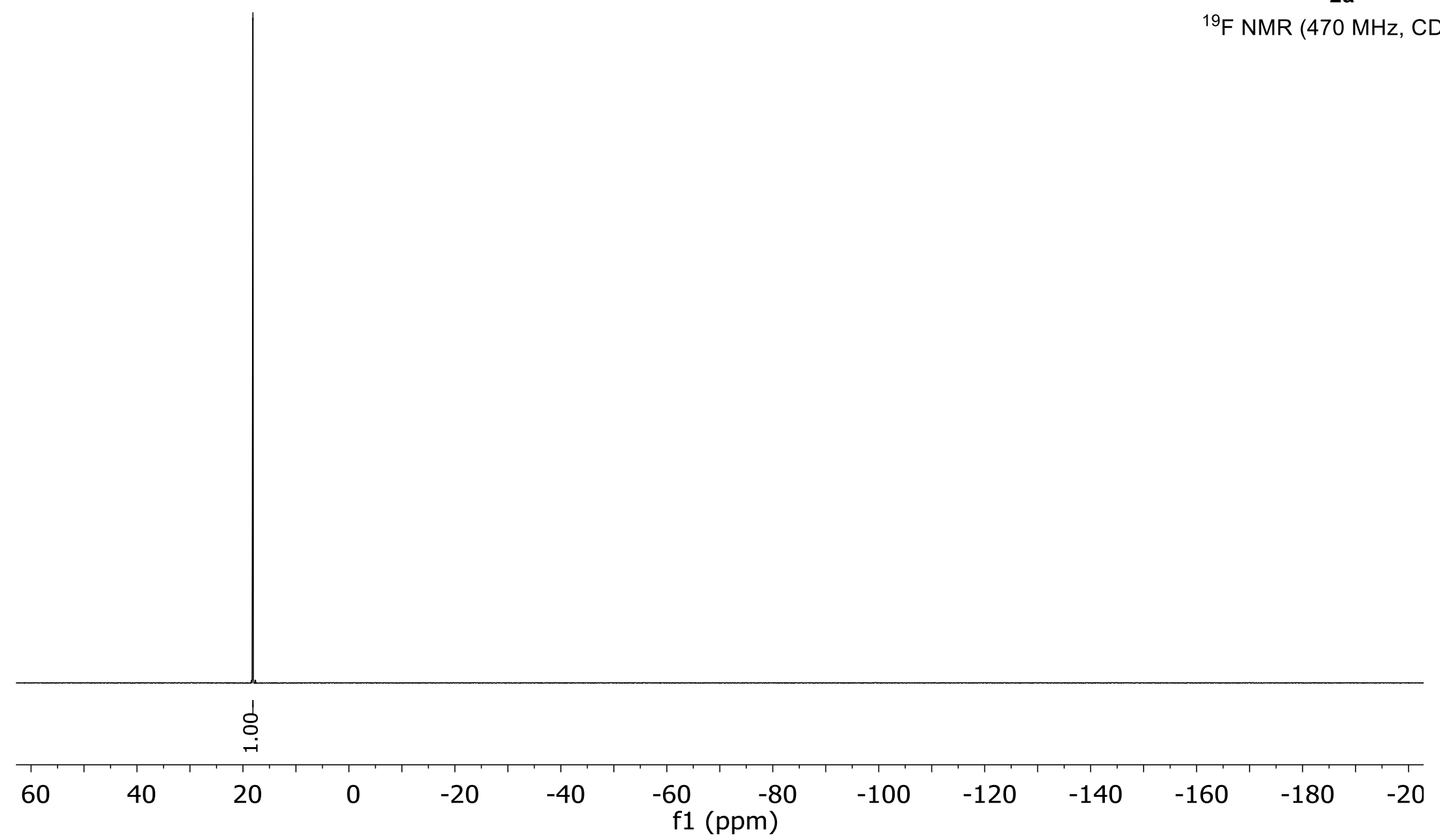



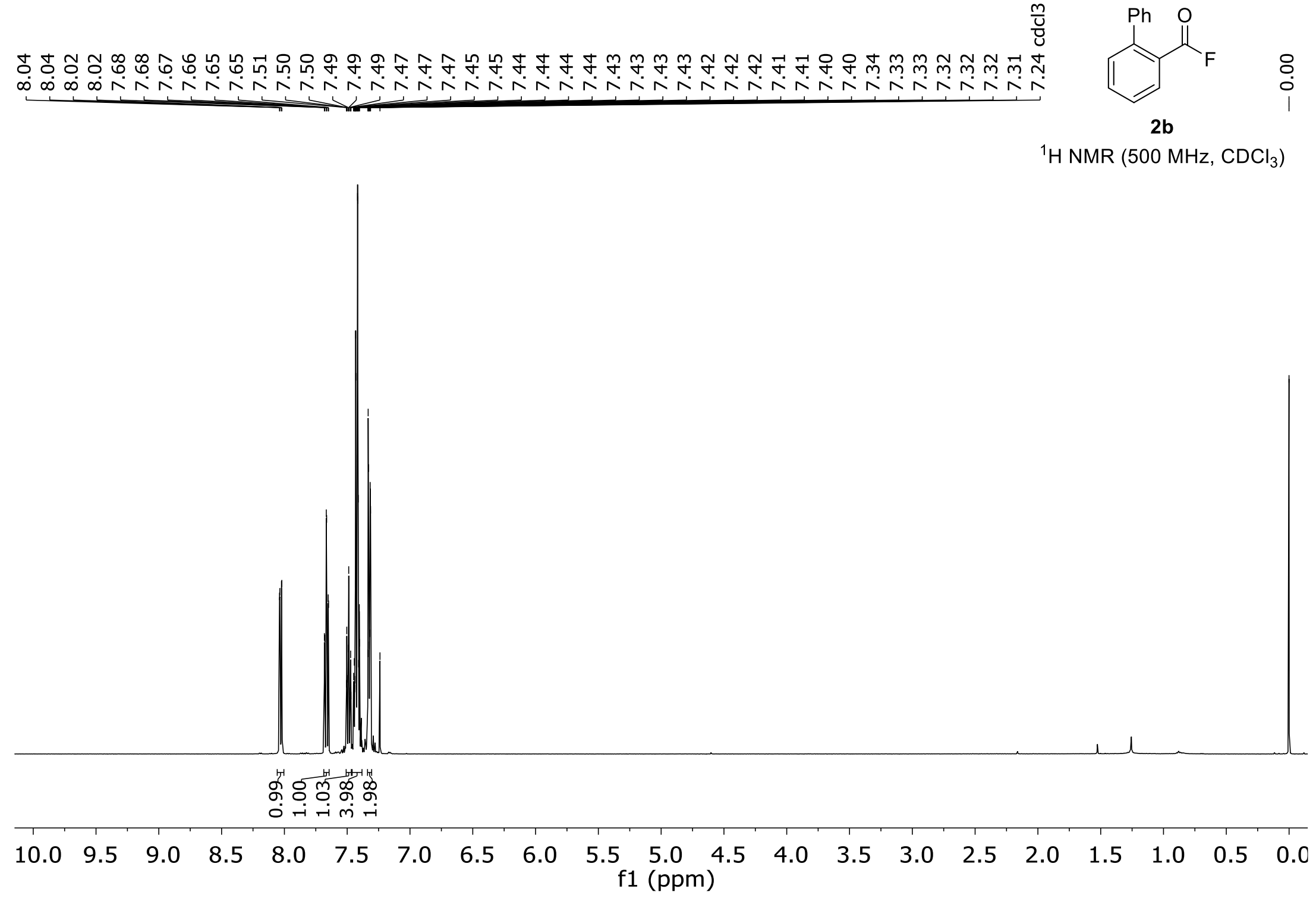
$\stackrel{\circ}{\stackrel{\rho}{m}}$

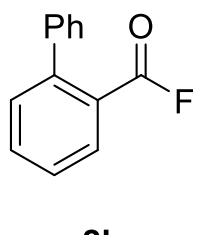

2b

${ }^{19} \mathrm{~F} \mathrm{NMR}\left(470 \mathrm{MHz}, \mathrm{CDCl}_{3}\right.$ )

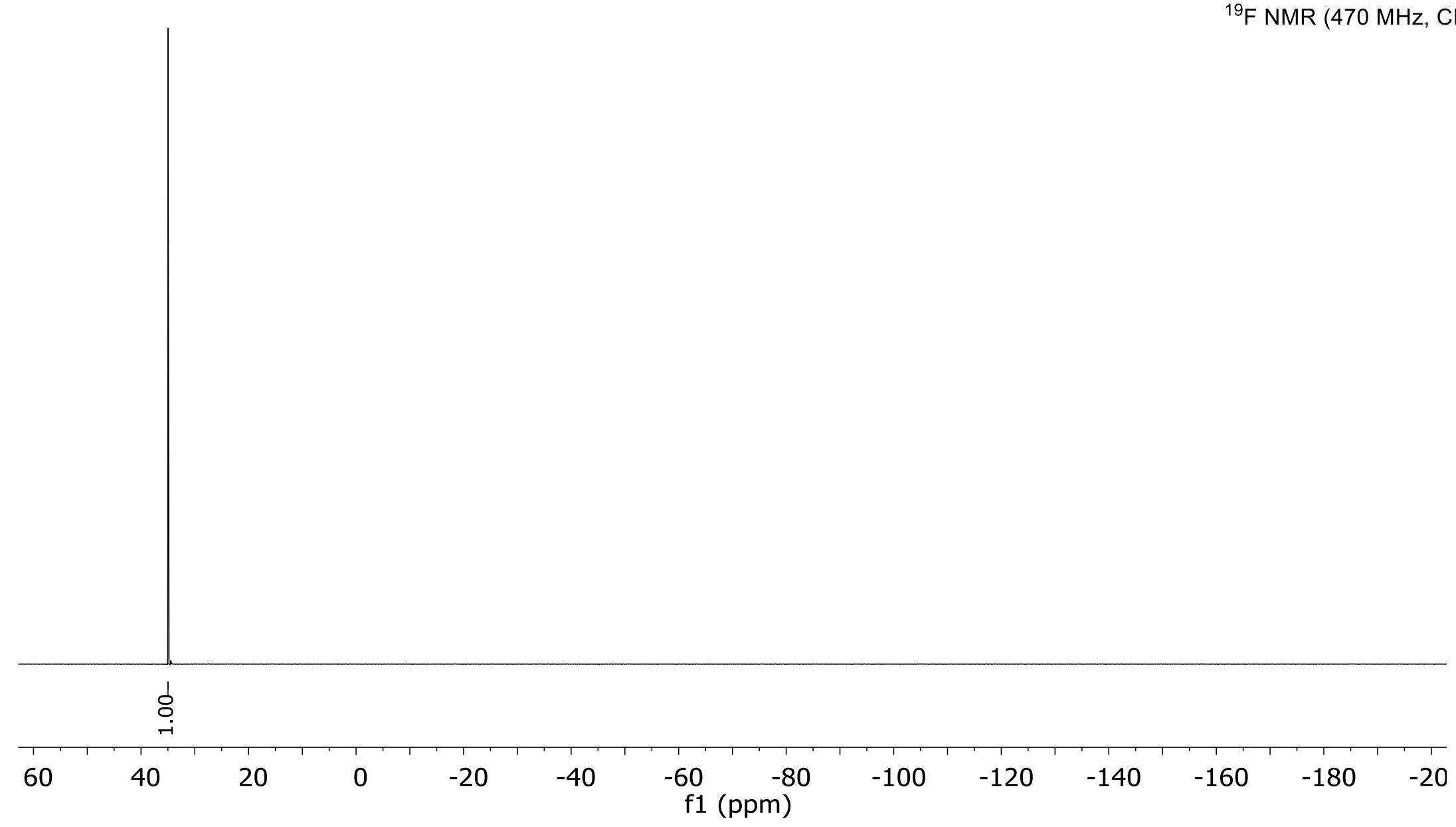




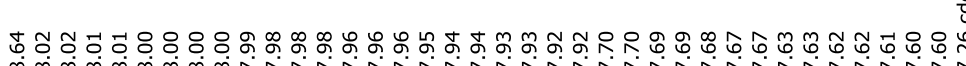

$\sqrt{\frac{10}{3}}$

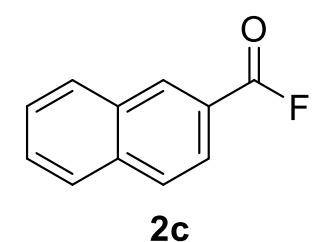

${ }^{1} \mathrm{H}$ NMR $\left(500 \mathrm{MHz}, \mathrm{CDCl}_{3}\right)$

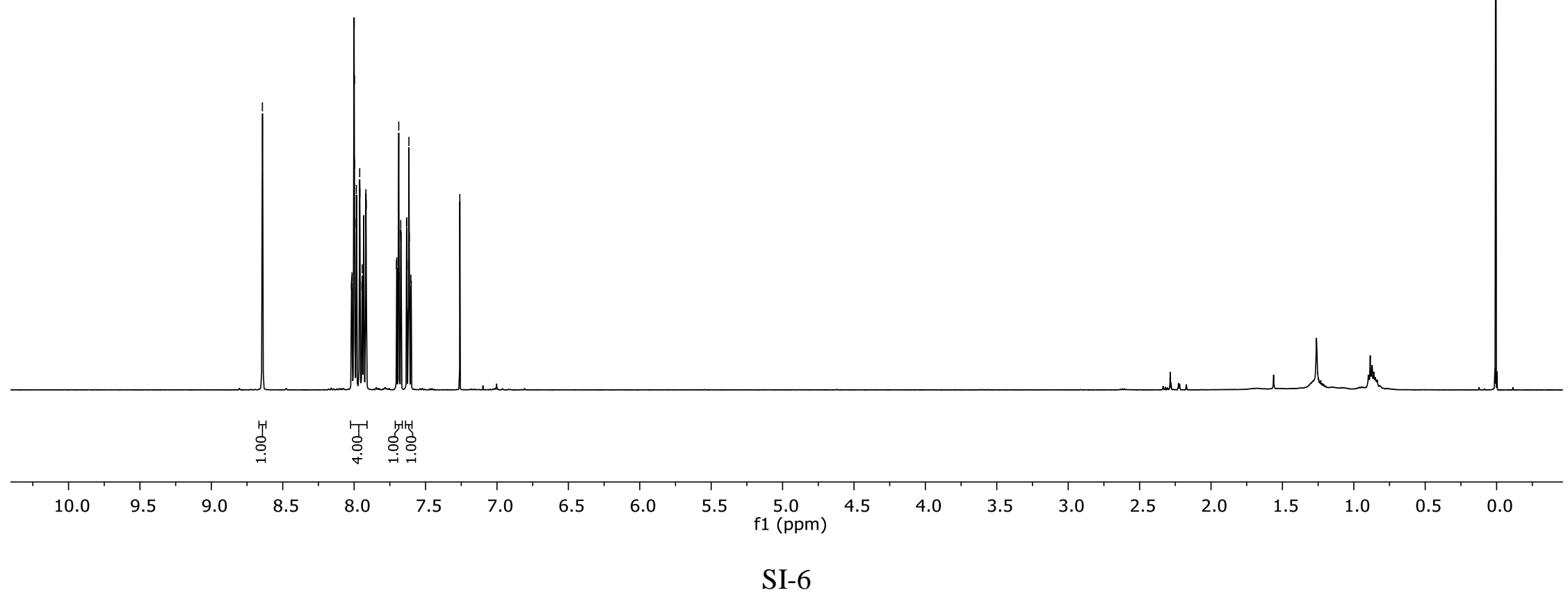




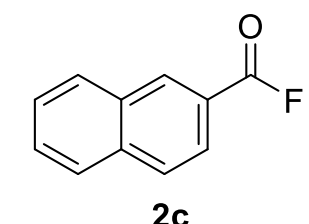

${ }^{19} \mathrm{~F}$ NMR $\left(470 \mathrm{MHz}, \mathrm{CDCl}_{3}\right.$ )

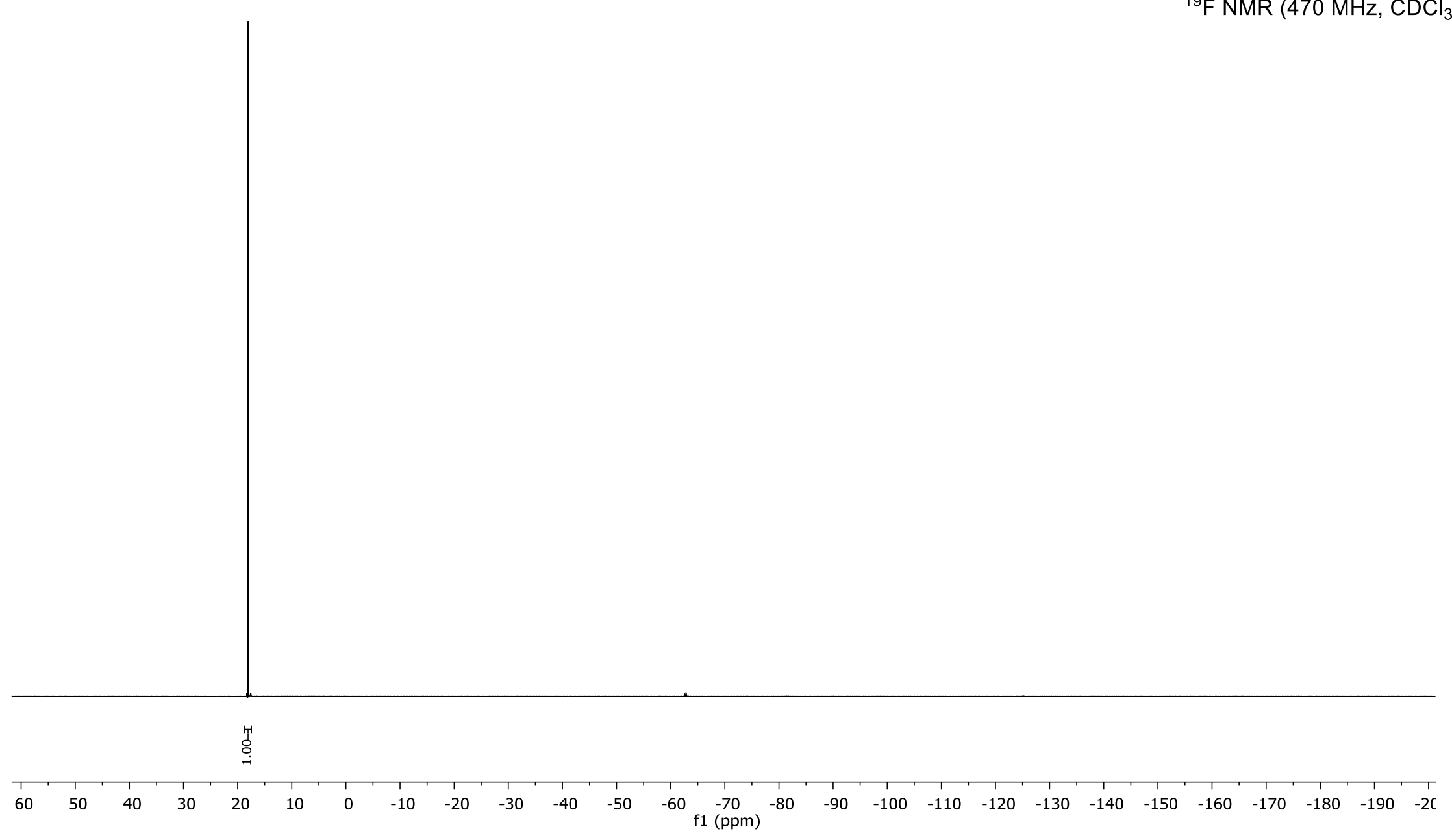




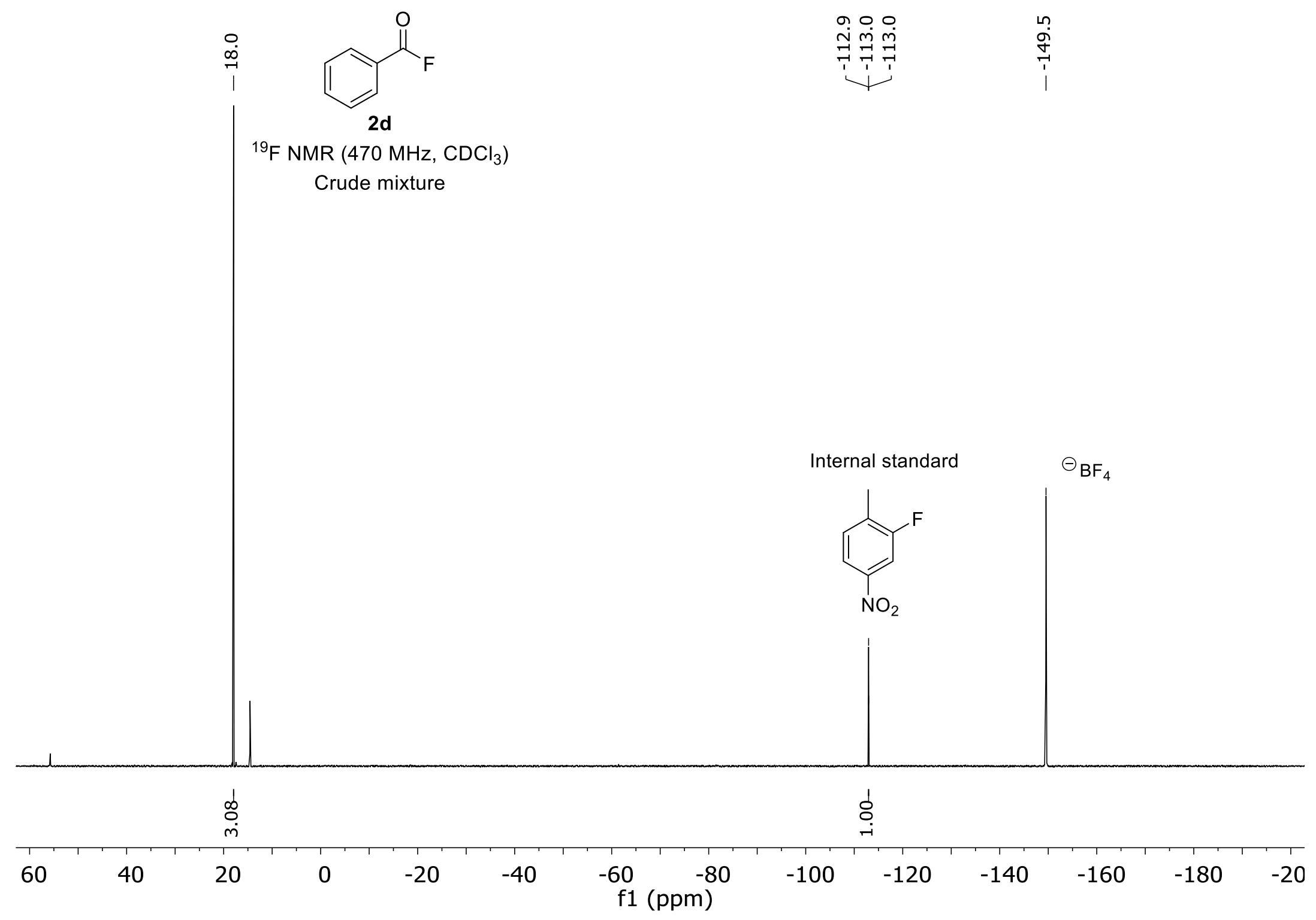




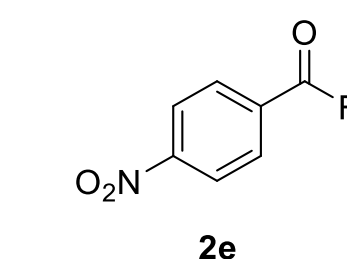

${ }^{1} \mathrm{HNMR}\left(500 \mathrm{MHz}, \mathrm{CDCl}_{3}\right)$

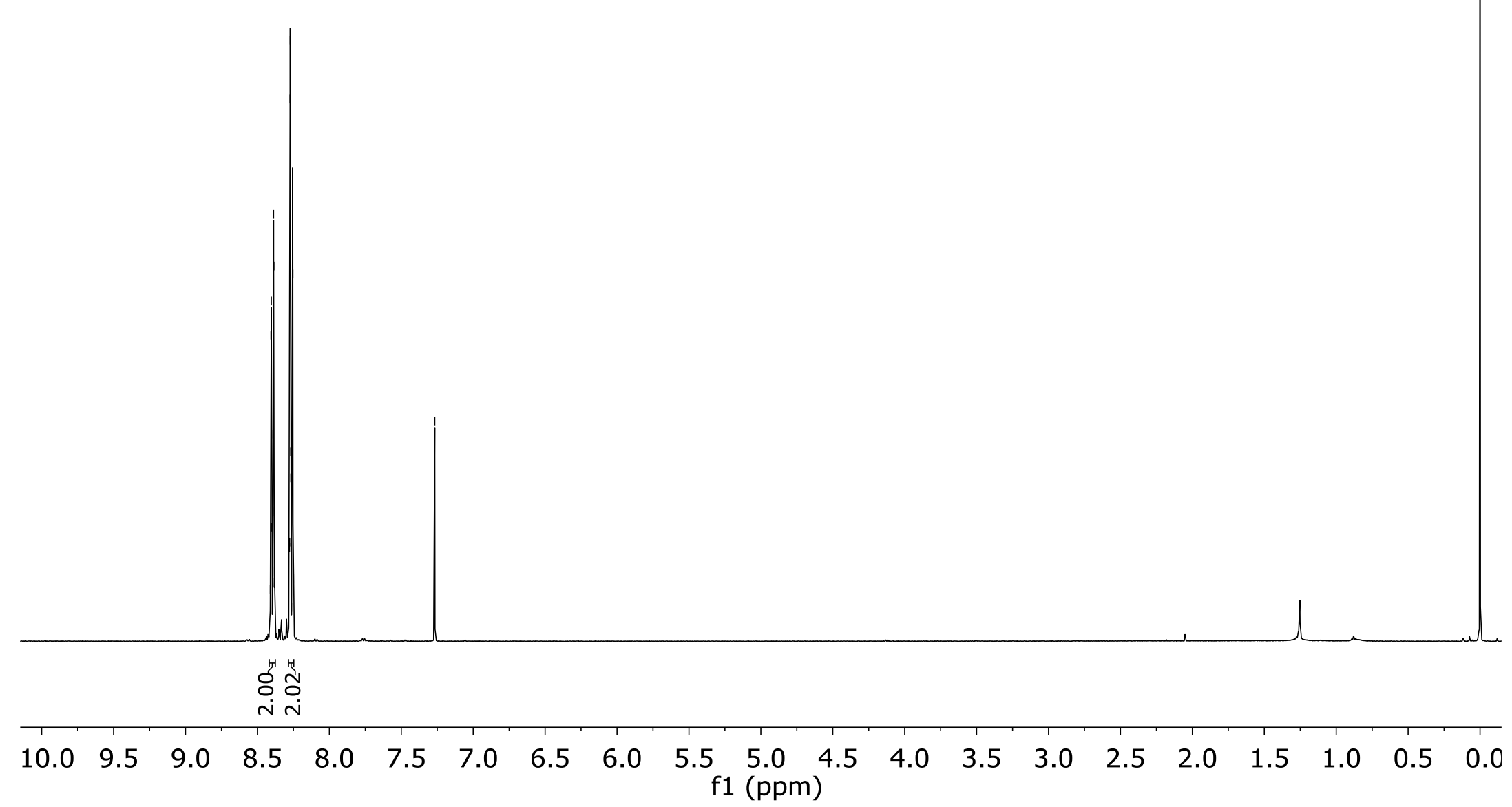




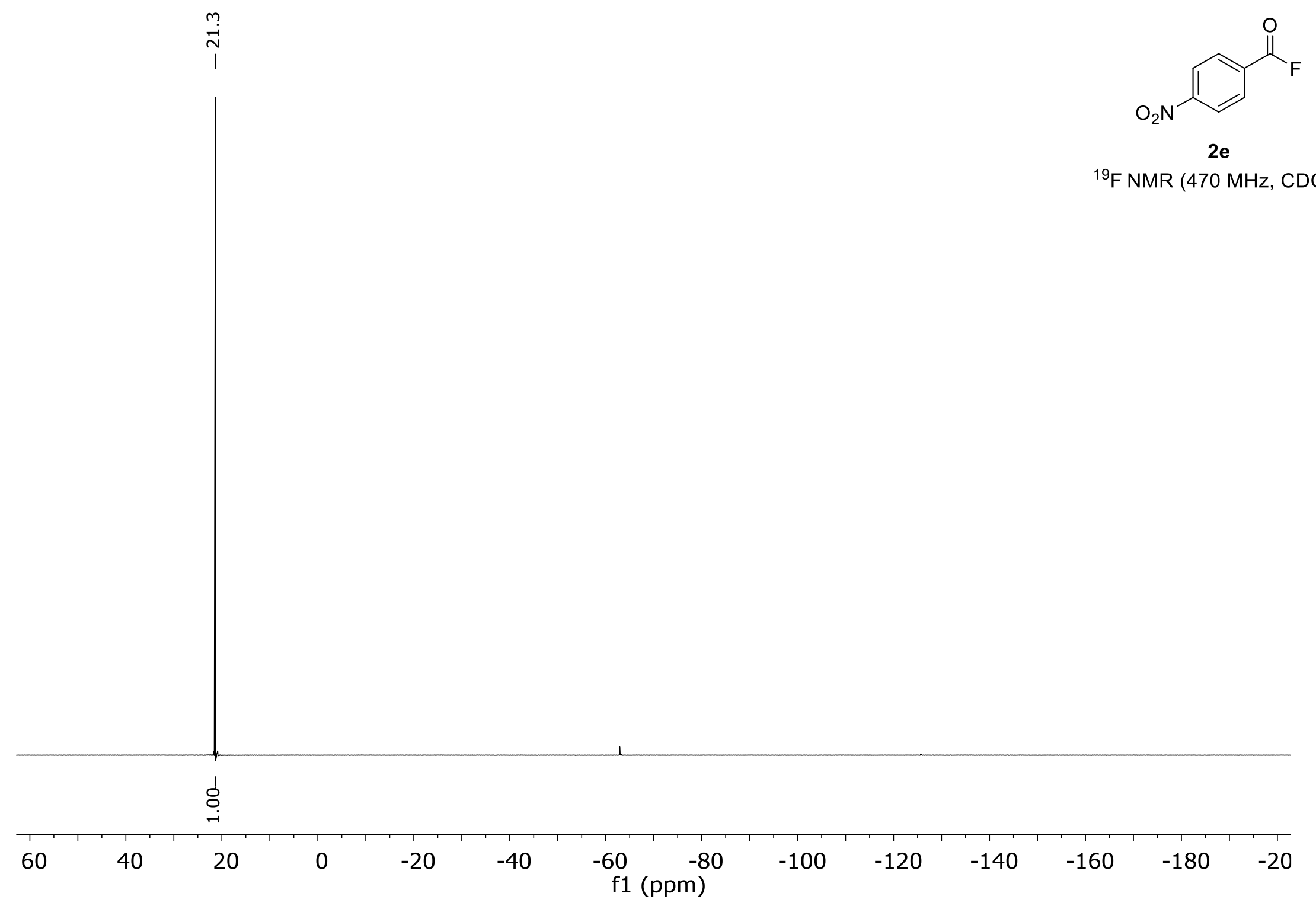

SI-10 

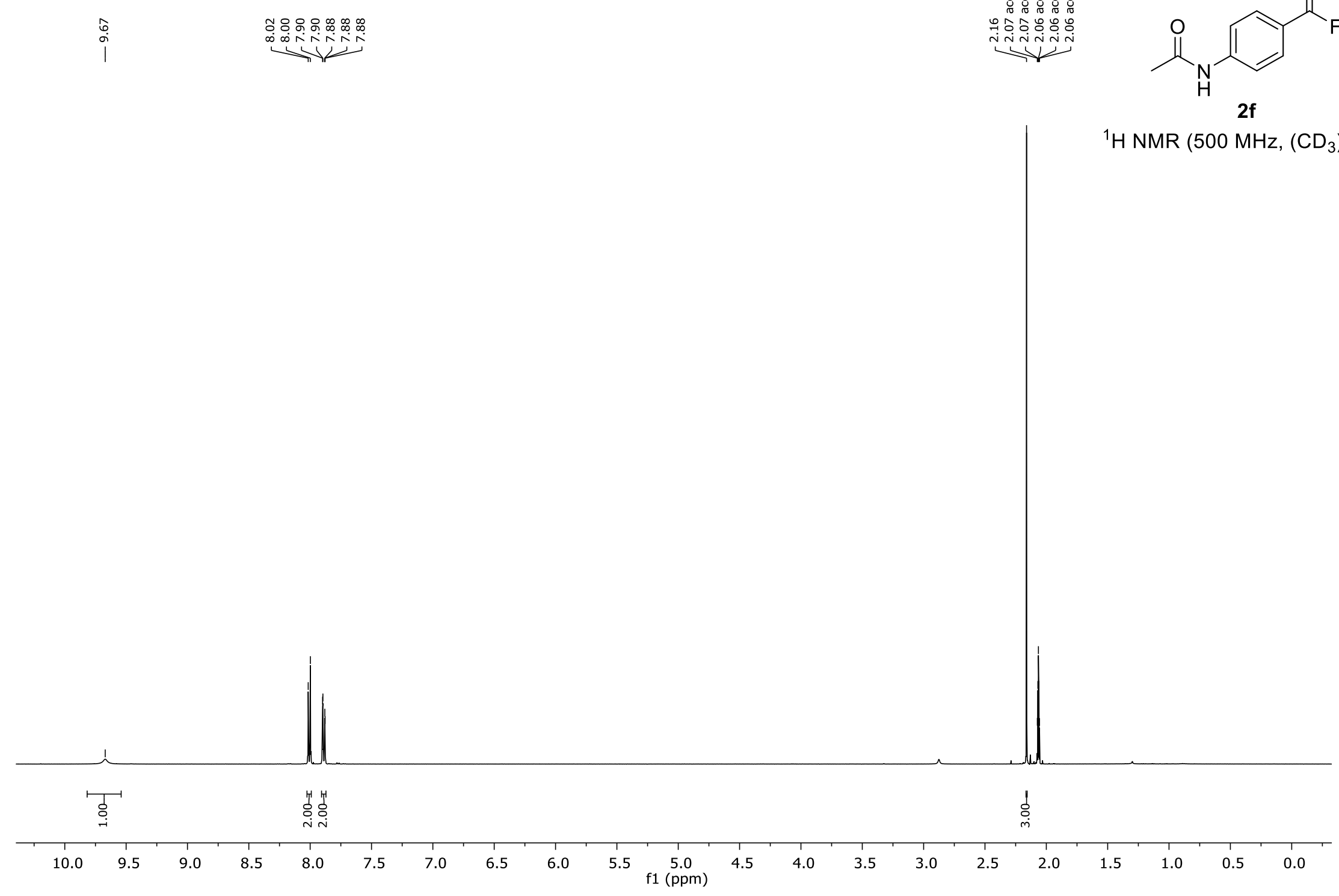
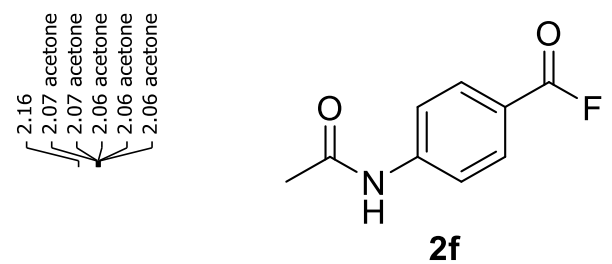

$\left.\mathrm{D}_{3}\right)_{2} \mathrm{CO}$ ) 


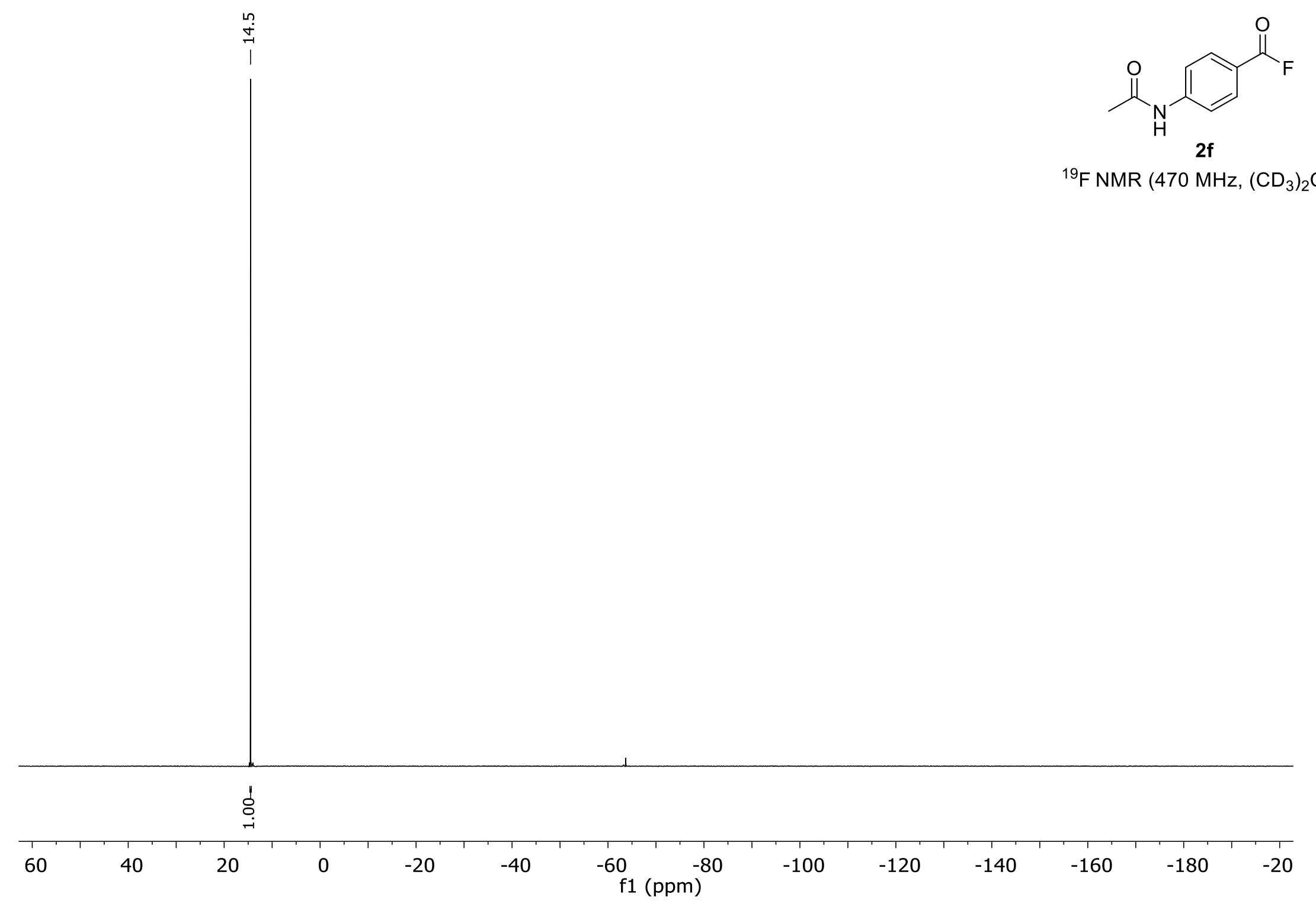

SI-12 


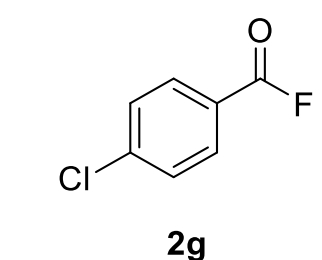

${ }^{1} \mathrm{HNMR}\left(500 \mathrm{MHz}, \mathrm{CDCl}_{3}\right)$

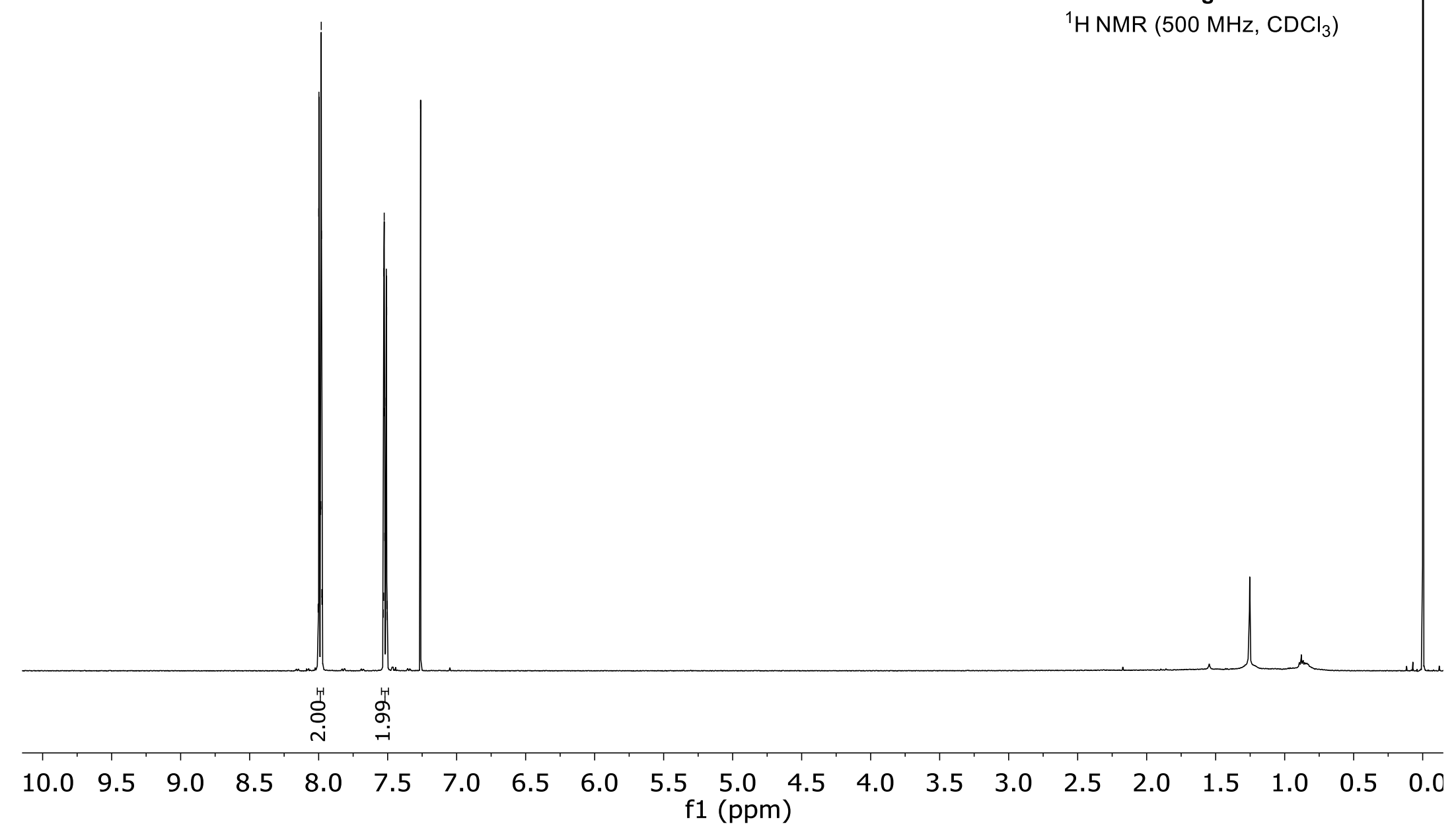




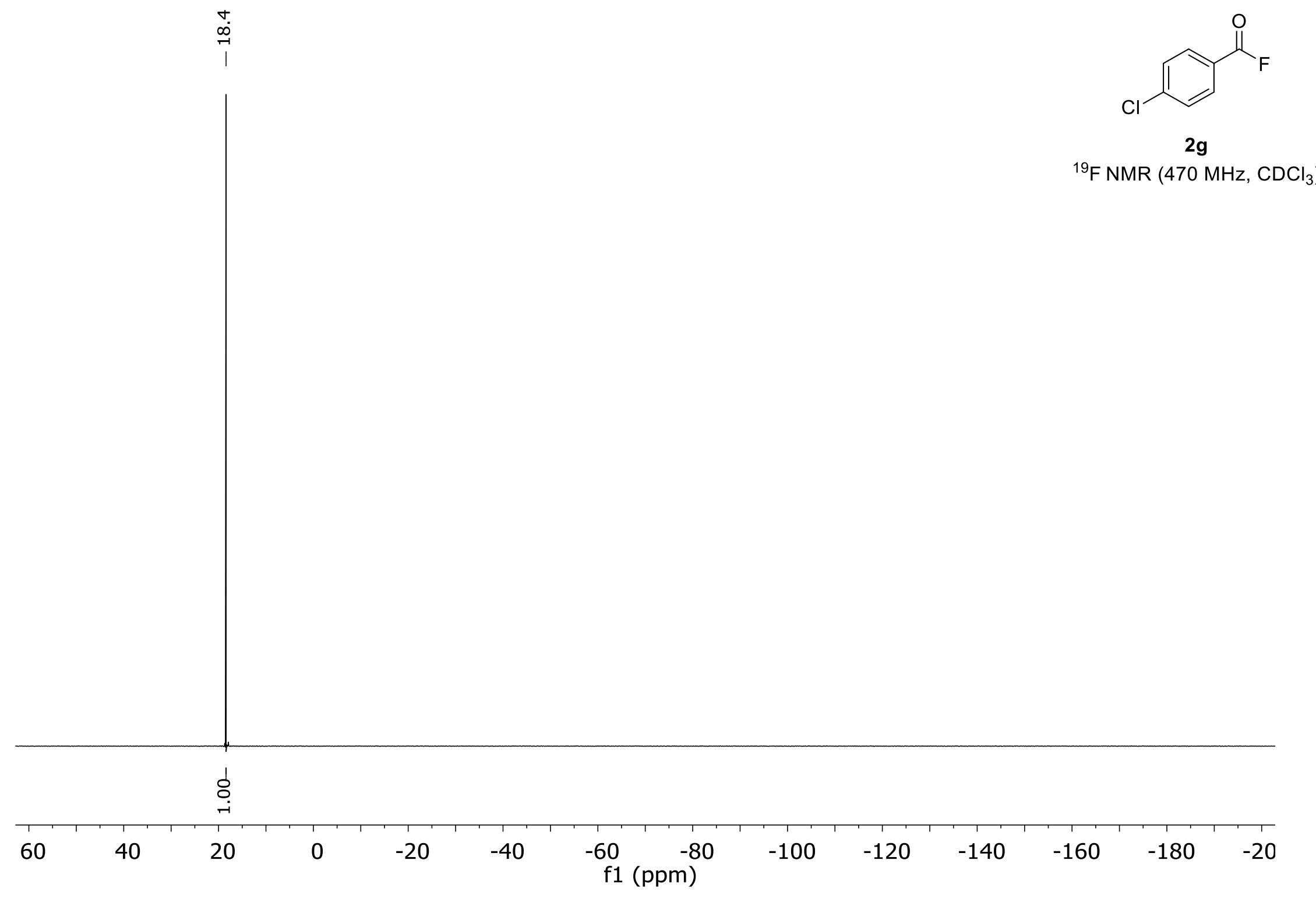

SI-14 

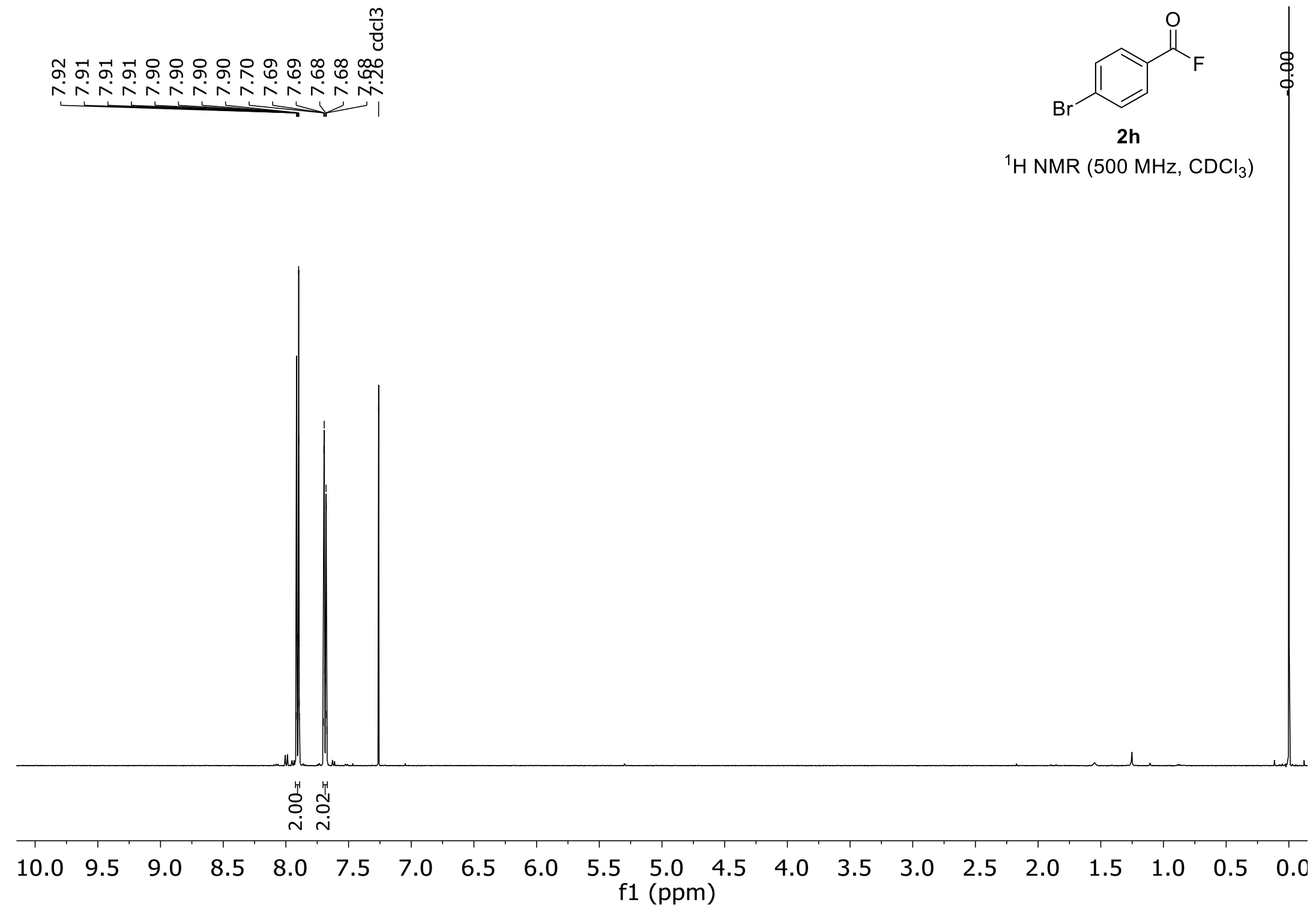


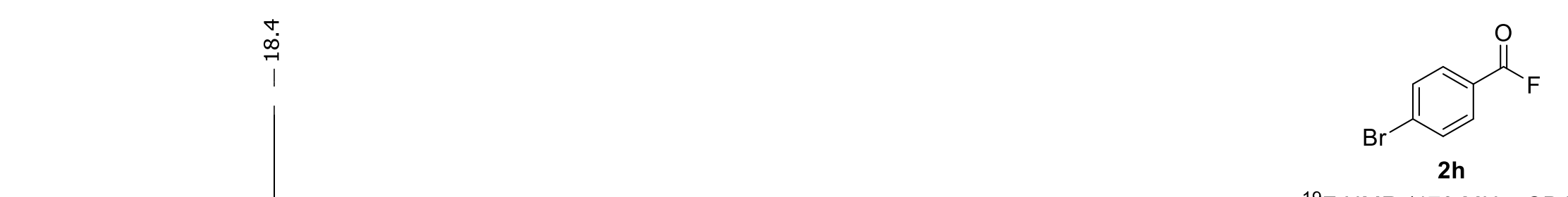

${ }^{19} \mathrm{~F}$ NMR $\left(470 \mathrm{MHz}, \mathrm{CDCl}_{3}\right)$

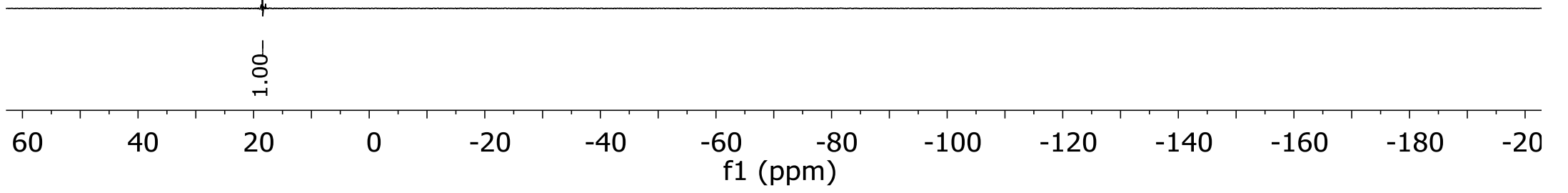

SI-16 


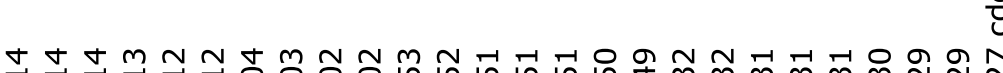

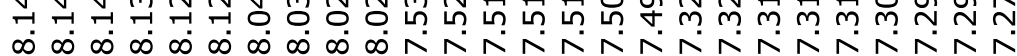

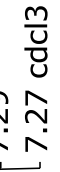

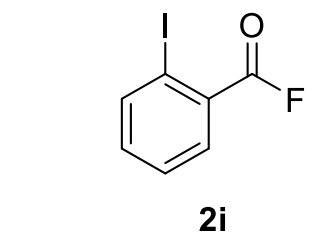

${ }^{1} \mathrm{H}$ NMR $\left(500 \mathrm{MHz}, \mathrm{CDCl}_{3}\right)$

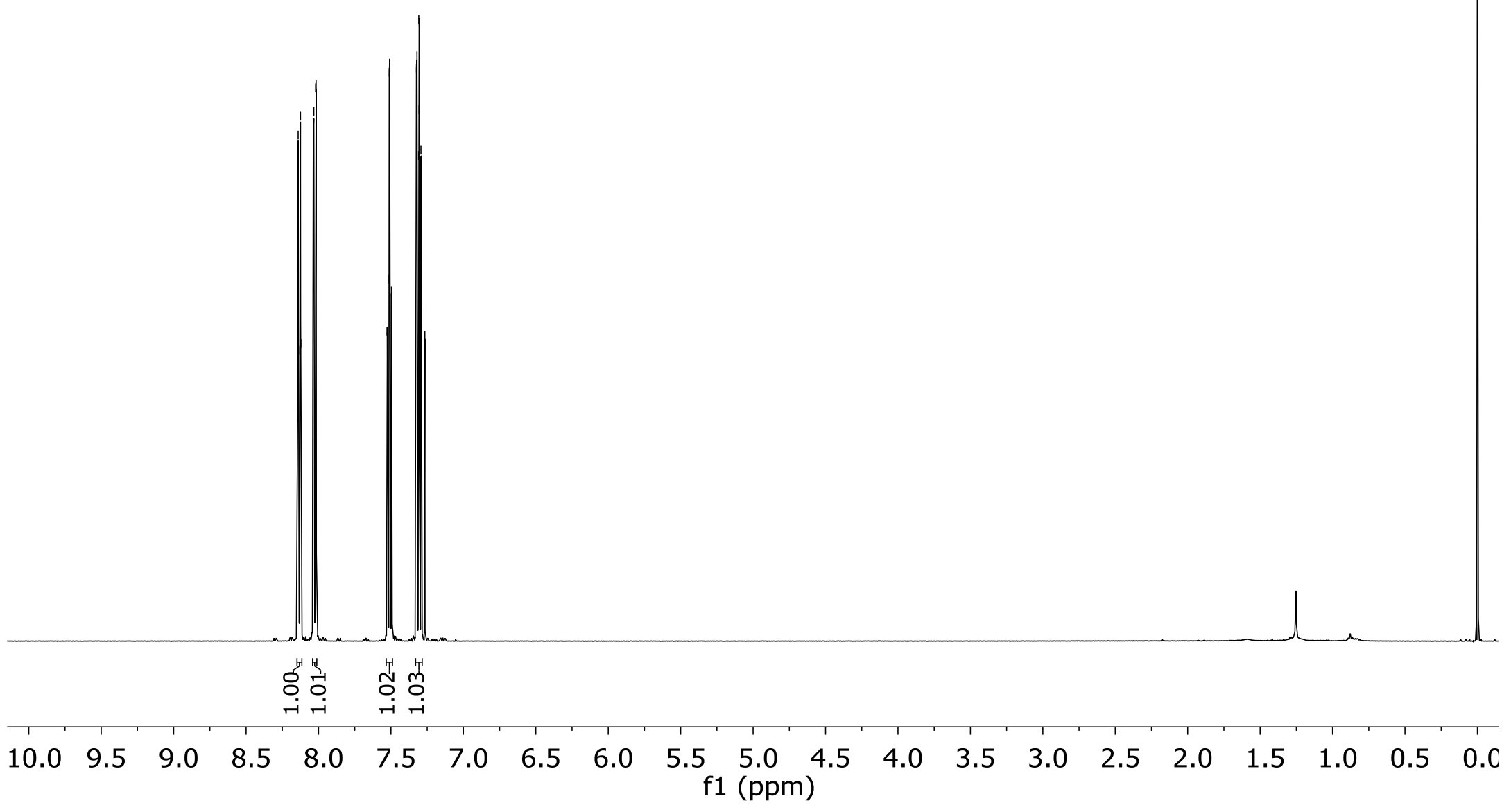




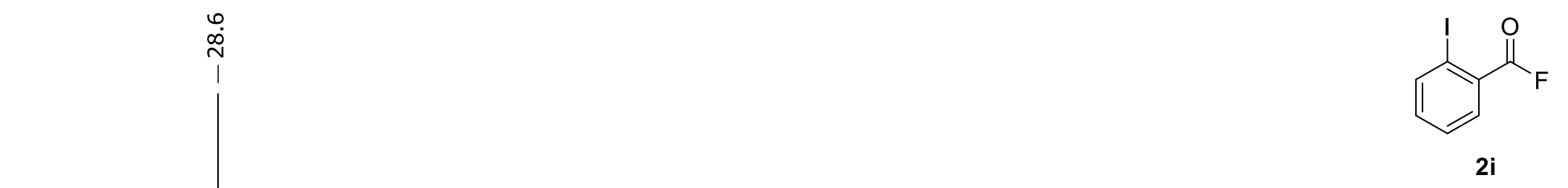

${ }^{19} \mathrm{~F} \mathrm{NMR}\left(470 \mathrm{MHz}, \mathrm{CDCl}_{3}\right)$

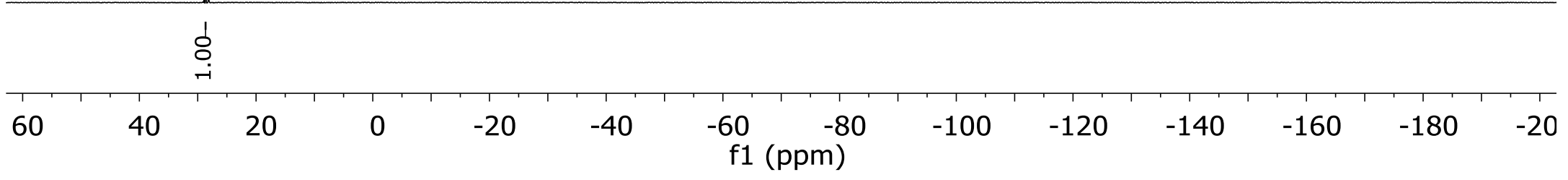

SI-18 
$\frac{m}{\mathrm{v}}$

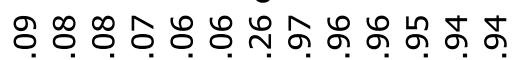

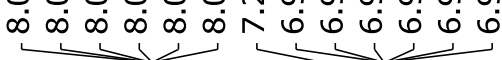

$\infty$

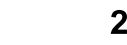

2.

${ }^{1} \mathrm{H}$ NMR $\left(500 \mathrm{MHz}, \mathrm{CDCl}_{3}\right)$

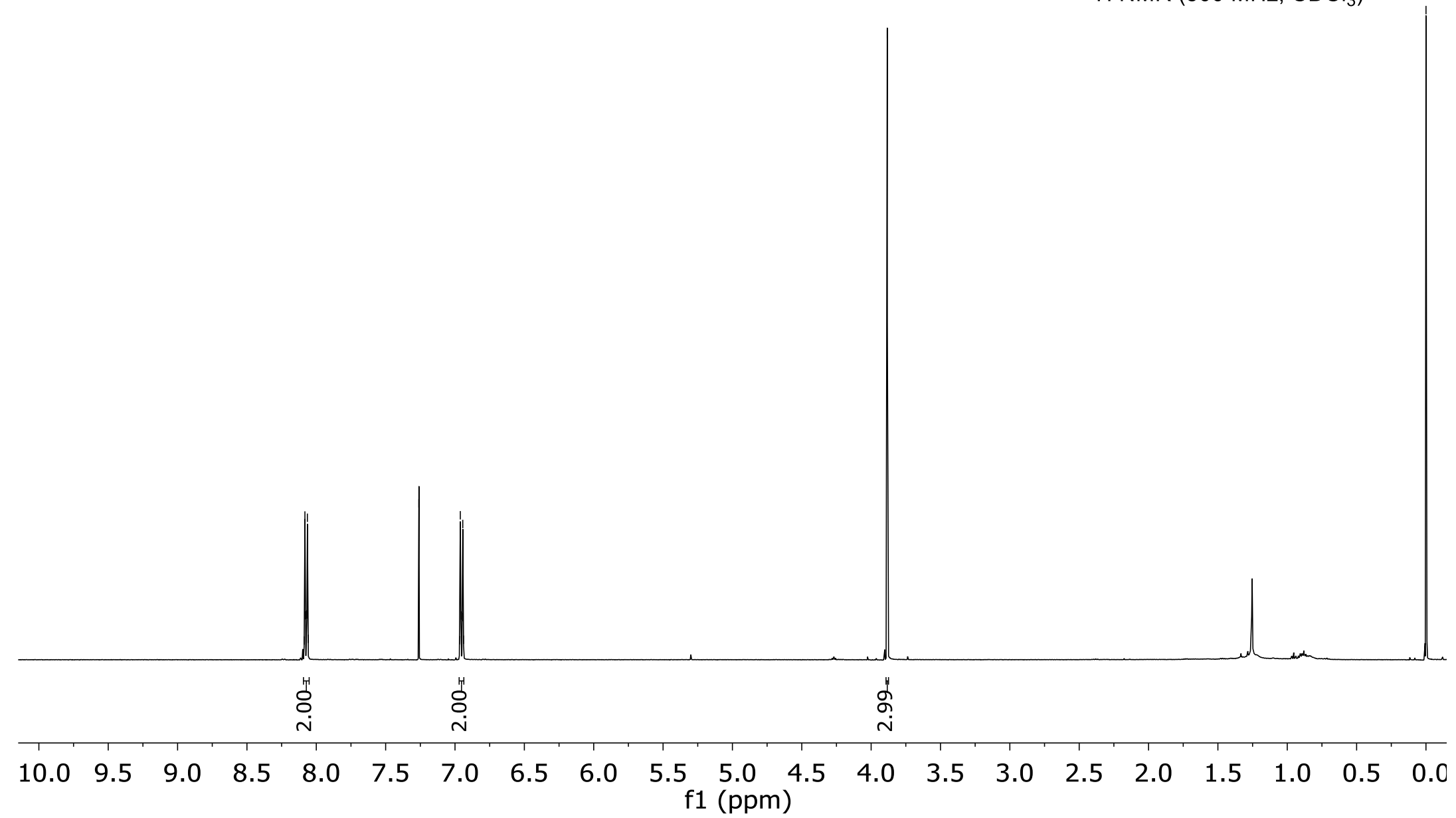

SI-19 


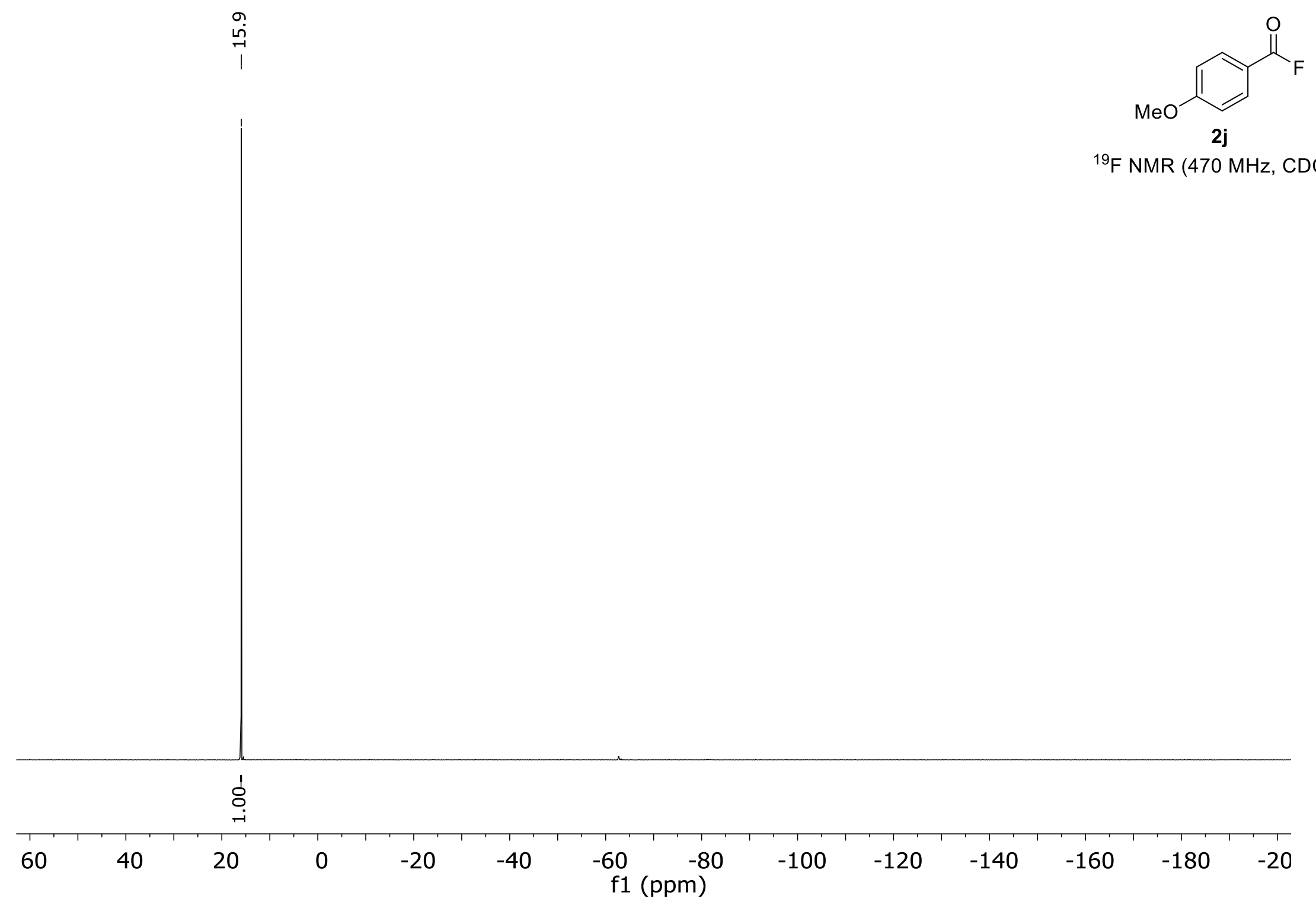




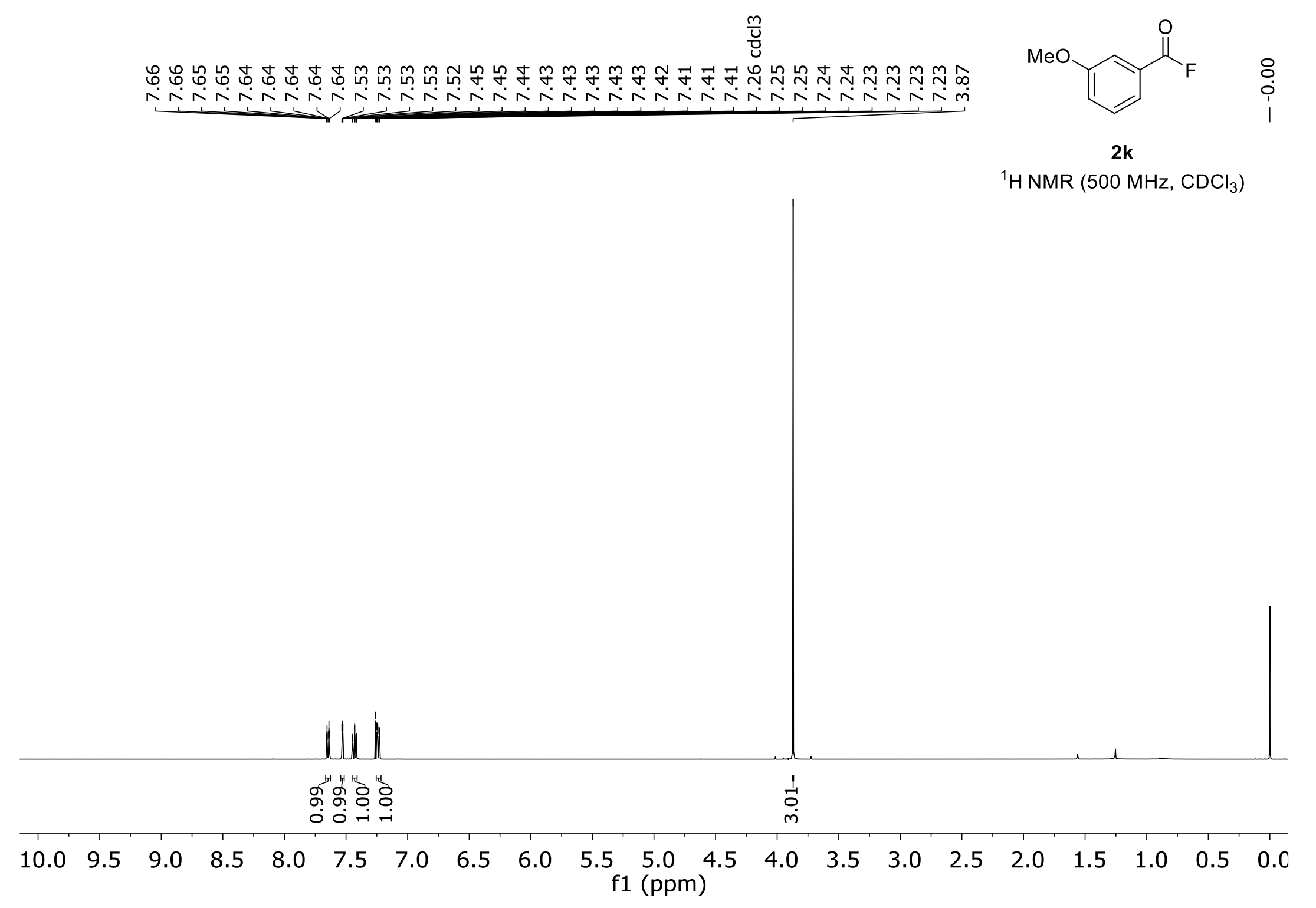


두우의

mก ก 0 ด 0 .

○ீ

ำ
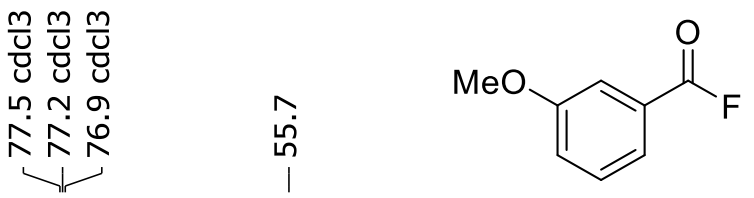

กั

2k

${ }^{13} \mathrm{C}$ NMR $\left(126 \mathrm{MHz}, \mathrm{CDCl}_{3}\right)$

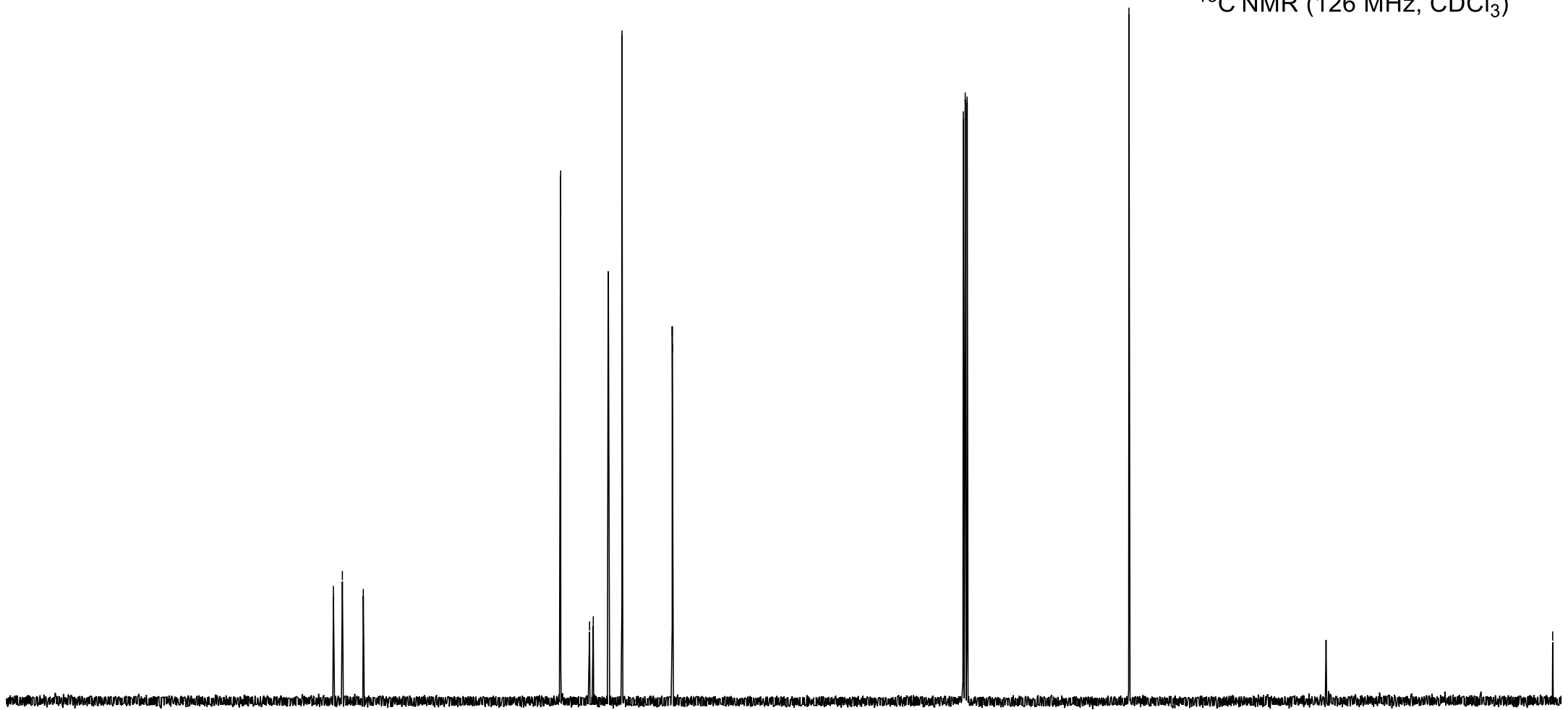

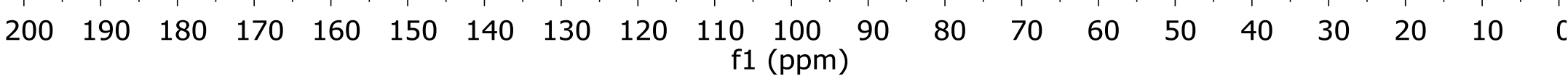




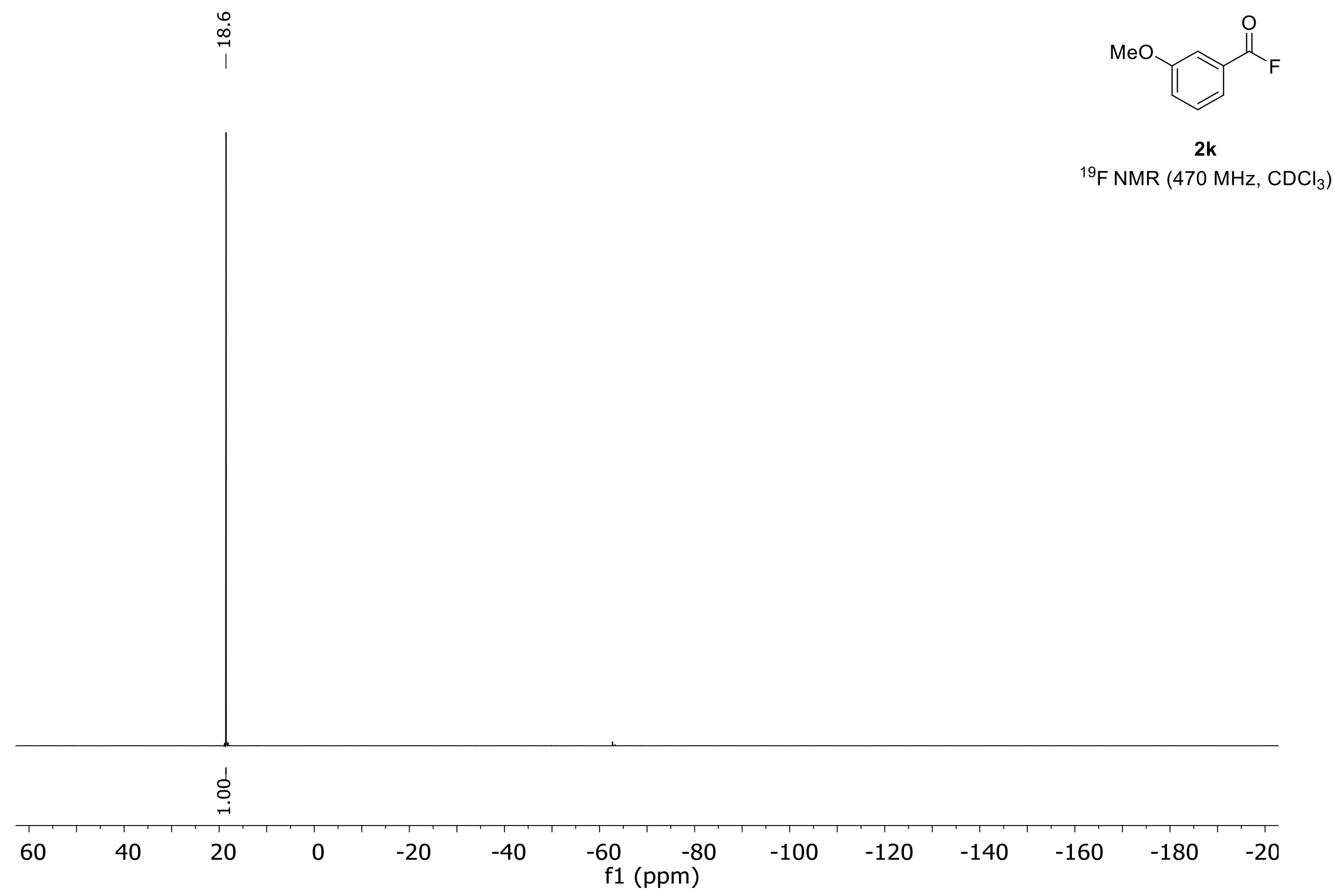




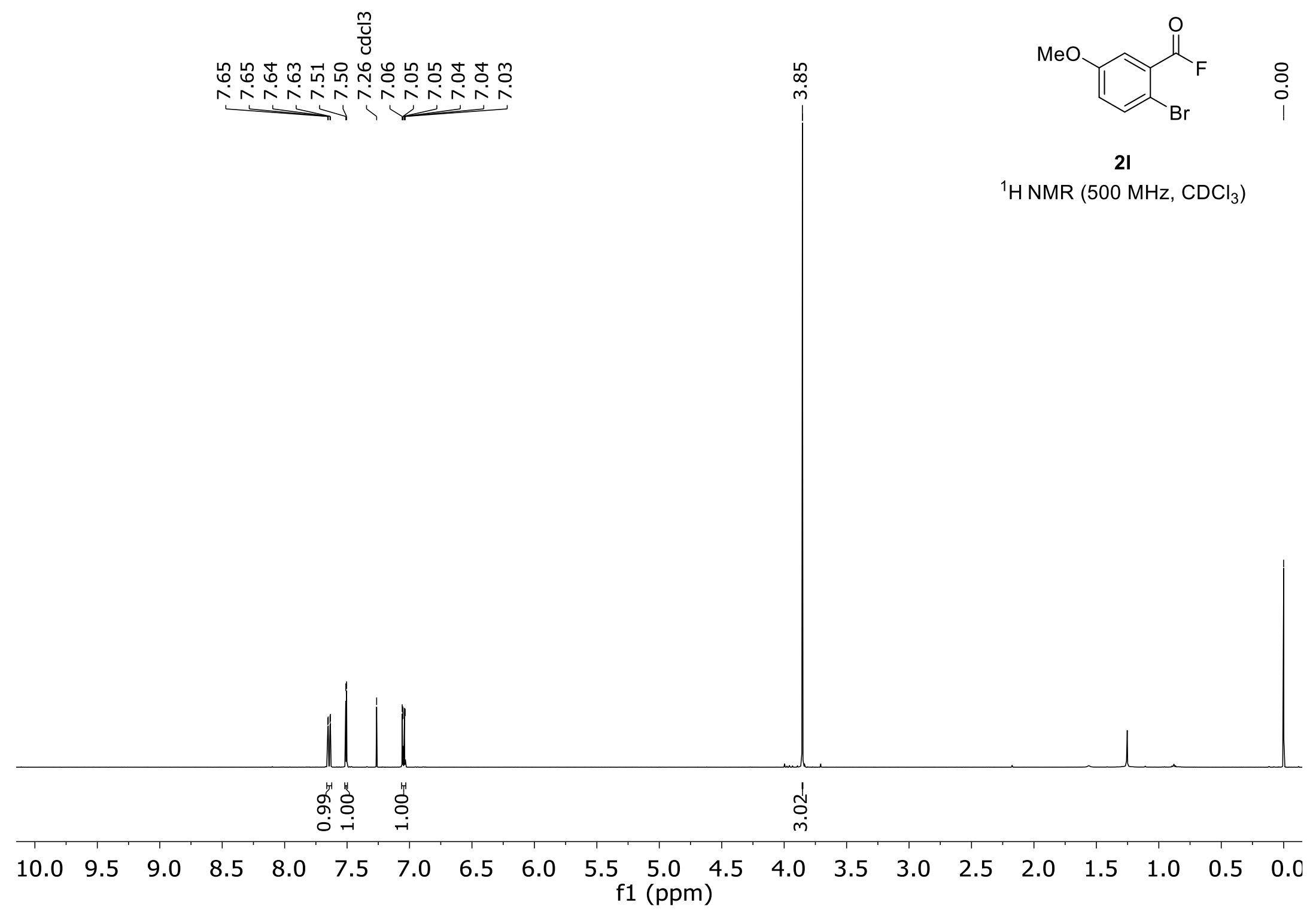




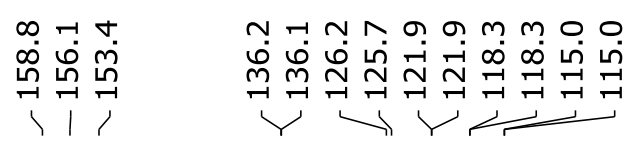

$\begin{array}{lll}\infty & -1 \\ \infty & 0 \\ 0 & \text { m } \\ 1 & 1\end{array}$

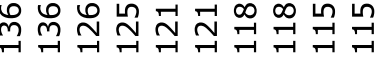

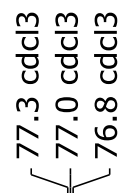

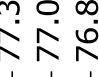

กุ

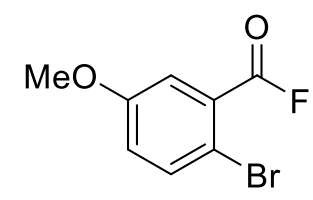

2I

${ }^{13} \mathrm{C} \mathrm{NMR}\left(126 \mathrm{MHz}, \mathrm{CDCl}_{3}\right)$

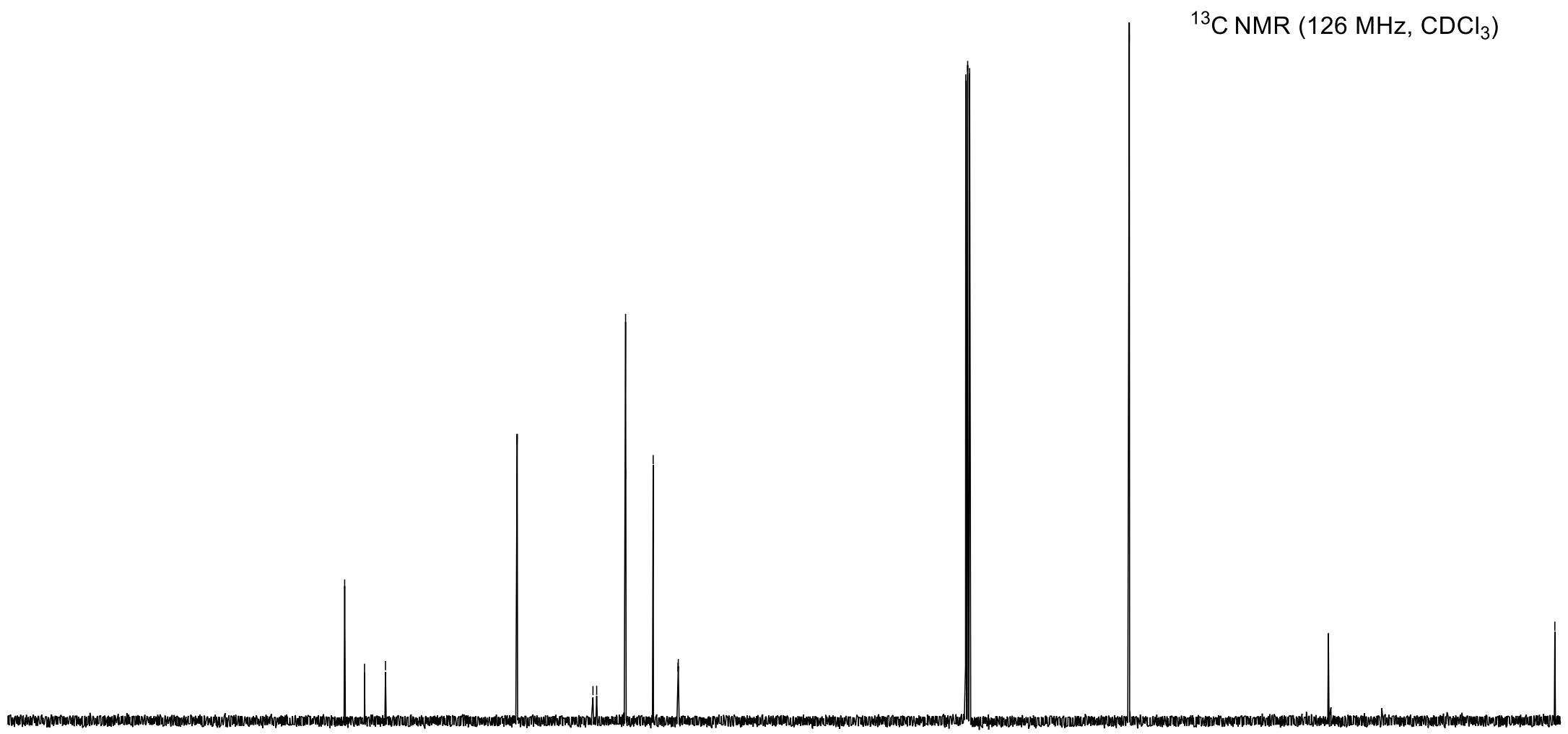

$\begin{array}{llllllllllllllllllll}200 & 190 & 180 & 170 & 160 & 150 & 140 & 130 & 120 & \begin{array}{c}110 \\ \mathrm{f} 1(\mathrm{ppm})\end{array} & 100 & 80 & 70 & 60 & 50 & 40 & 30 & 20 & 10 & \mathrm{c}\end{array}$ 


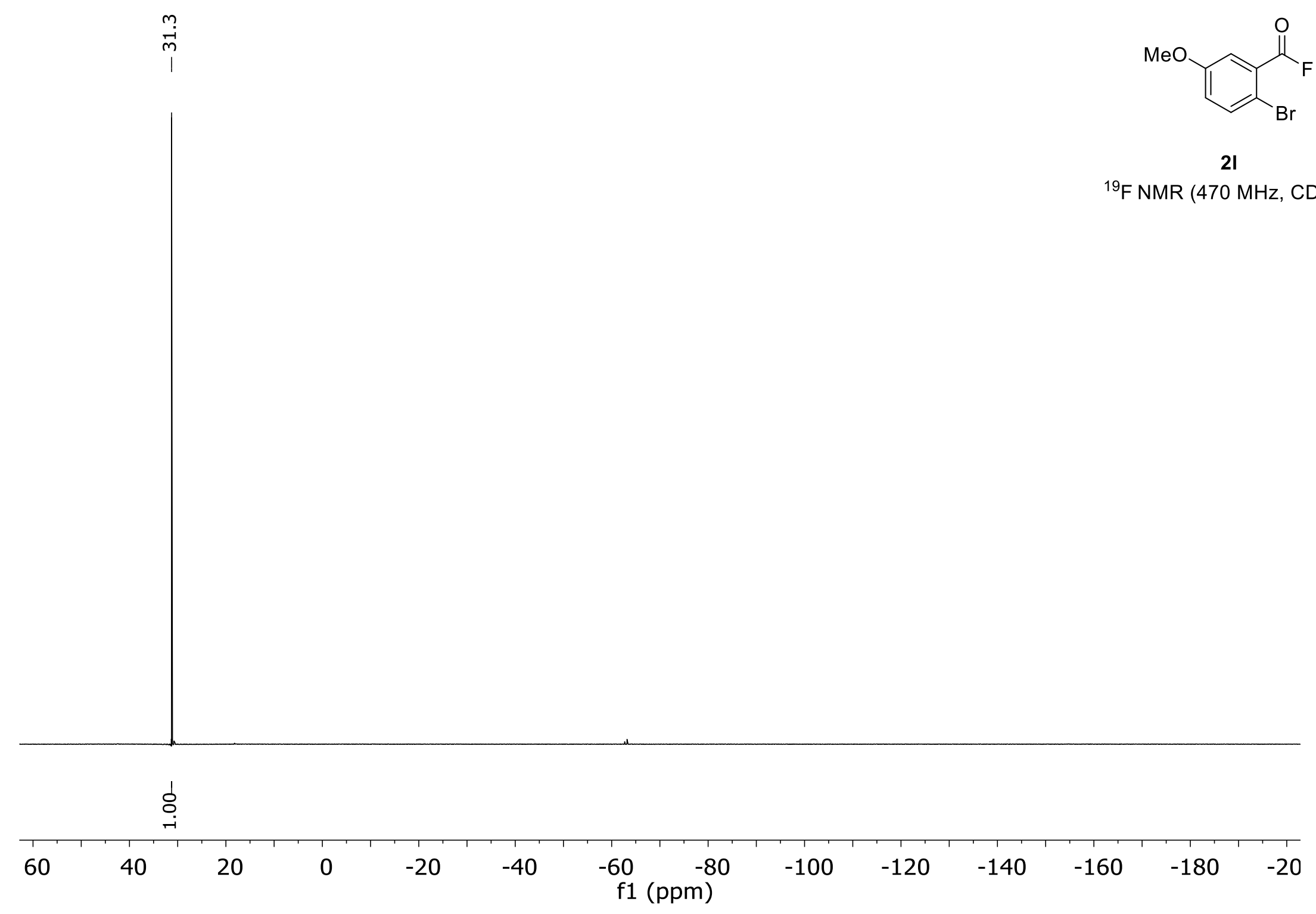




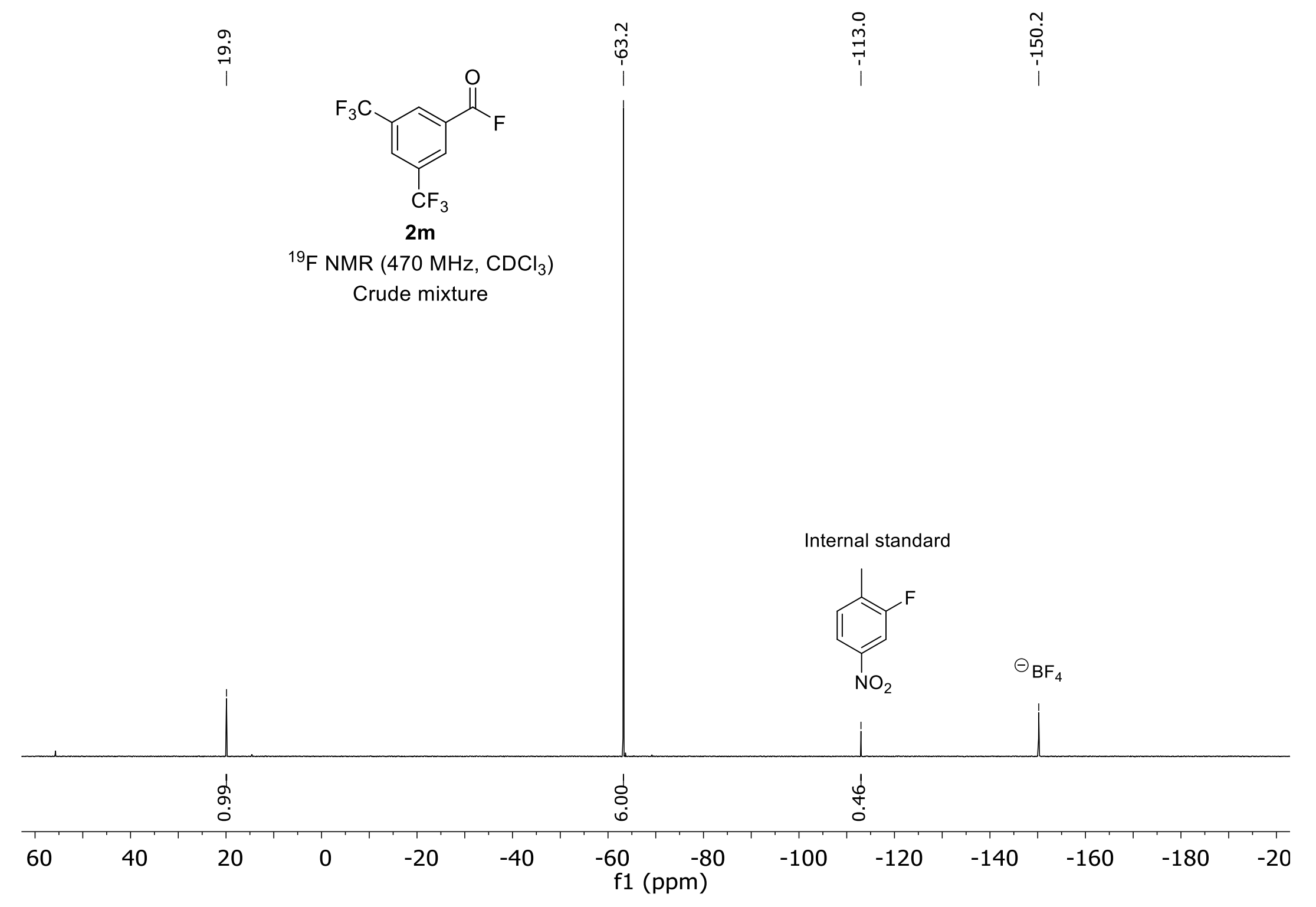




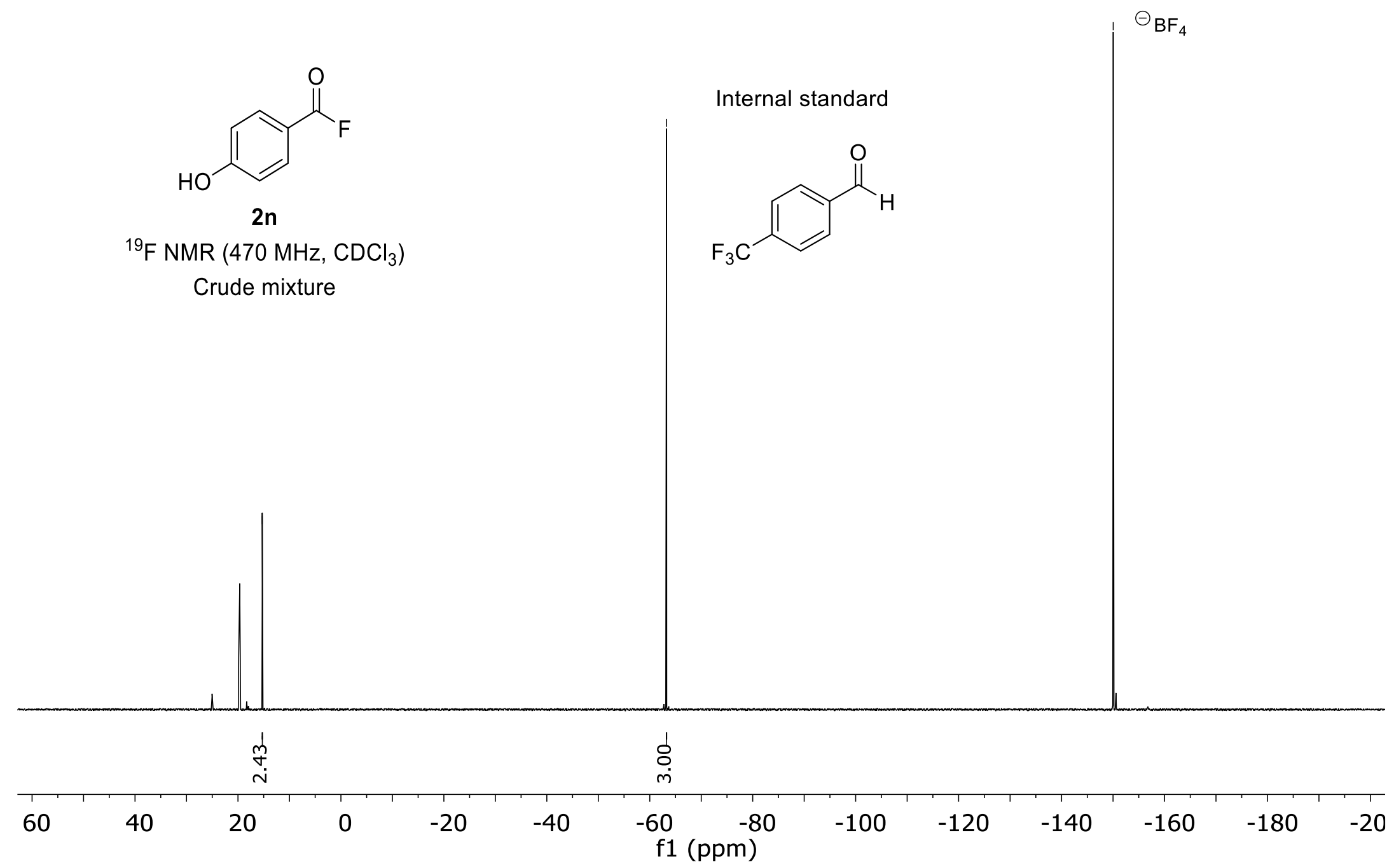


$\stackrel{9}{i}$

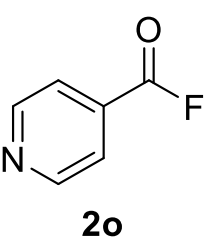

${ }^{19} \mathrm{~F}$ NMR $\left(470 \mathrm{MHz}, \mathrm{CDCl}_{3}\right)$

Crude mixture

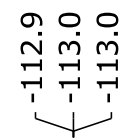

ก

$\ominus_{\mathrm{BF}_{4}}$

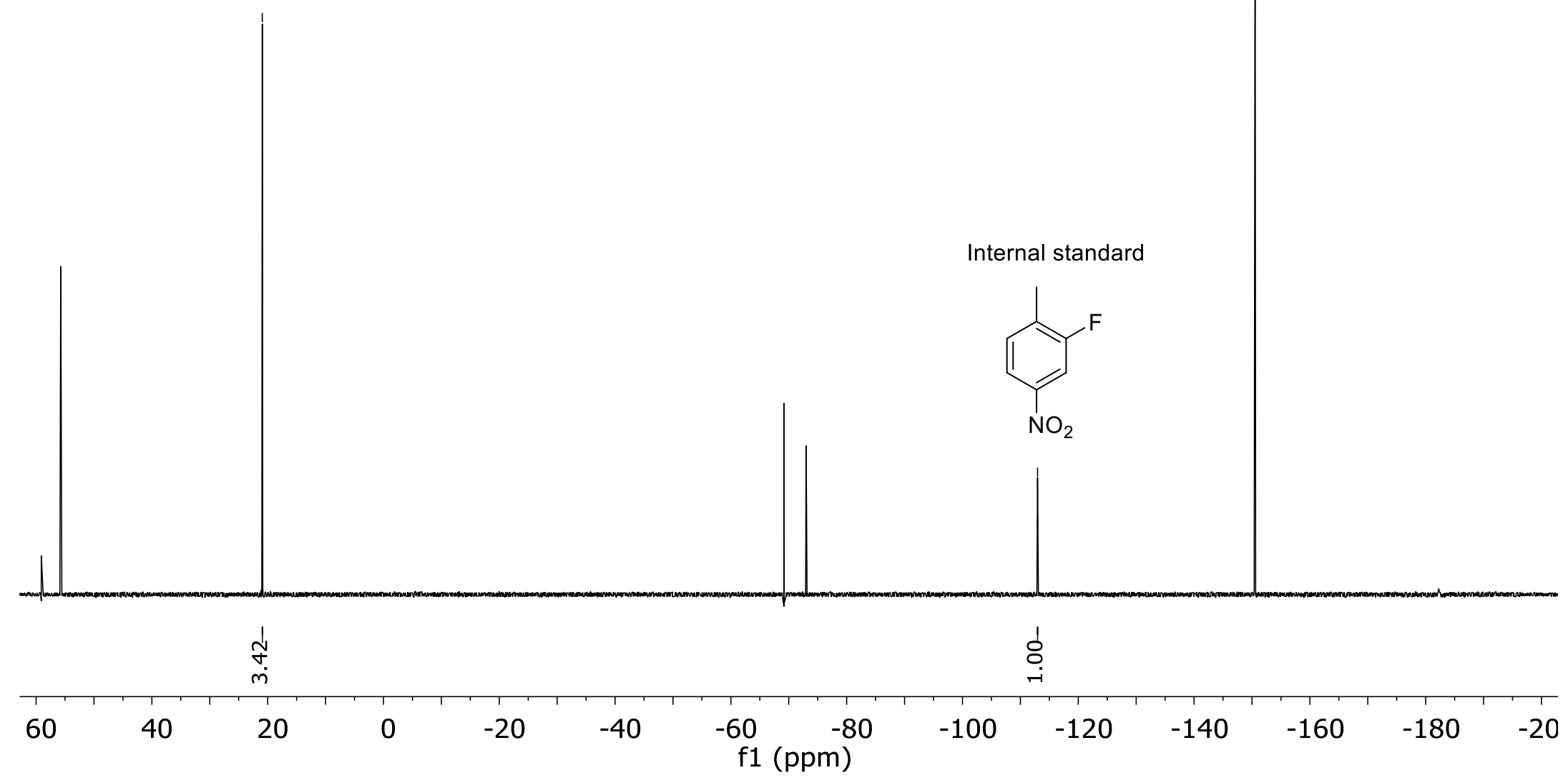




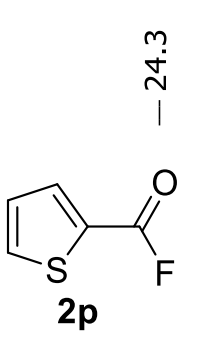

${ }^{19} \mathrm{~F} \mathrm{NMR}\left(470 \mathrm{MHz}, \mathrm{CDCl}_{3}\right.$ )

Crude mixture

Internal standard
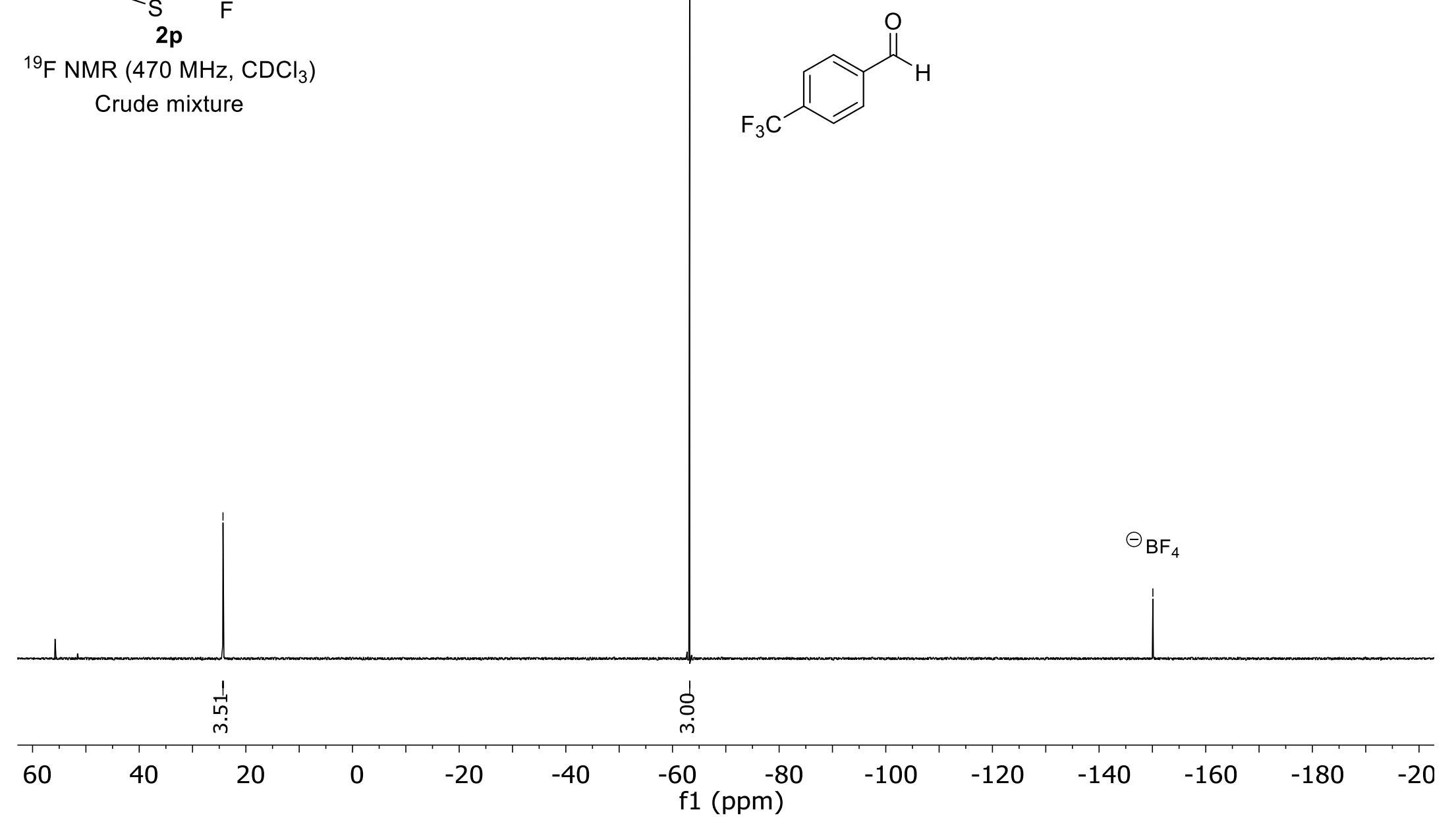


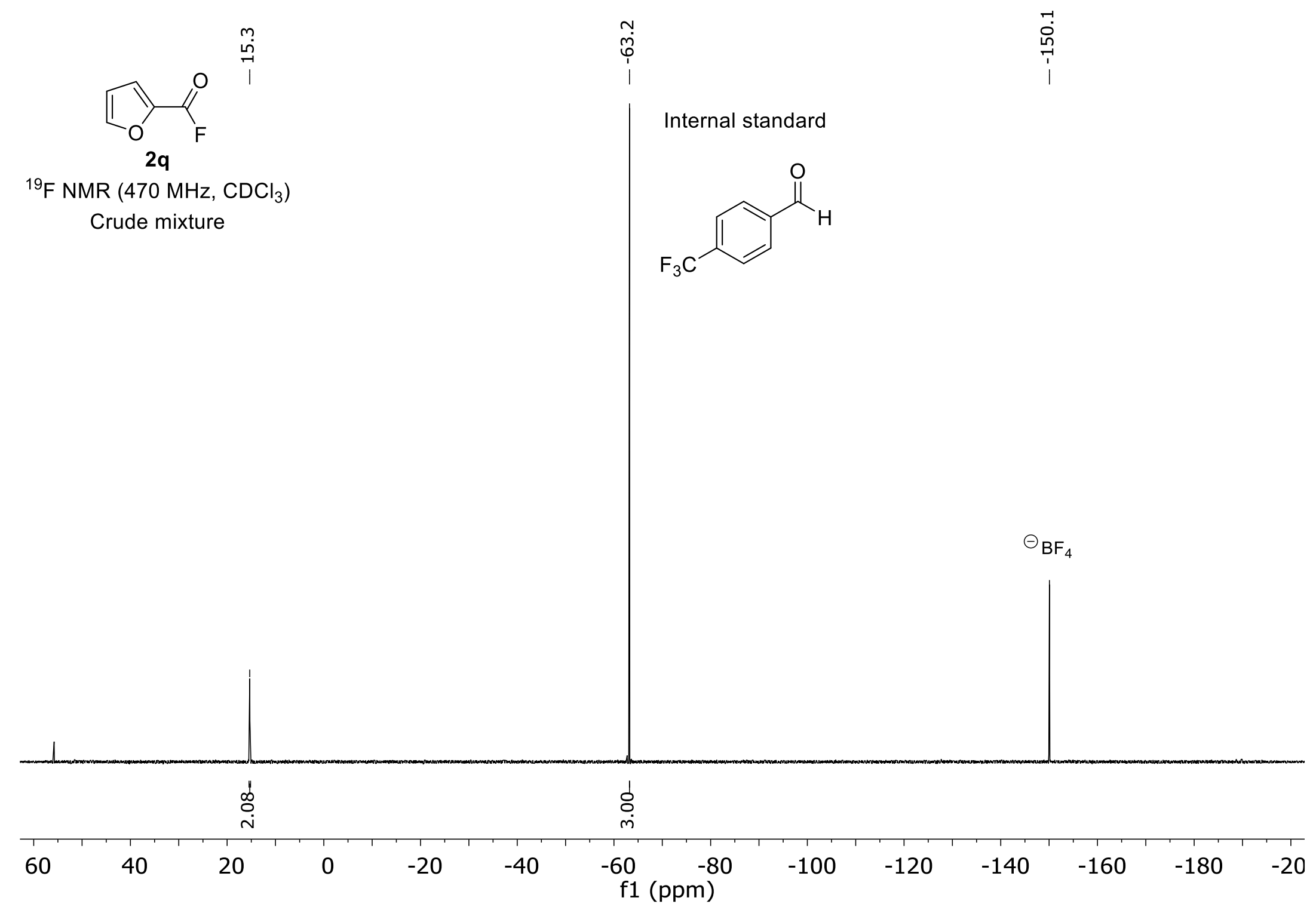

SI-31 


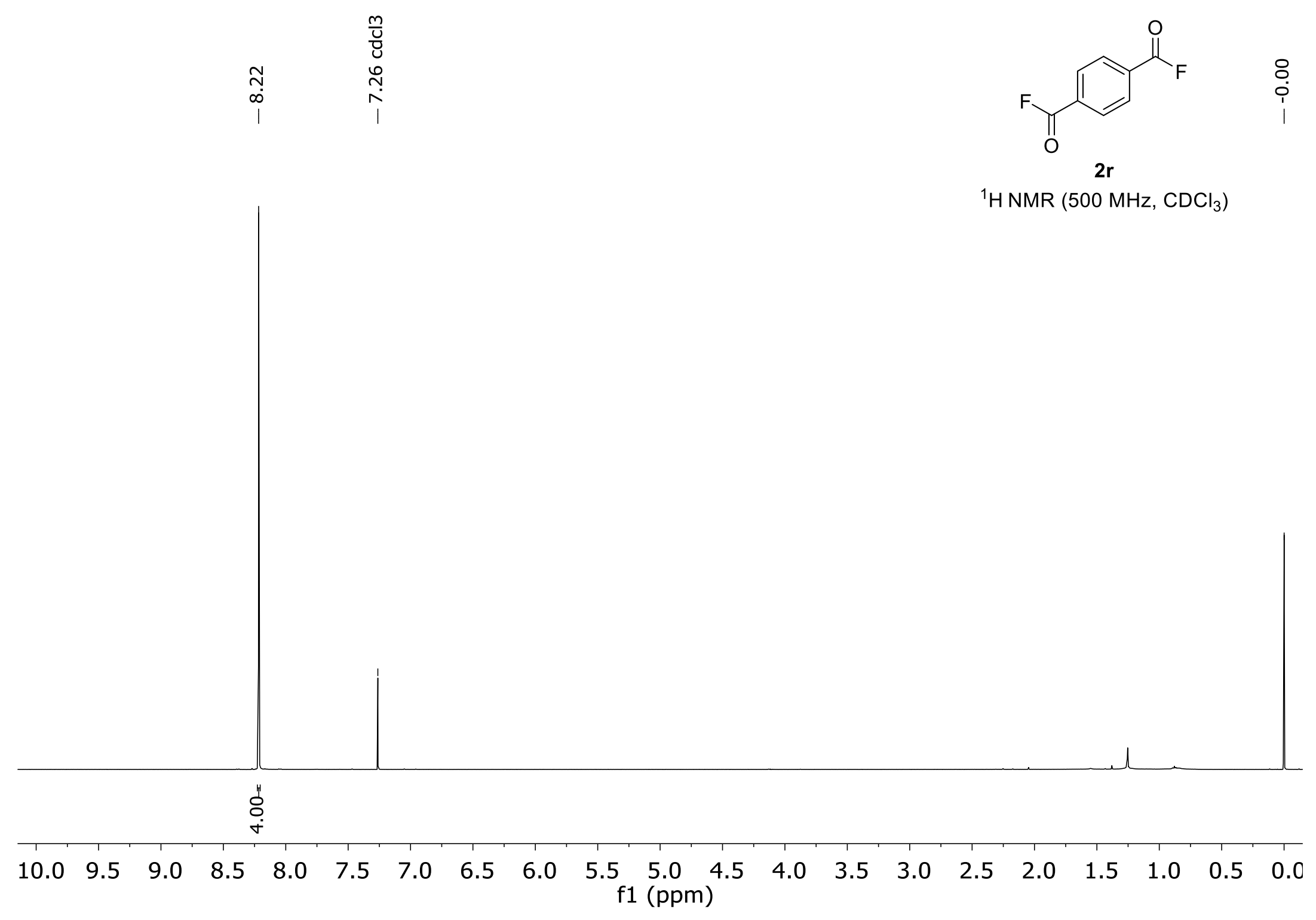




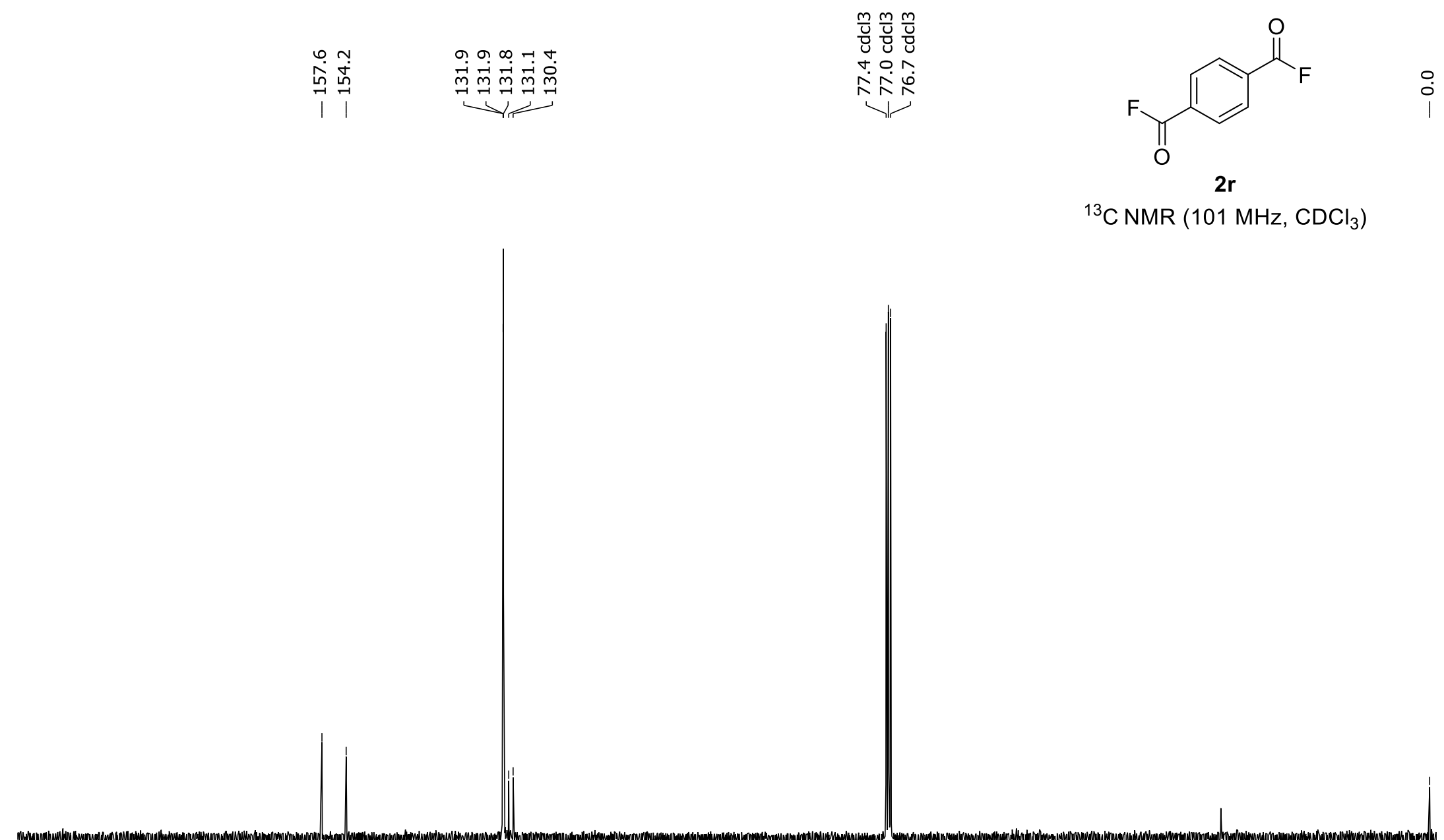




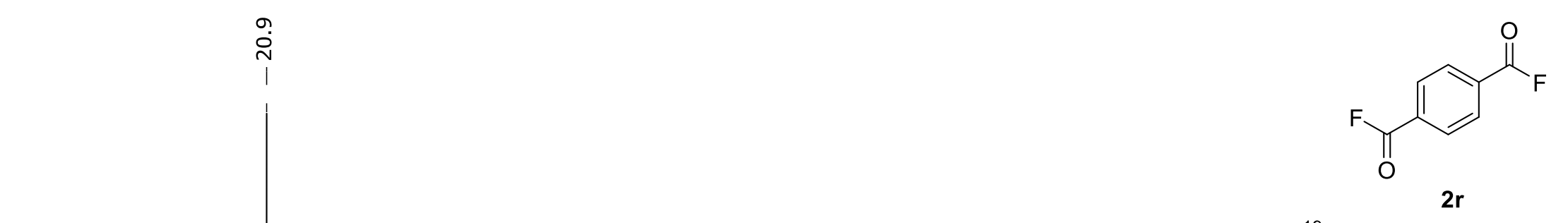

${ }^{19} \mathrm{~F} \mathrm{NMR} \mathrm{(470} \mathrm{MHz,} \mathrm{CDCl}_{3}$ )

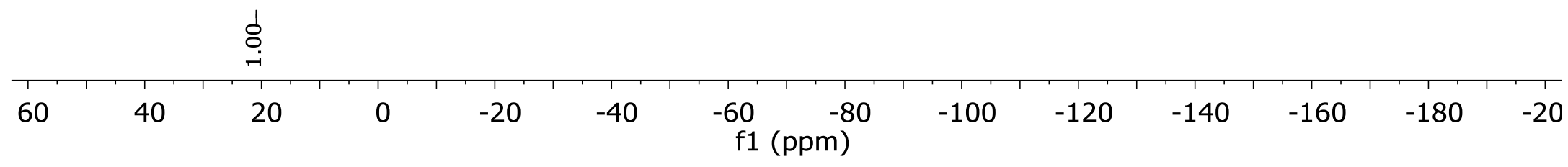

SI-34 
爱

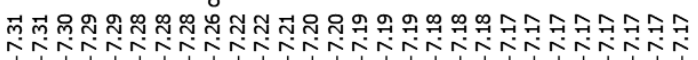

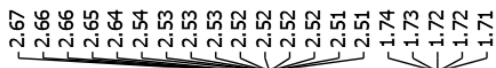

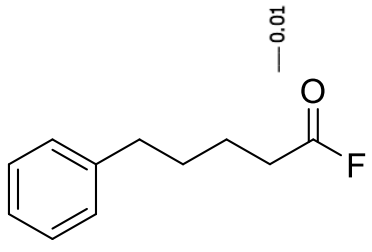

$2 \mathrm{~s}$

${ }^{1} \mathrm{H}$ NMR $\left(500 \mathrm{MHz}, \mathrm{CDCl}_{3}\right)$

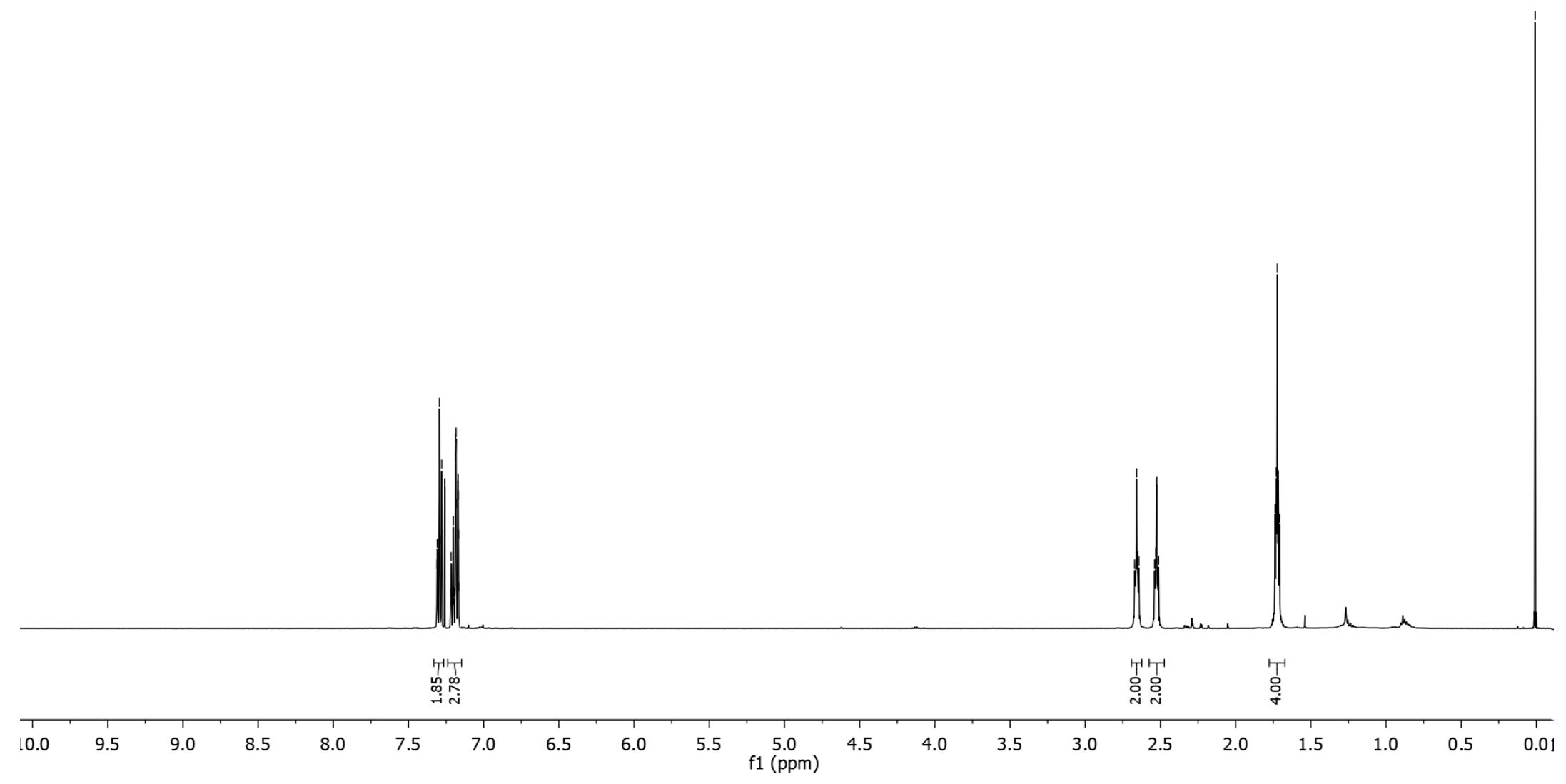

SI-35 


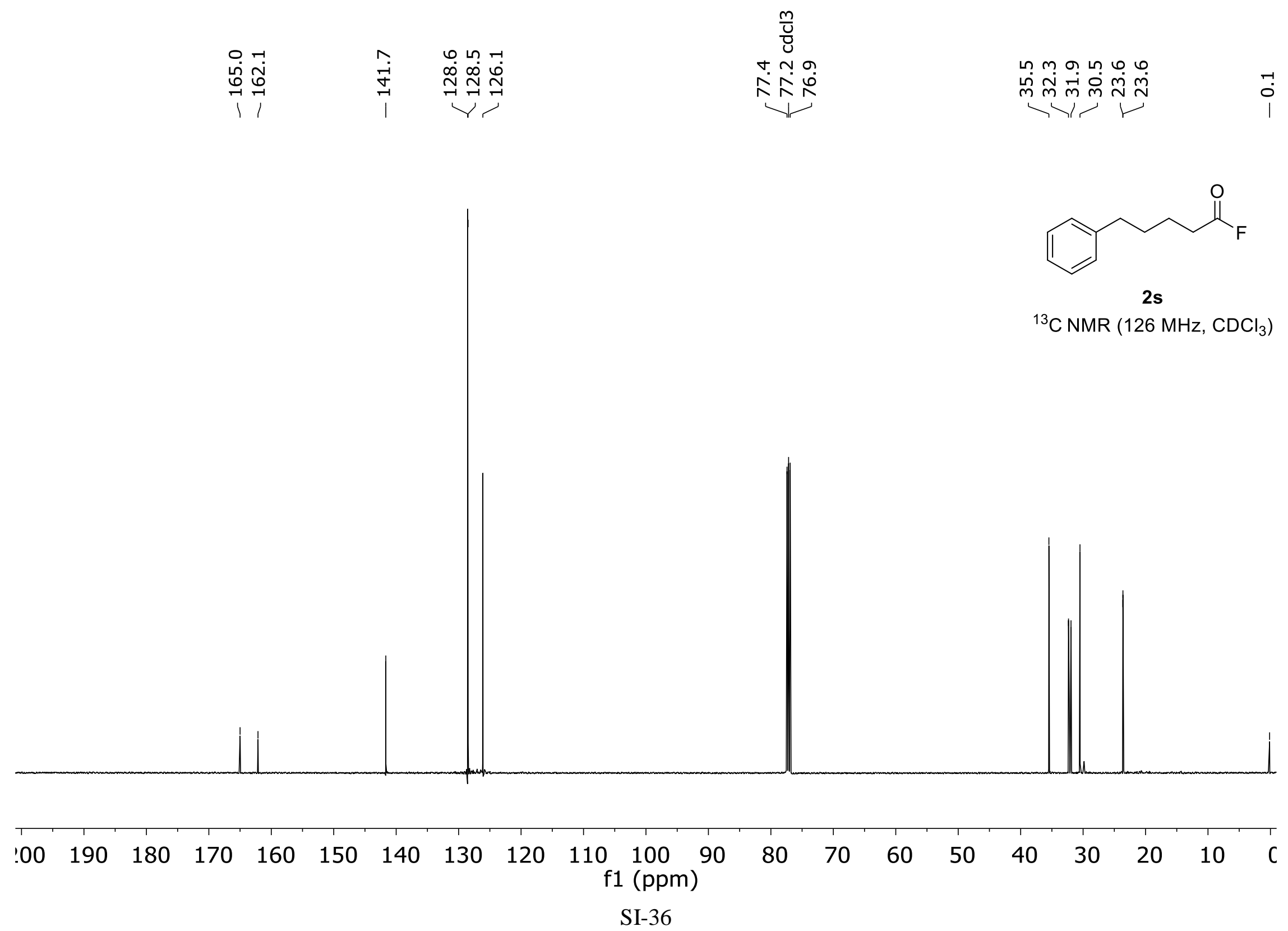




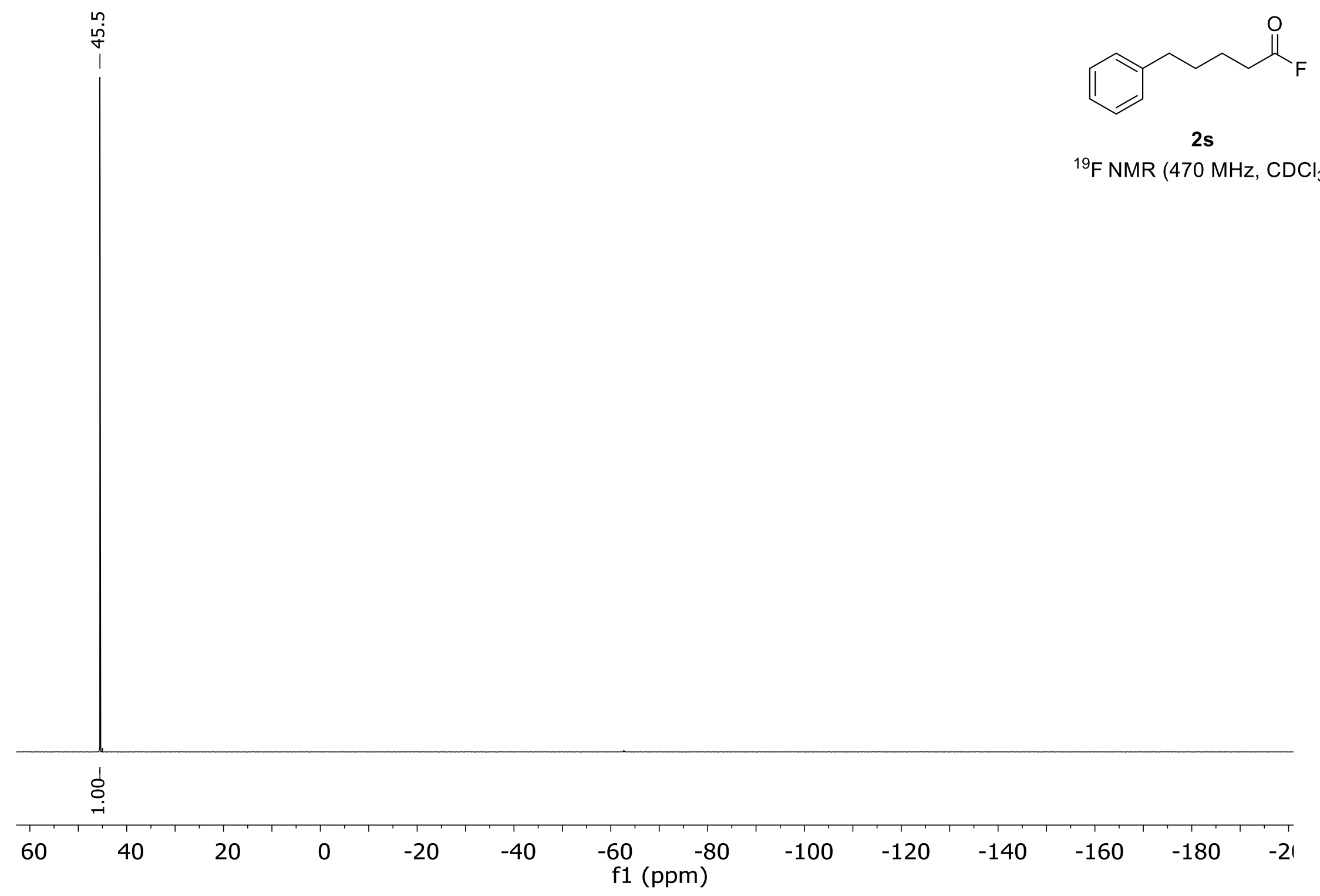

SI-37 


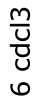

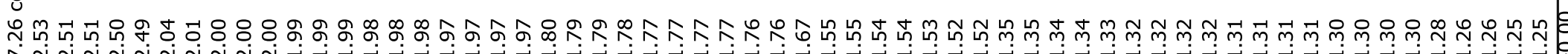

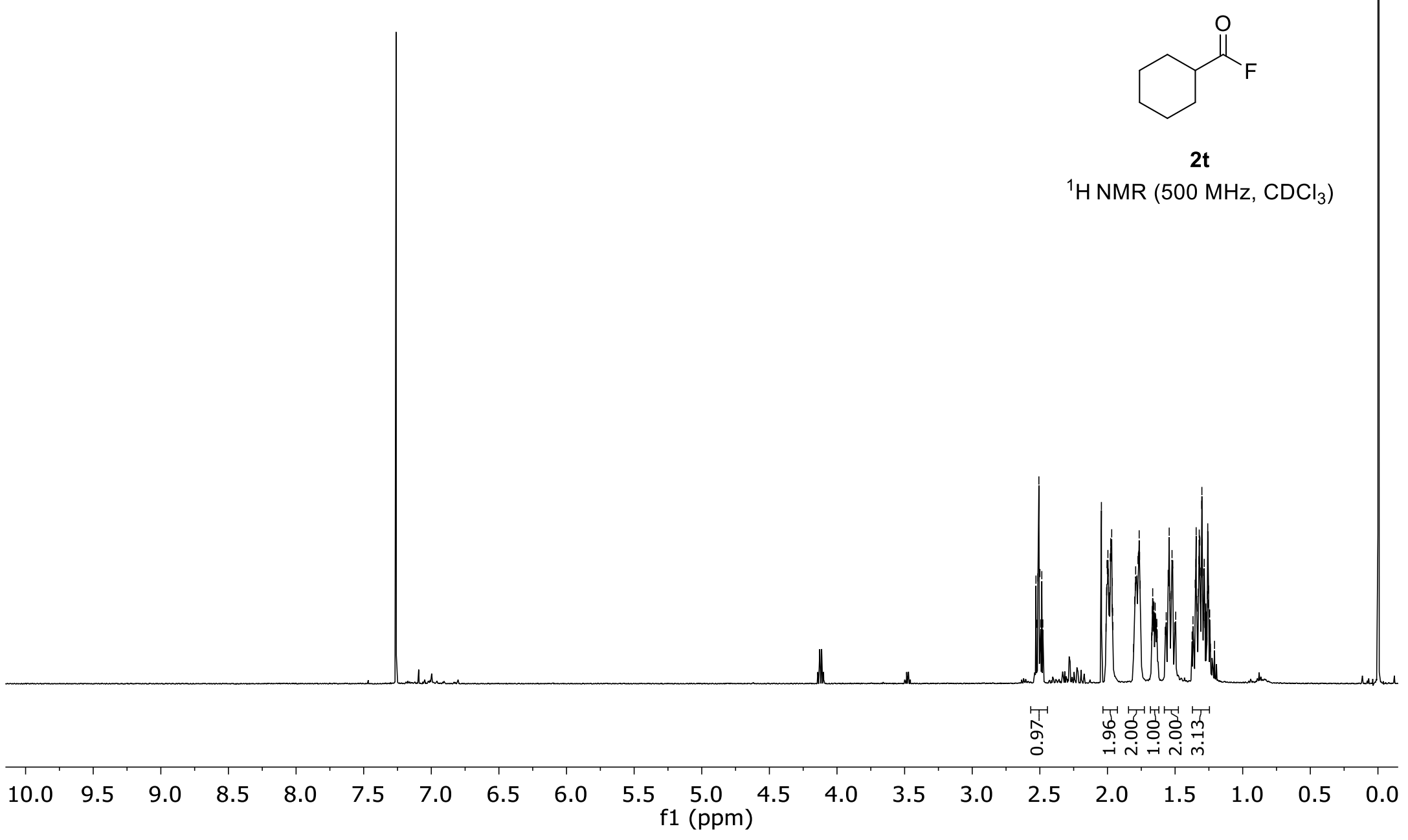




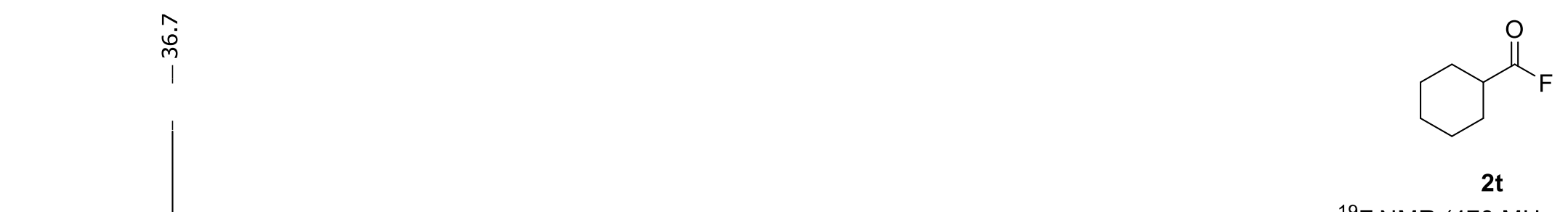

${ }^{19} \mathrm{~F} \mathrm{NMR}\left(470 \mathrm{MHz}, \mathrm{CDCl}_{3}\right)$

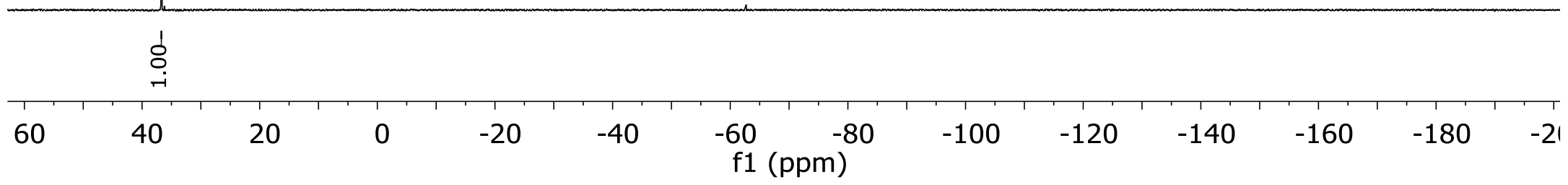

SI-39 


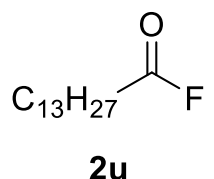

${ }^{1} \mathrm{H} \mathrm{NMR}\left(500 \mathrm{MHz}, \mathrm{CDCl}_{3}\right)$

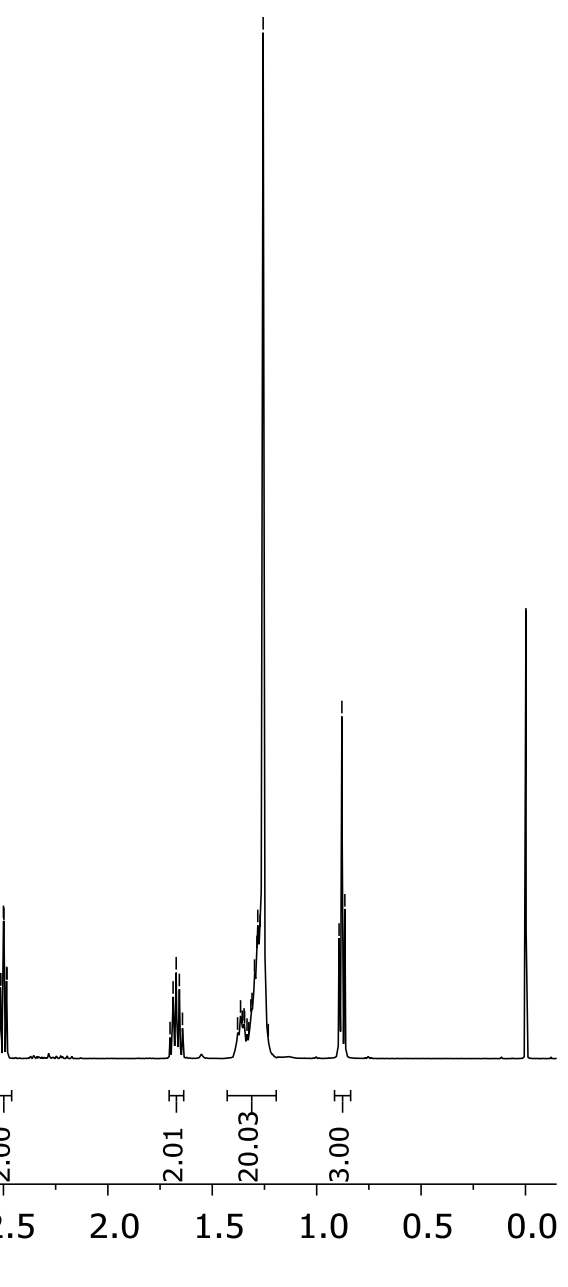

SI-40 


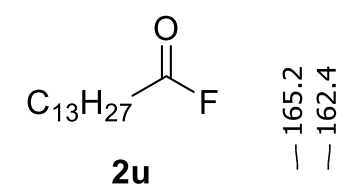

$\stackrel{\frac{1}{\mathrm{u}}}{\mathrm{m}}$

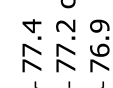

น

m

-

${ }^{13} \mathrm{C}$ NMR $\left(126 \mathrm{MHz}, \mathrm{CDCl}_{3}\right)$

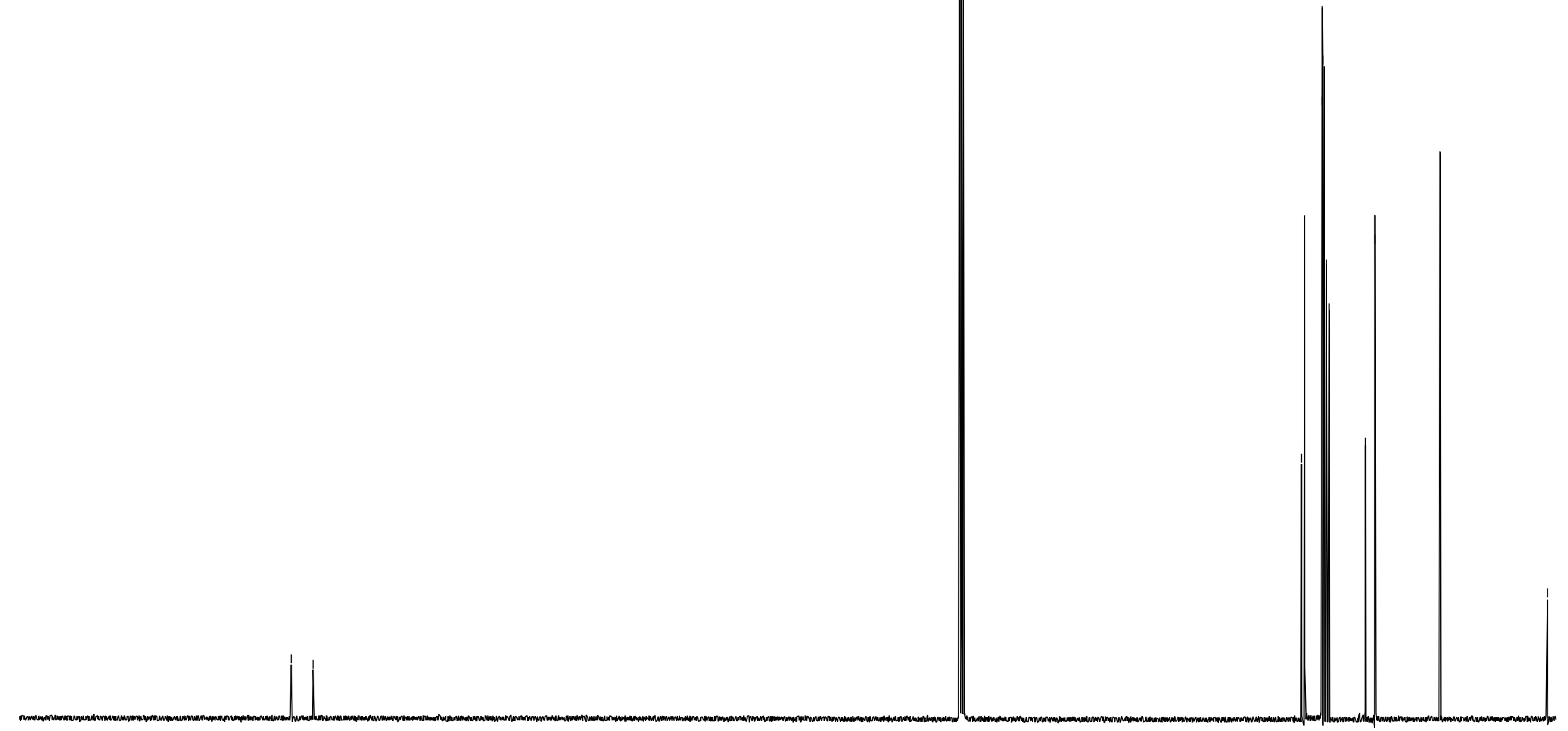

$: 00$

190

$180 \quad 170$

160

150

140

130

120

$110 \quad 100$ f1 (ppm)

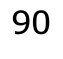

$80 \quad 70$

60

50

40

30

$20 \quad 10 \quad 0$

$$
\text { SI-41 }
$$




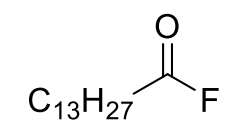

$2 \mathbf{u}$

${ }^{19} \mathrm{~F}$ NMR $\left(470 \mathrm{MHz}, \mathrm{CDCl}_{3}\right)$

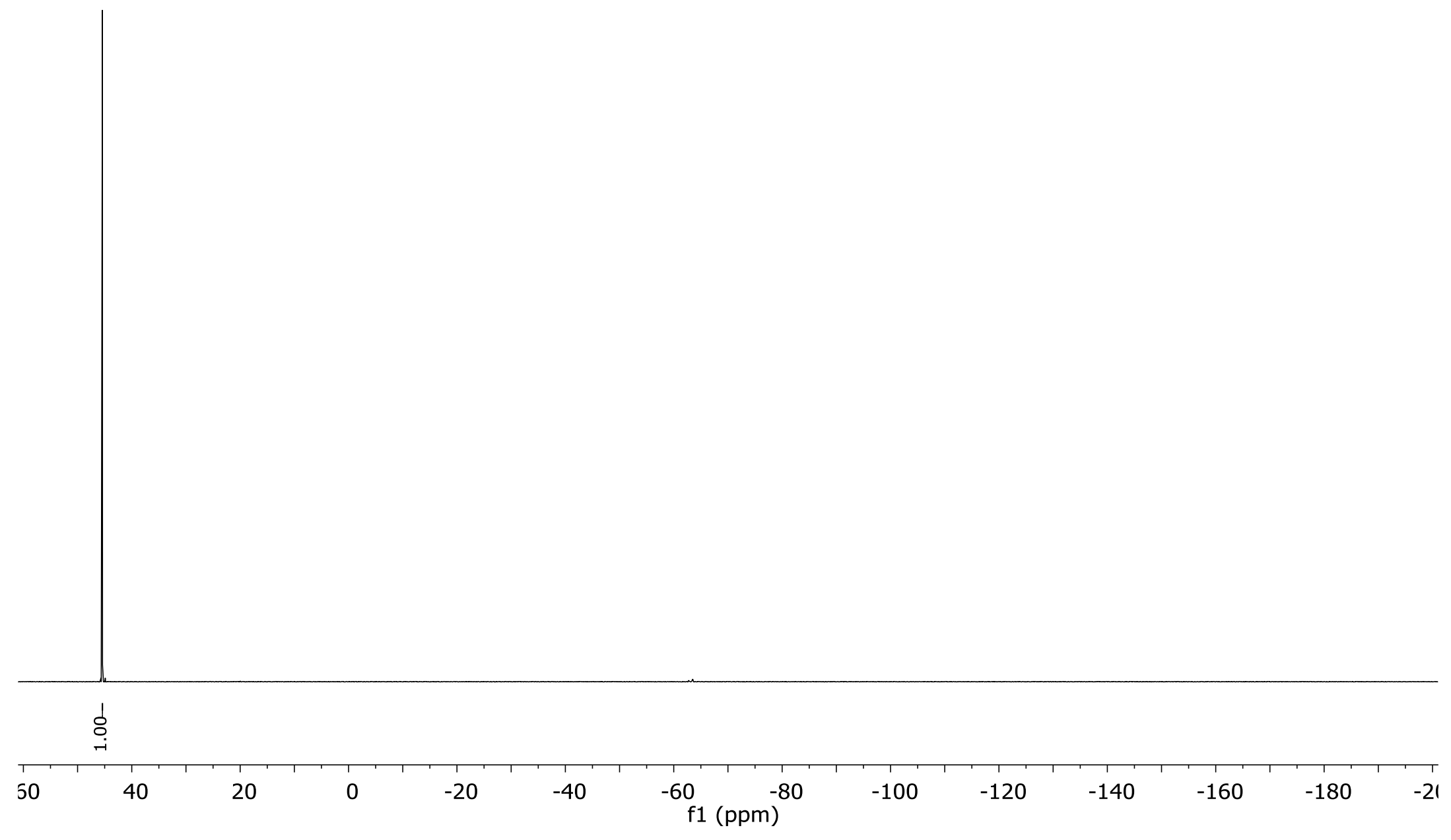

SI-42 
${ }^{1} \mathrm{H}$ NMR (500 MHz, CDCl ${ }_{3}$ )

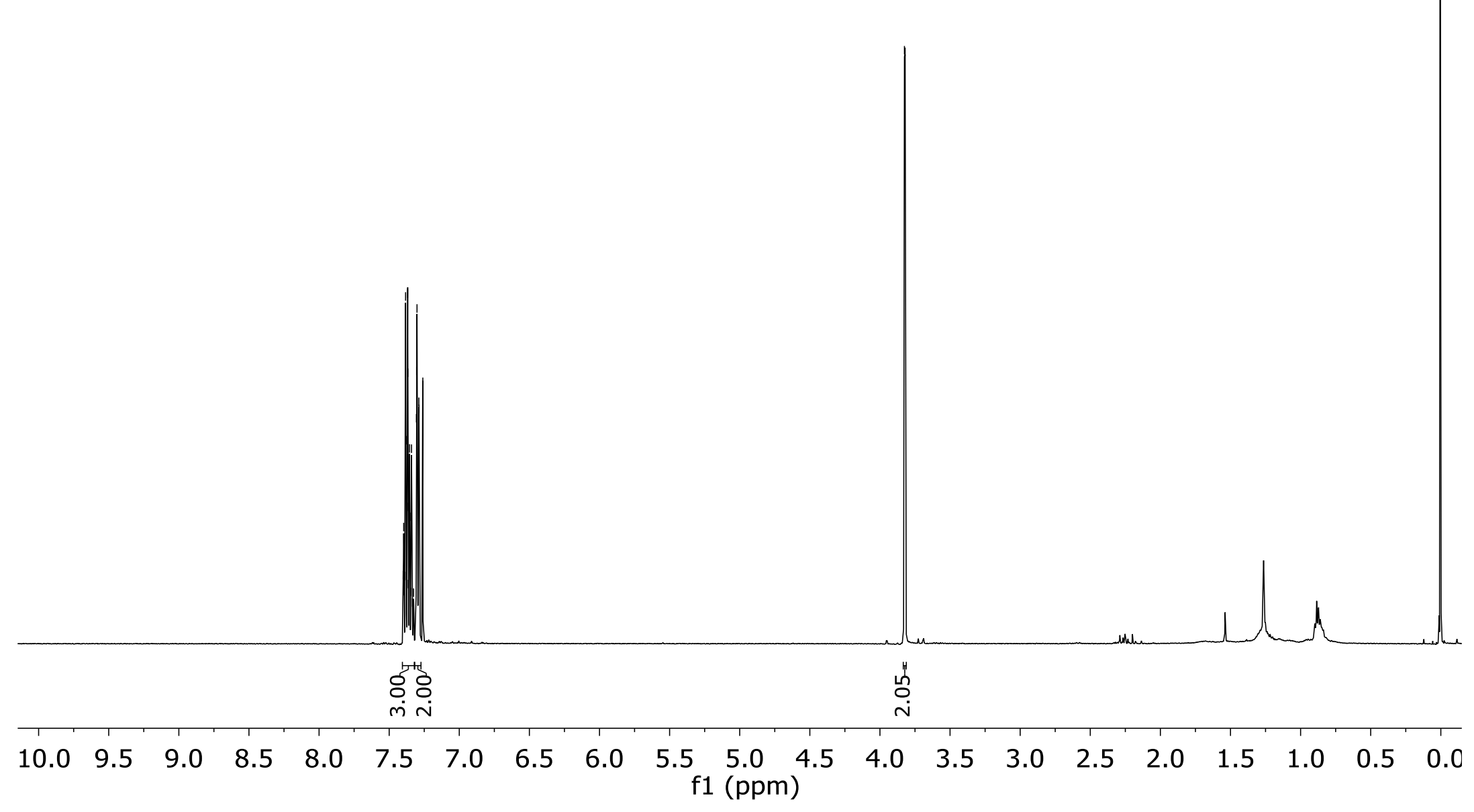




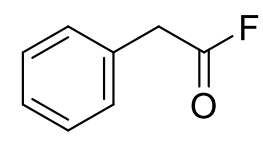

2v

${ }^{19} \mathrm{~F}$ NMR $\left(470 \mathrm{MHz}, \mathrm{CDCl}_{3}\right)$

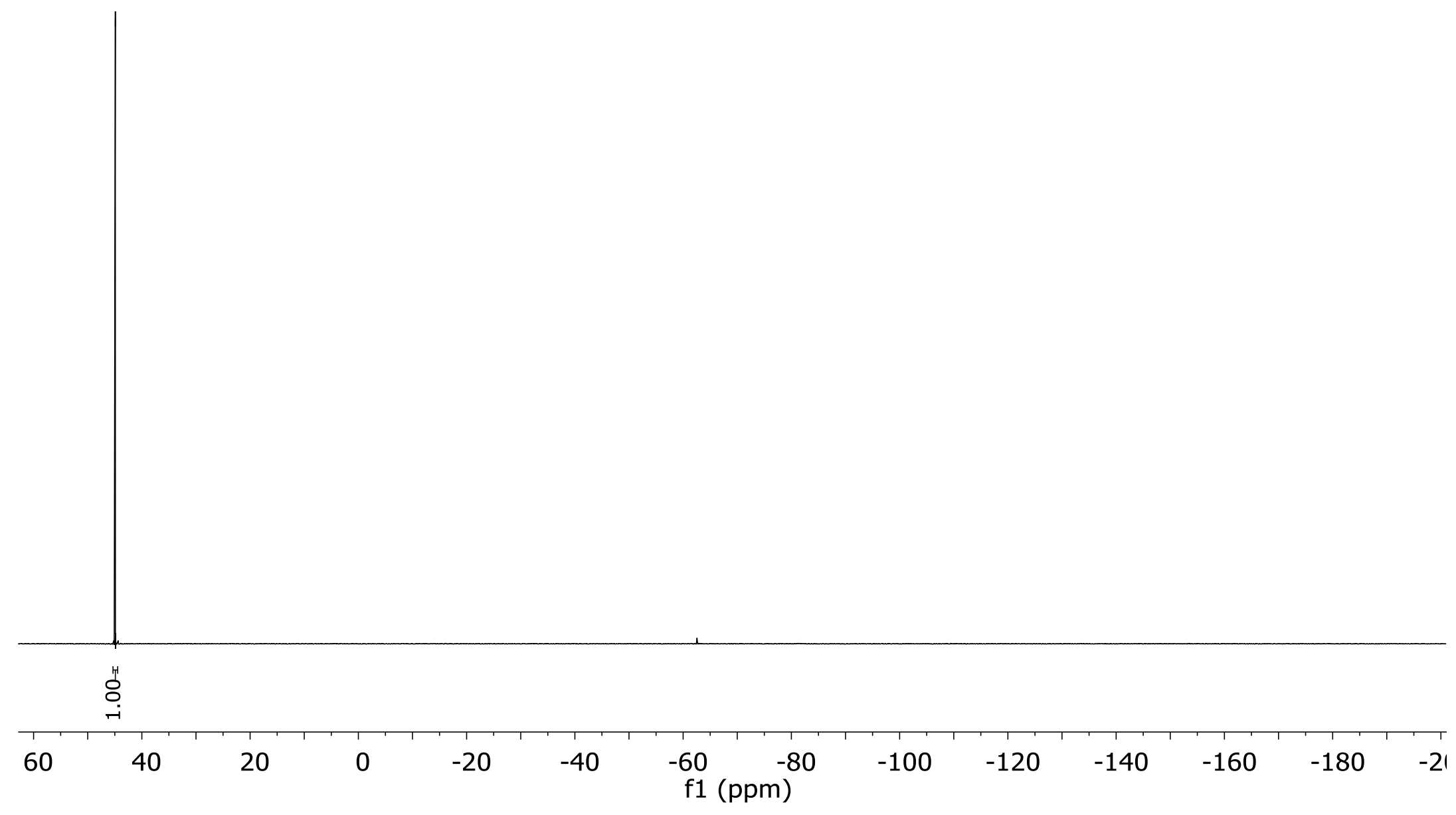

$$
\text { SI-44 }
$$




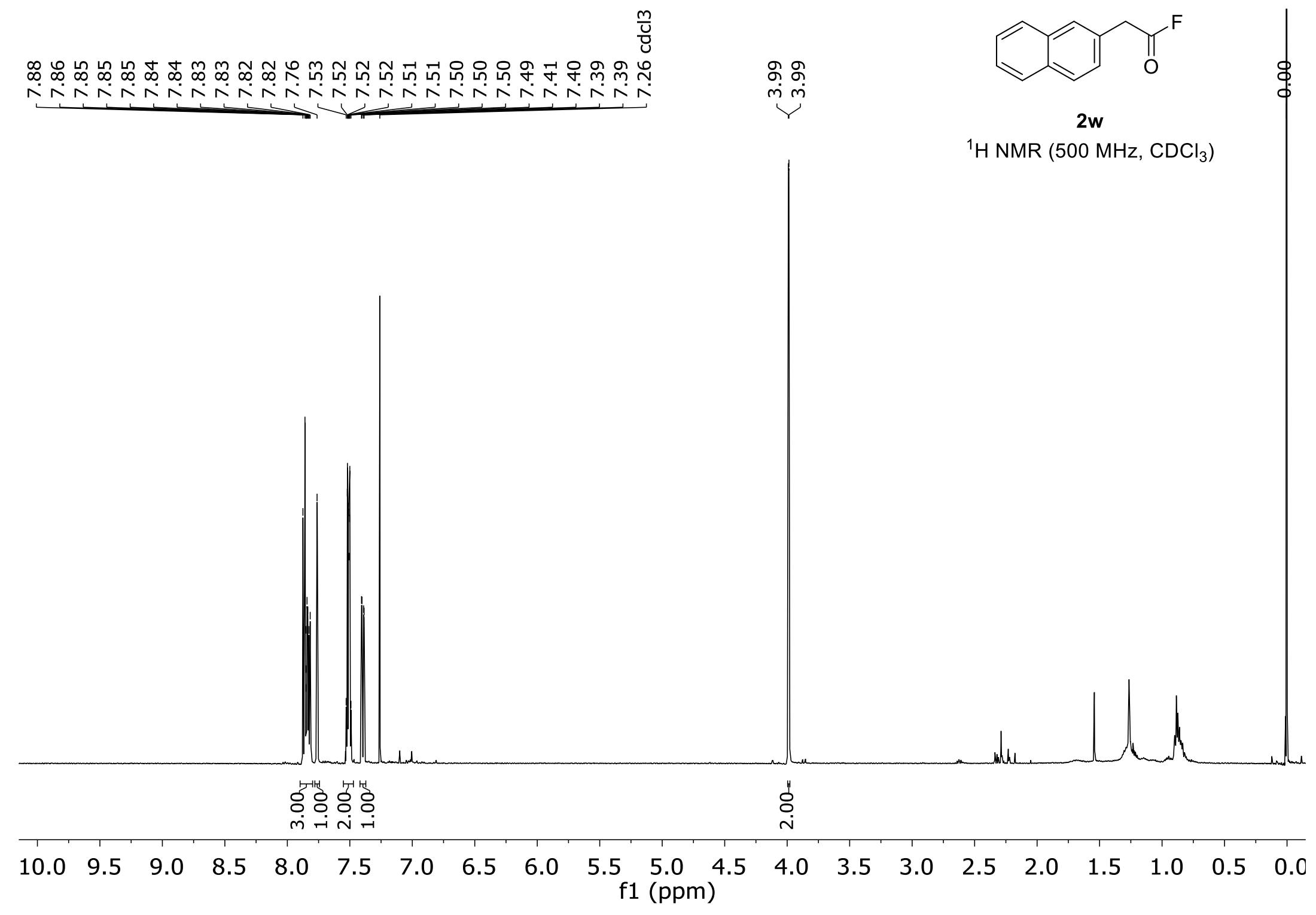




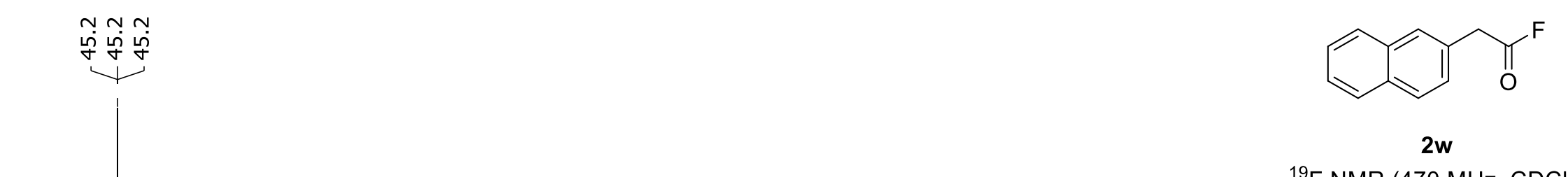

${ }^{19} \mathrm{~F}$ NMR $\left(470 \mathrm{MHz}, \mathrm{CDCl}_{3}\right)$

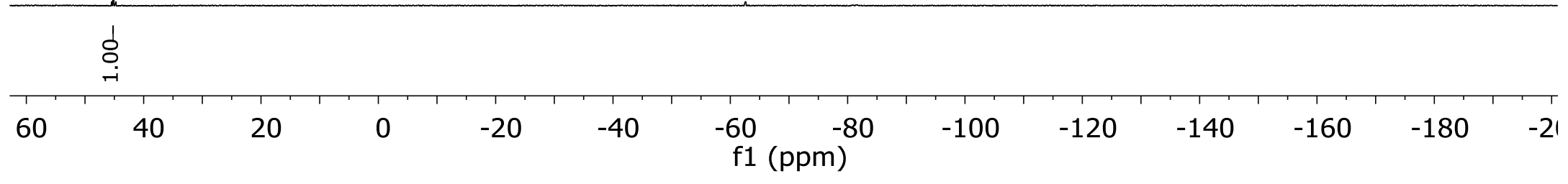

SI-46 


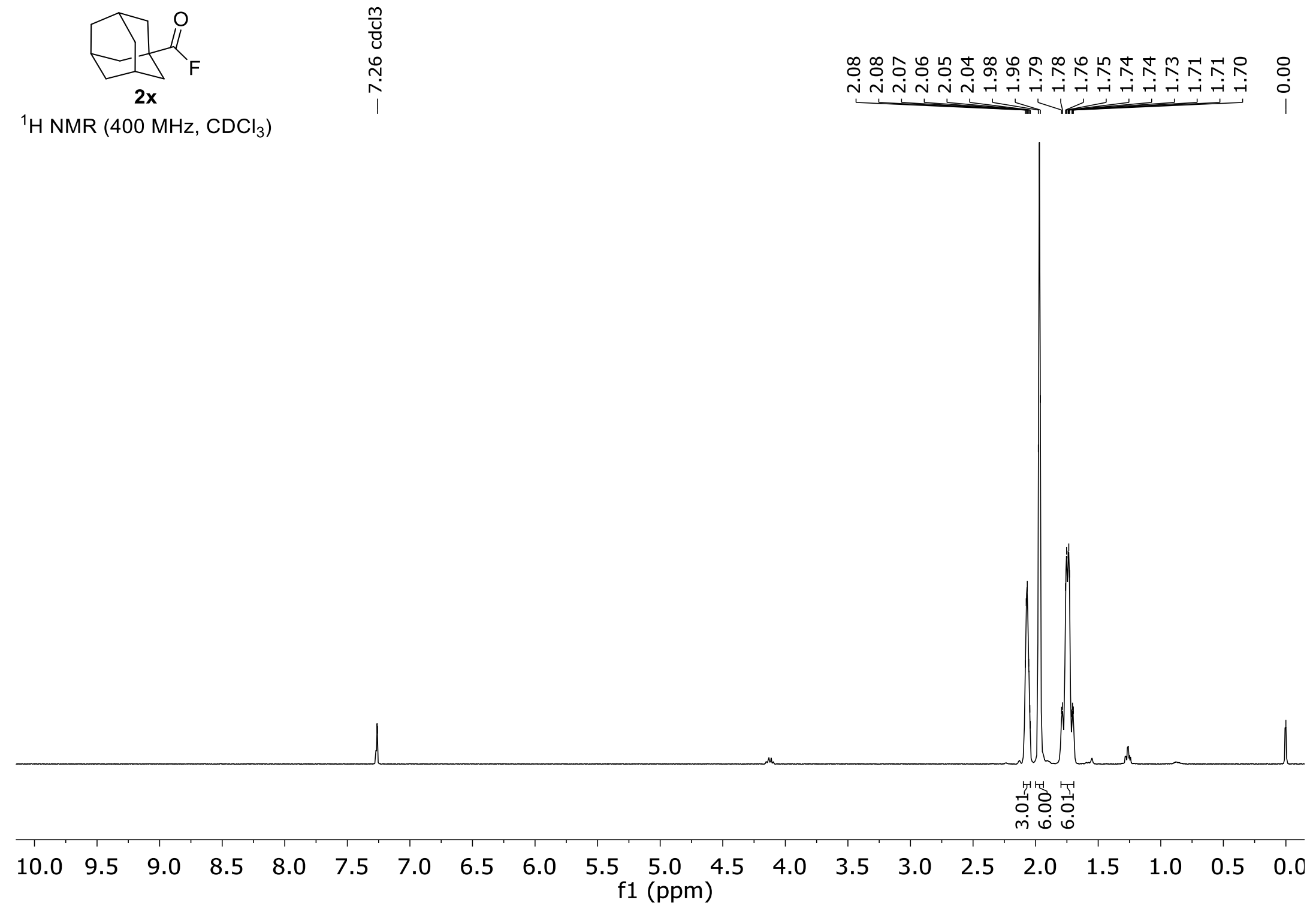

SI-47 


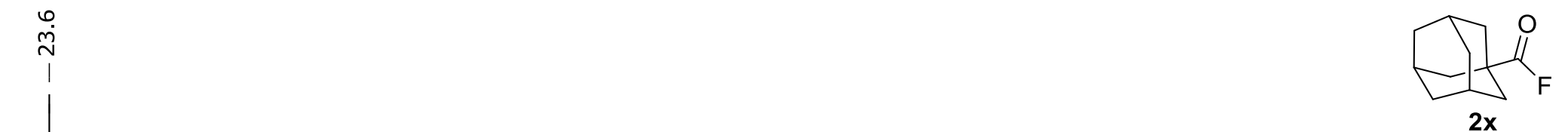

${ }^{19} \mathrm{~F} \mathrm{NMR}\left(376 \mathrm{MHz}, \mathrm{CDCl}_{3}\right.$ )

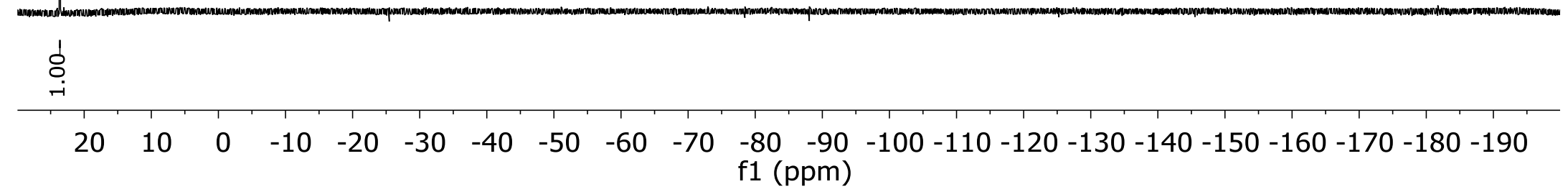

SI-48 


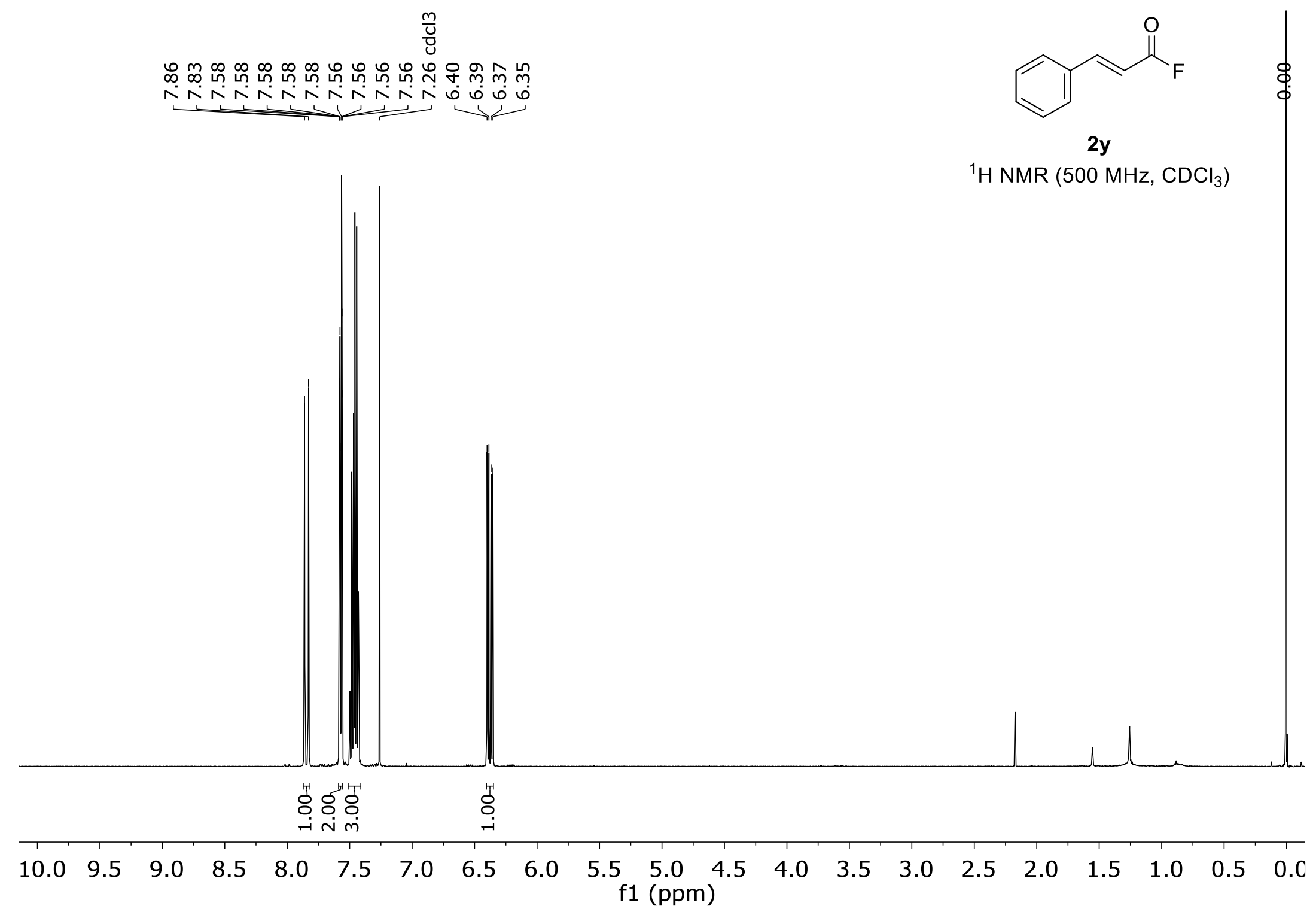

SI-49 
占
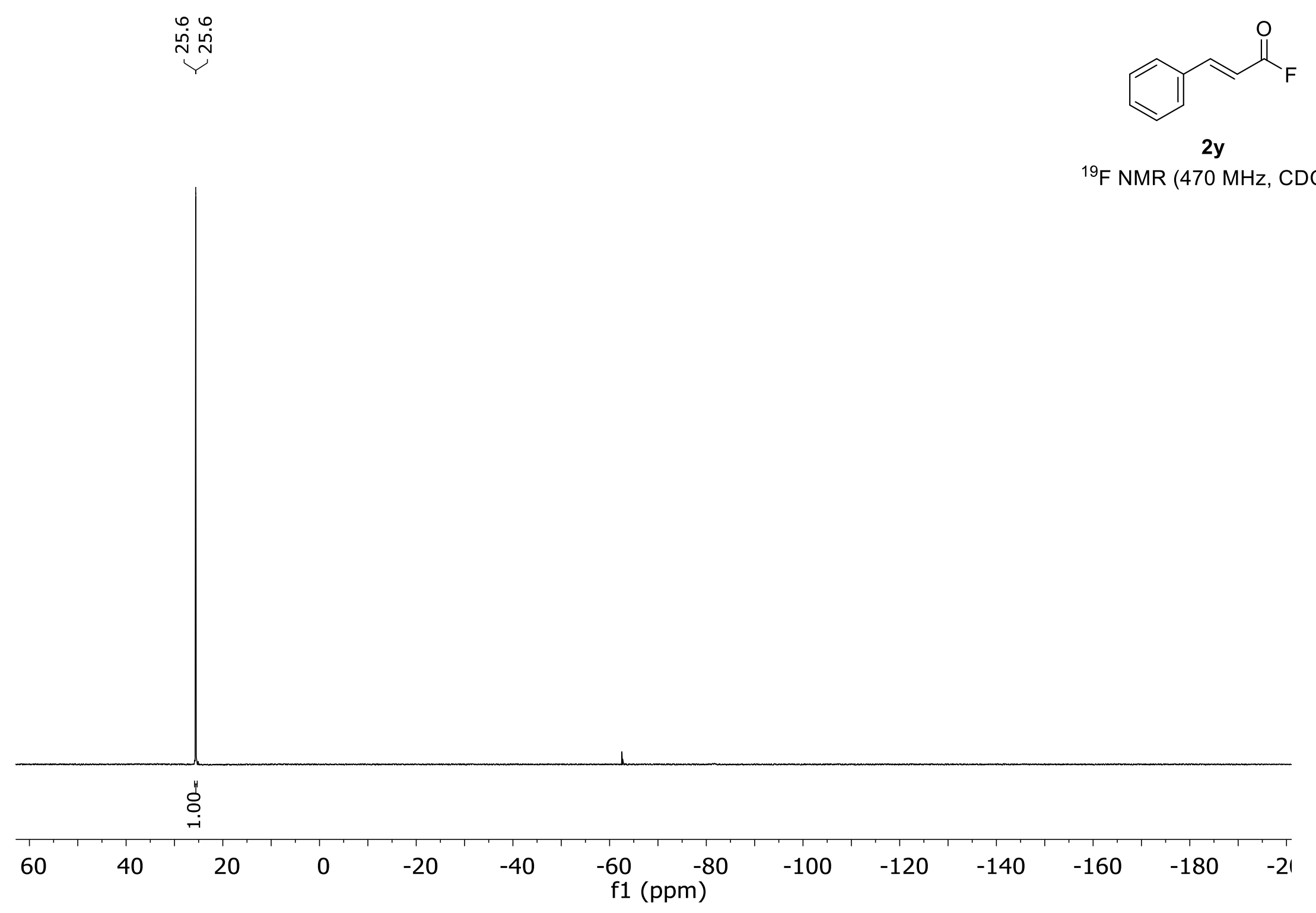

$2 y$ 


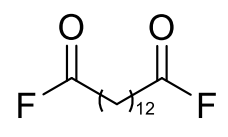

$2 z$

${ }^{1} \mathrm{H}$ NMR $\left(500 \mathrm{MHz}, \mathrm{CDCl}_{3}\right)$

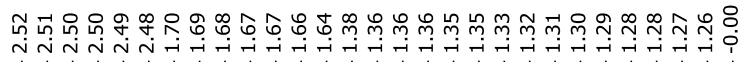

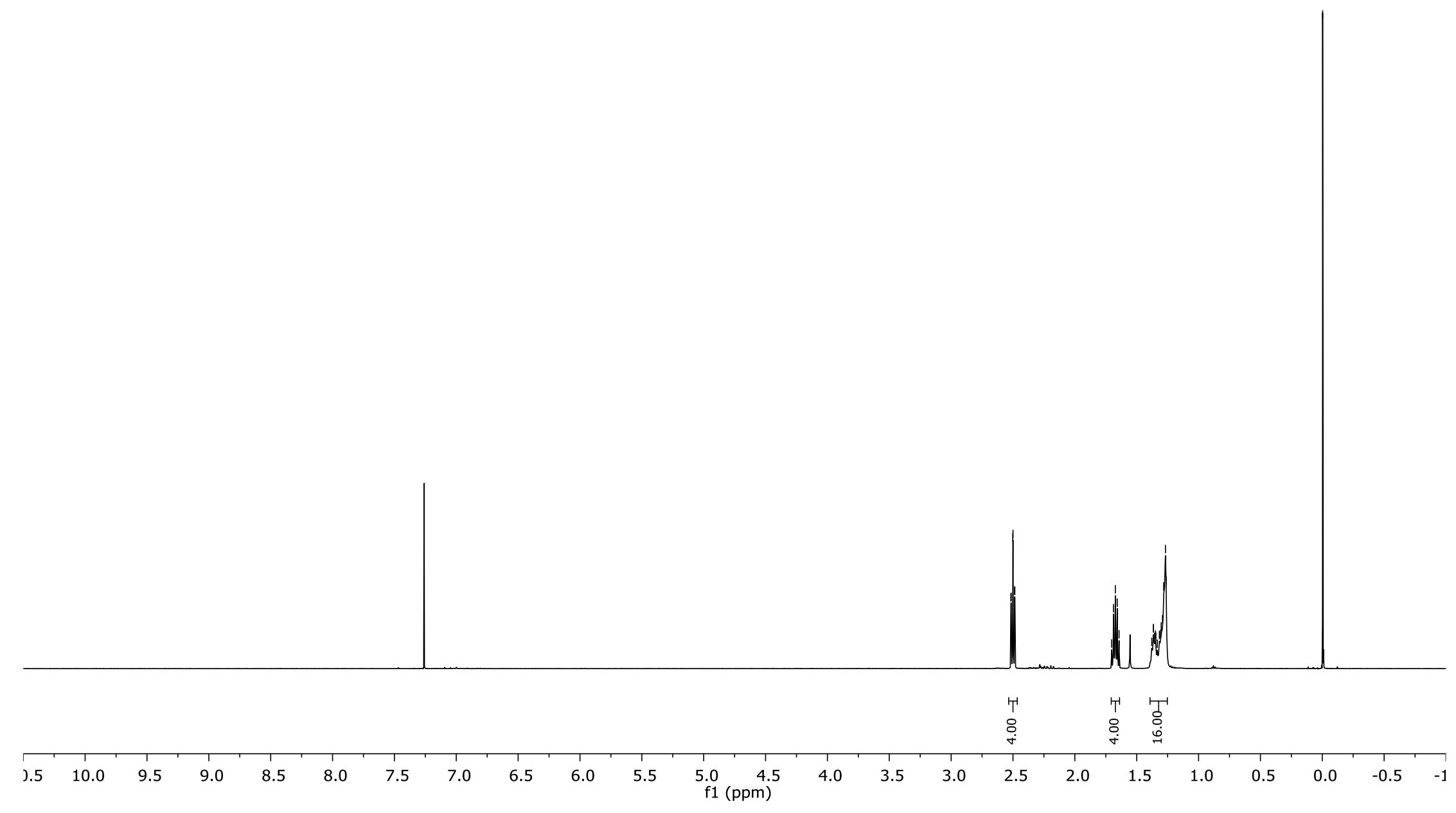

SI-51 
กั

กู่ ชู่

11 $\frac{m}{\mathrm{v}}$

ำ กิก

rin

1

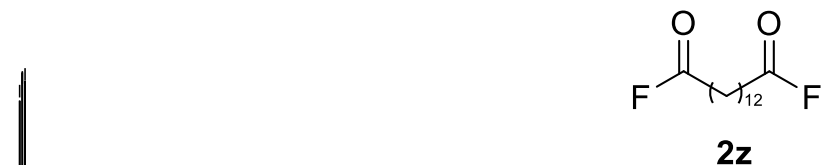

${ }^{13} \mathrm{C}$ NMR $\left(126 \mathrm{MHz}, \mathrm{CDCl}_{3}\right)$

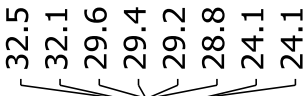

$\overrightarrow{0}$

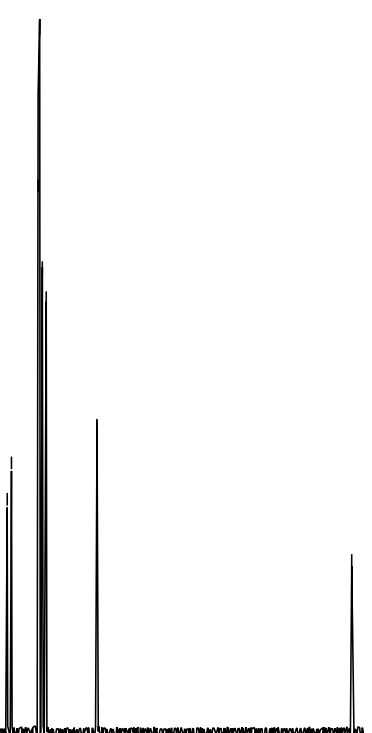

100

180

$170 \quad 160 \quad 150$

$140 \quad 130$

$\begin{array}{llll}120 & 110 & 100 & 90\end{array}$

f1 (ppm)

8070

60

$50 \quad 40 \quad 30$

$20 \quad 10 \quad C$ 


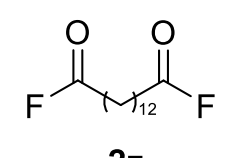

${ }^{19} \mathrm{~F} \mathrm{NMR}\left(470 \mathrm{MHz}, \mathrm{CDCl}_{3}\right)$

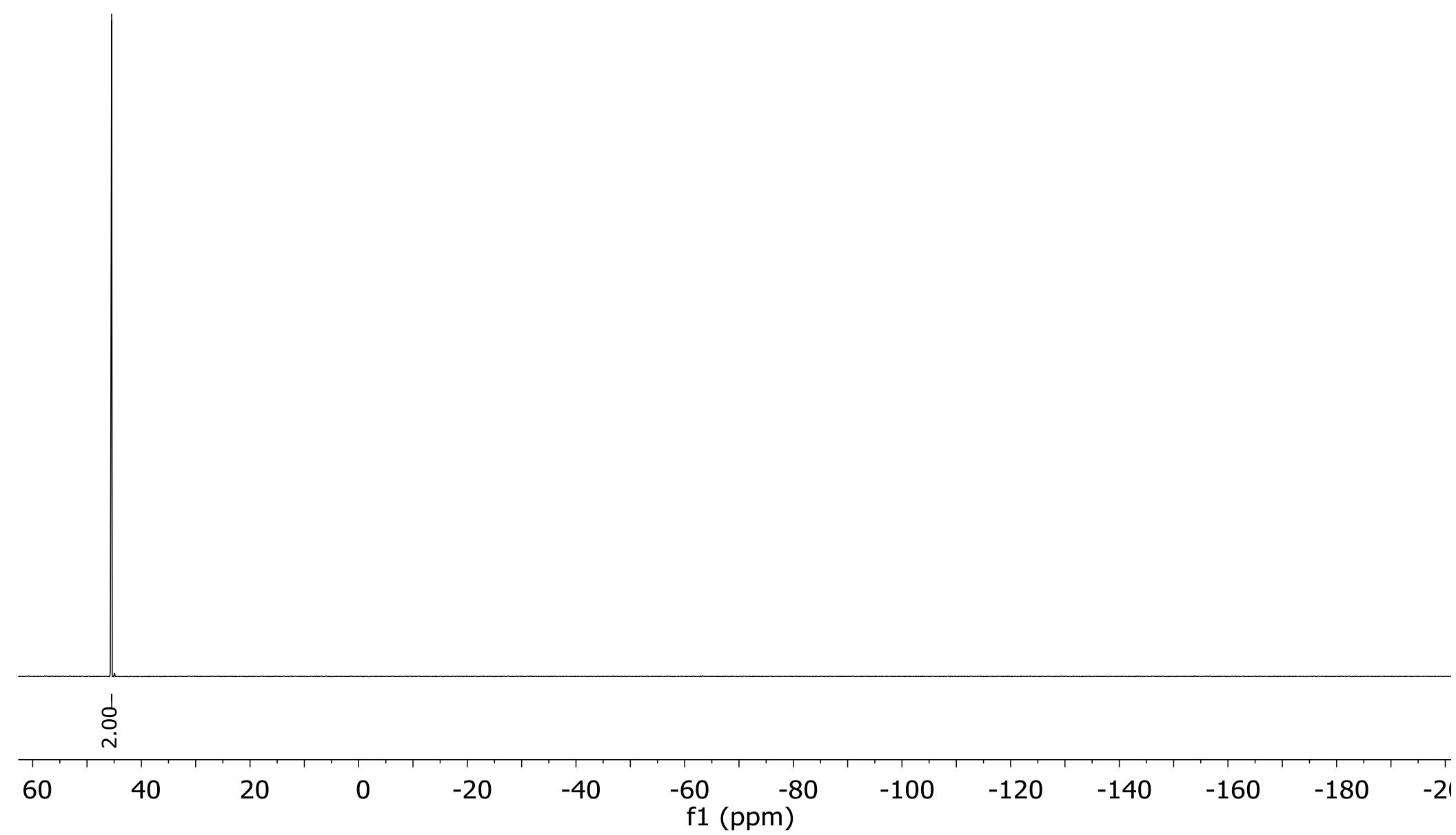




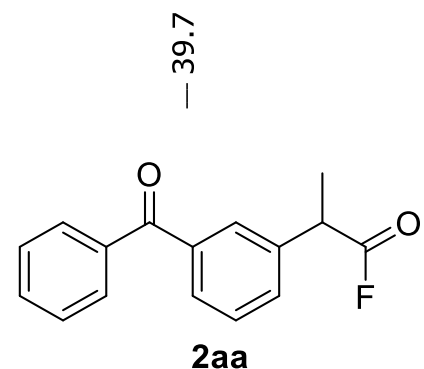

Crude mixture

${ }^{19} \mathrm{~F}$ NMR $\left(470 \mathrm{MHz}, \mathrm{CDCl}_{3}\right)$

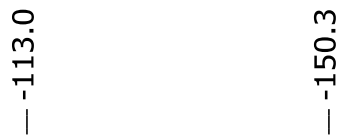

Internal standard

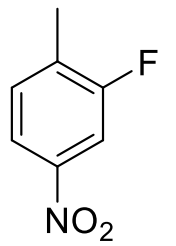

$\Theta_{\mathrm{BF}_{4}}$
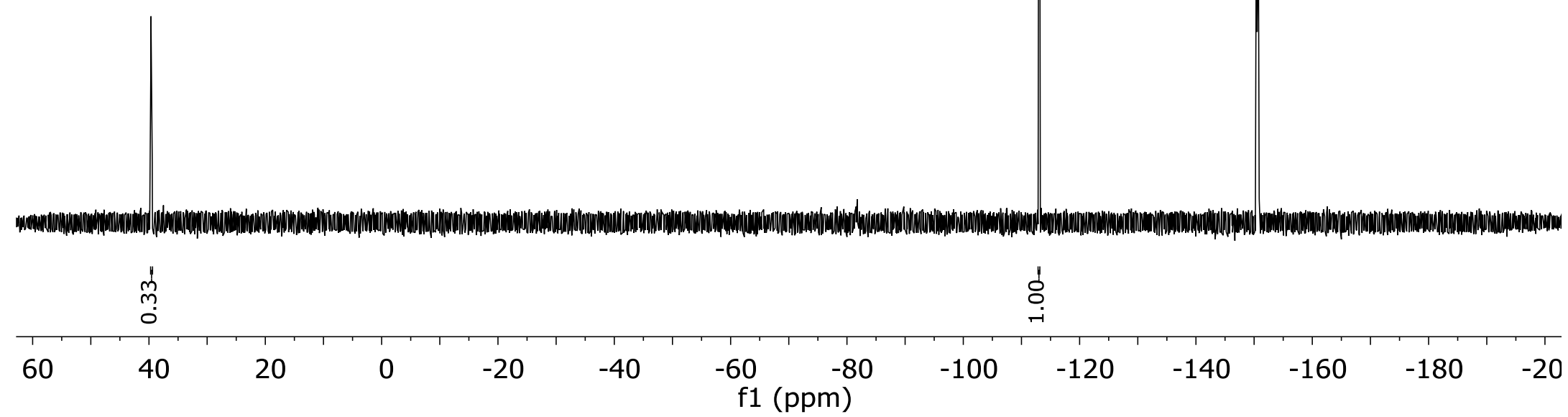
$\frac{m}{\mathrm{u}}$

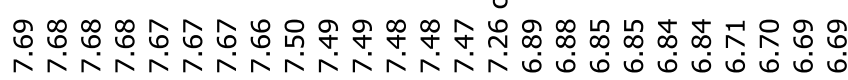

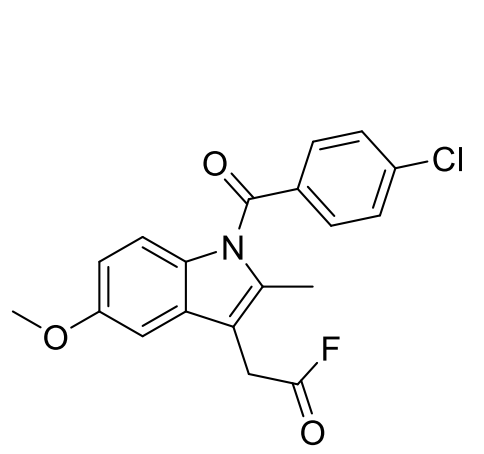

$2 a b$

${ }^{1} \mathrm{H}$ NMR $\left(500 \mathrm{MHz}, \mathrm{CDCl}_{3}\right)$

\section{مि}

$\underbrace{m i m}$

$\stackrel{\vec{j}}{\vec{j}}$

$\stackrel{8}{i}$

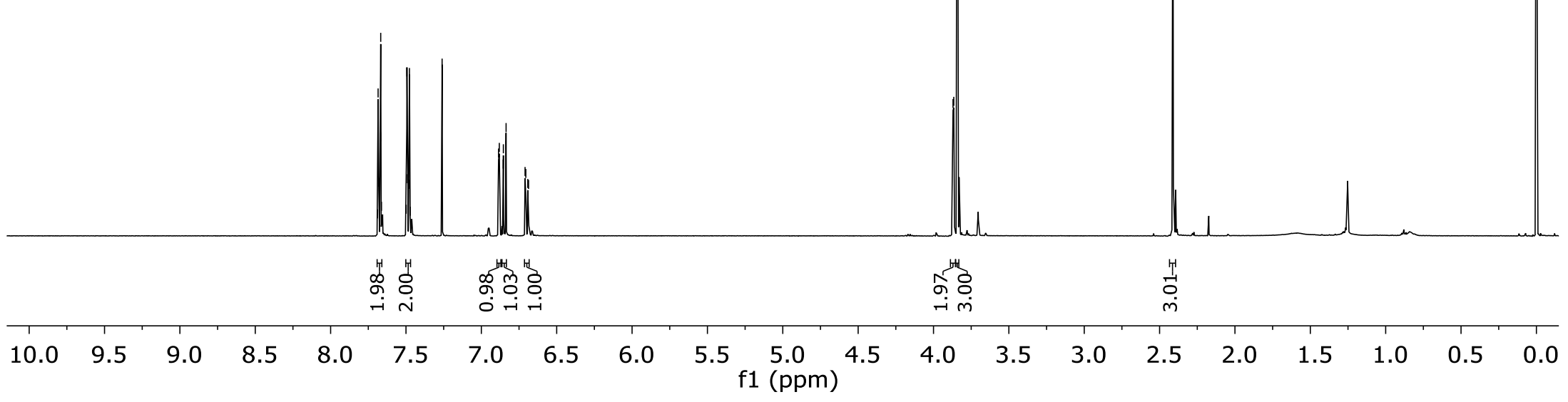




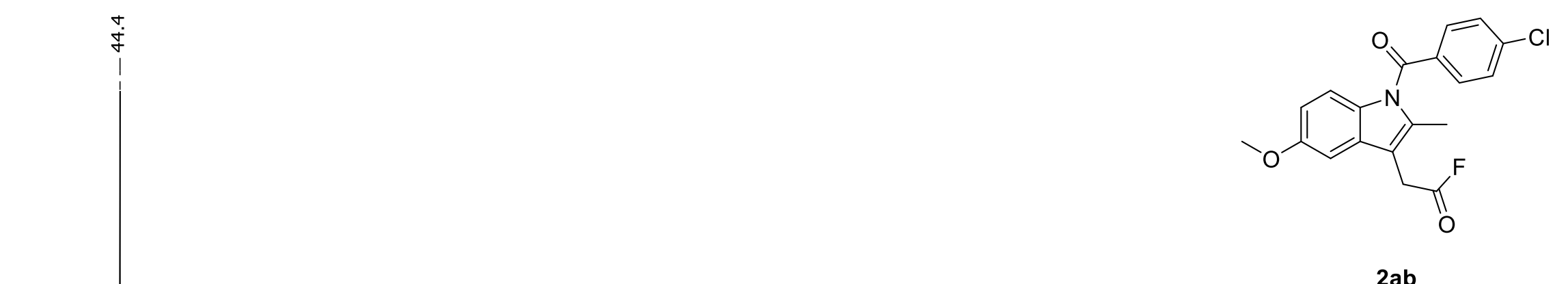

2ab

${ }^{19} \mathrm{~F} \mathrm{NMR} \mathrm{(470} \mathrm{MHz,} \mathrm{CDCl}_{3}$ )

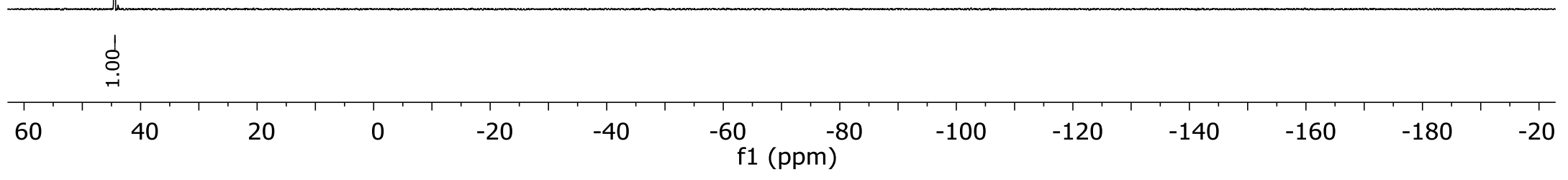

SI-56 


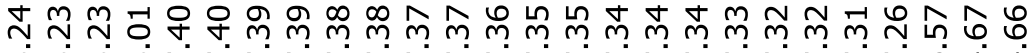

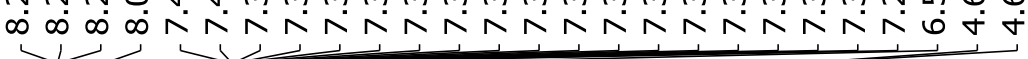

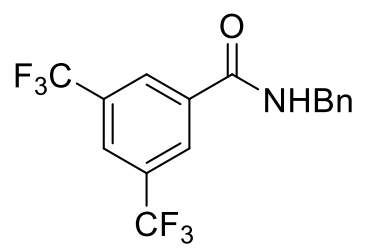

$3 \mathbf{a}$

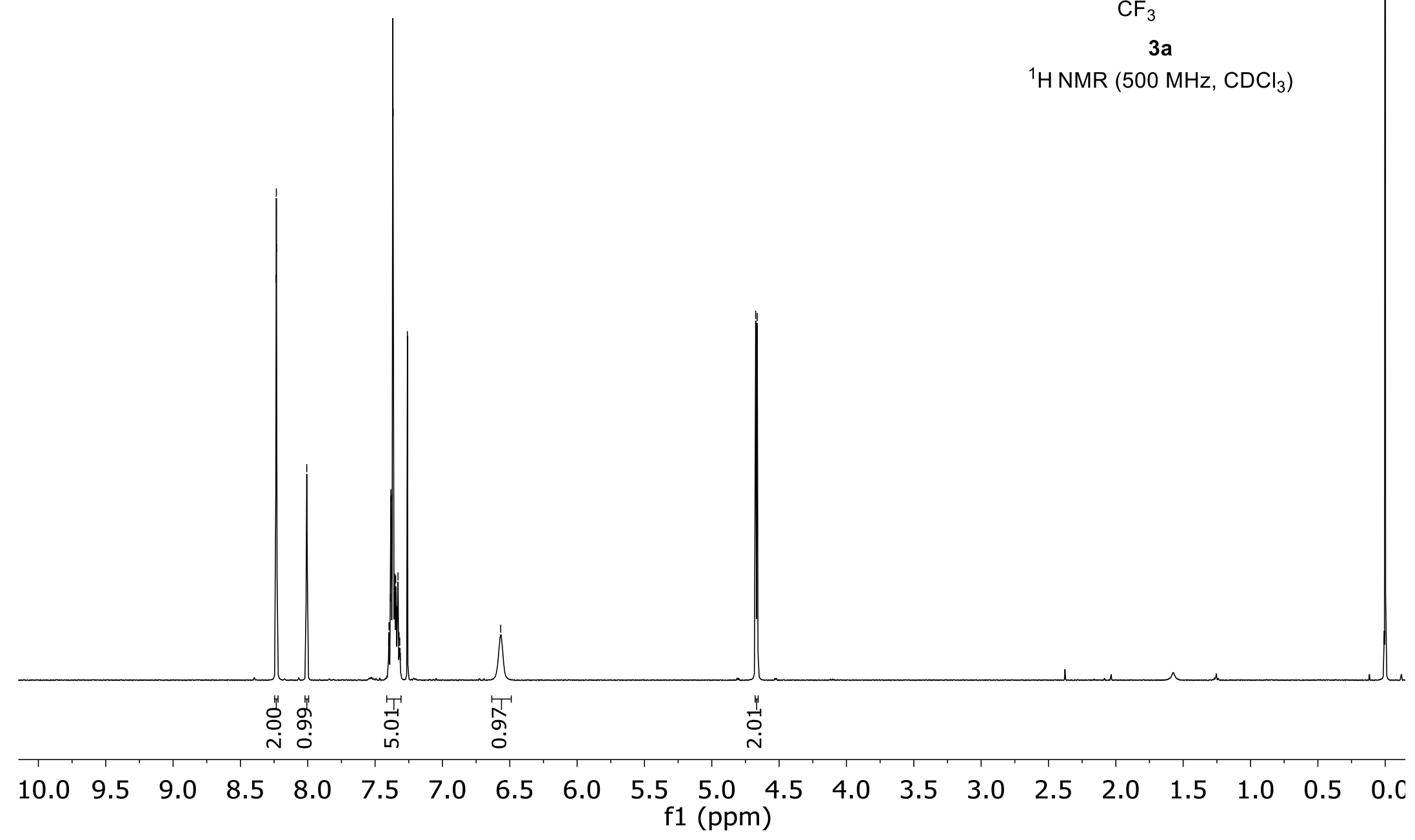

SI-57 


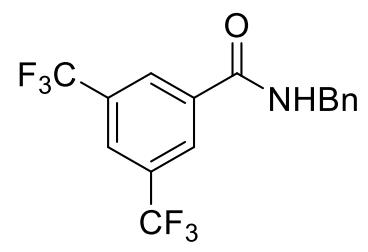

$3 a$

${ }^{19} \mathrm{~F} \mathrm{NMR}\left(470 \mathrm{MHz}, \mathrm{CDCl}_{3}\right)$

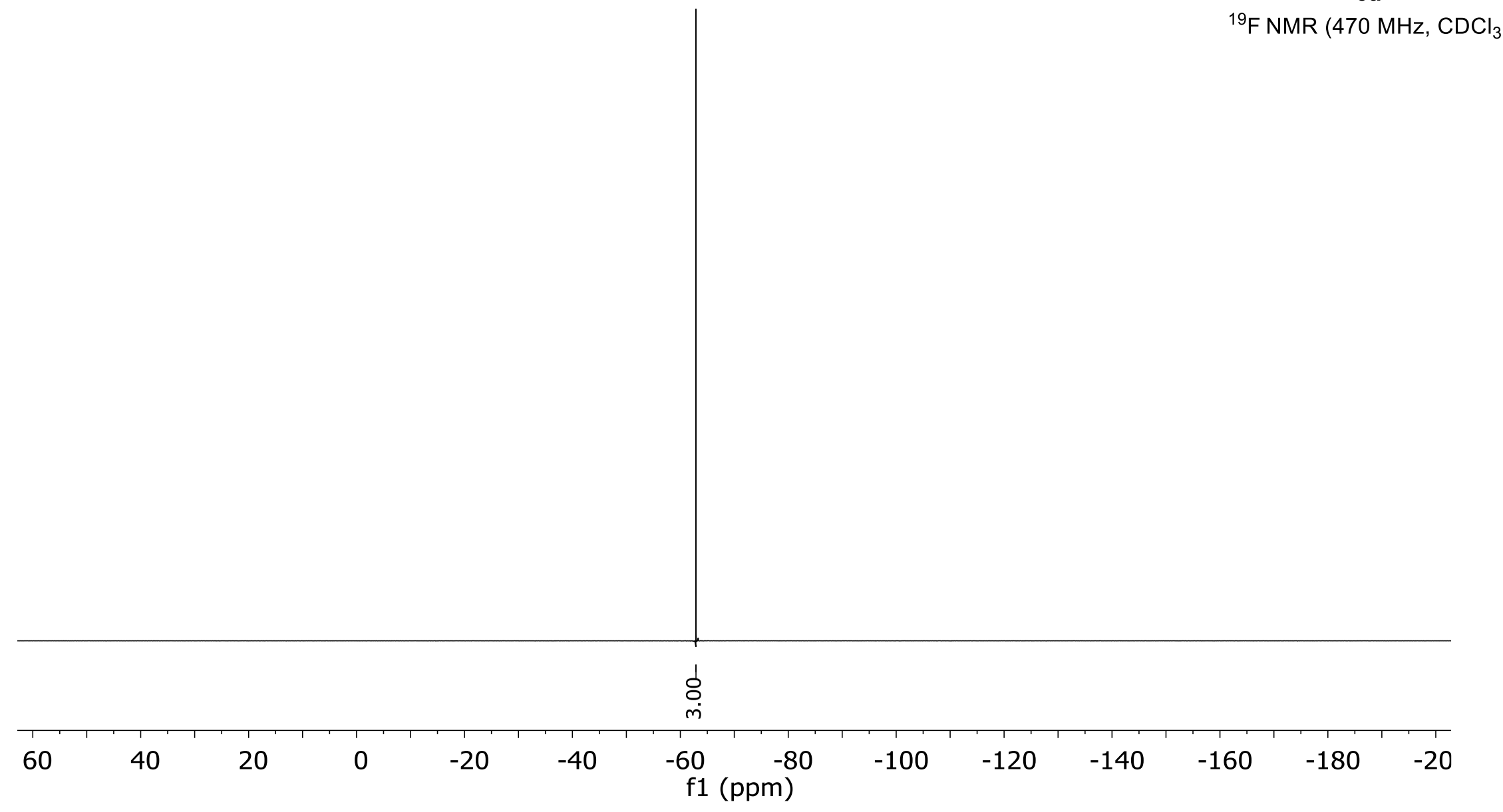

SI-58 
$\frac{m}{\mathrm{U}}$

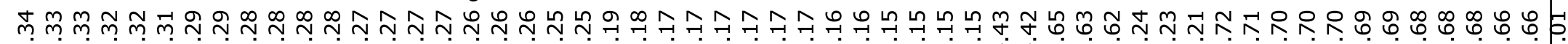

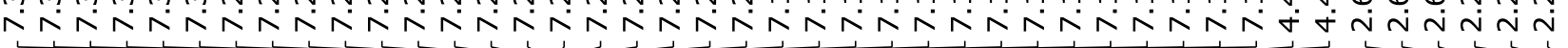

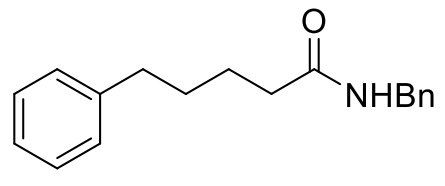

3b

${ }^{1} \mathrm{H} \mathrm{NMR}\left(500 \mathrm{MHz}, \mathrm{CDCl}_{3}\right)$

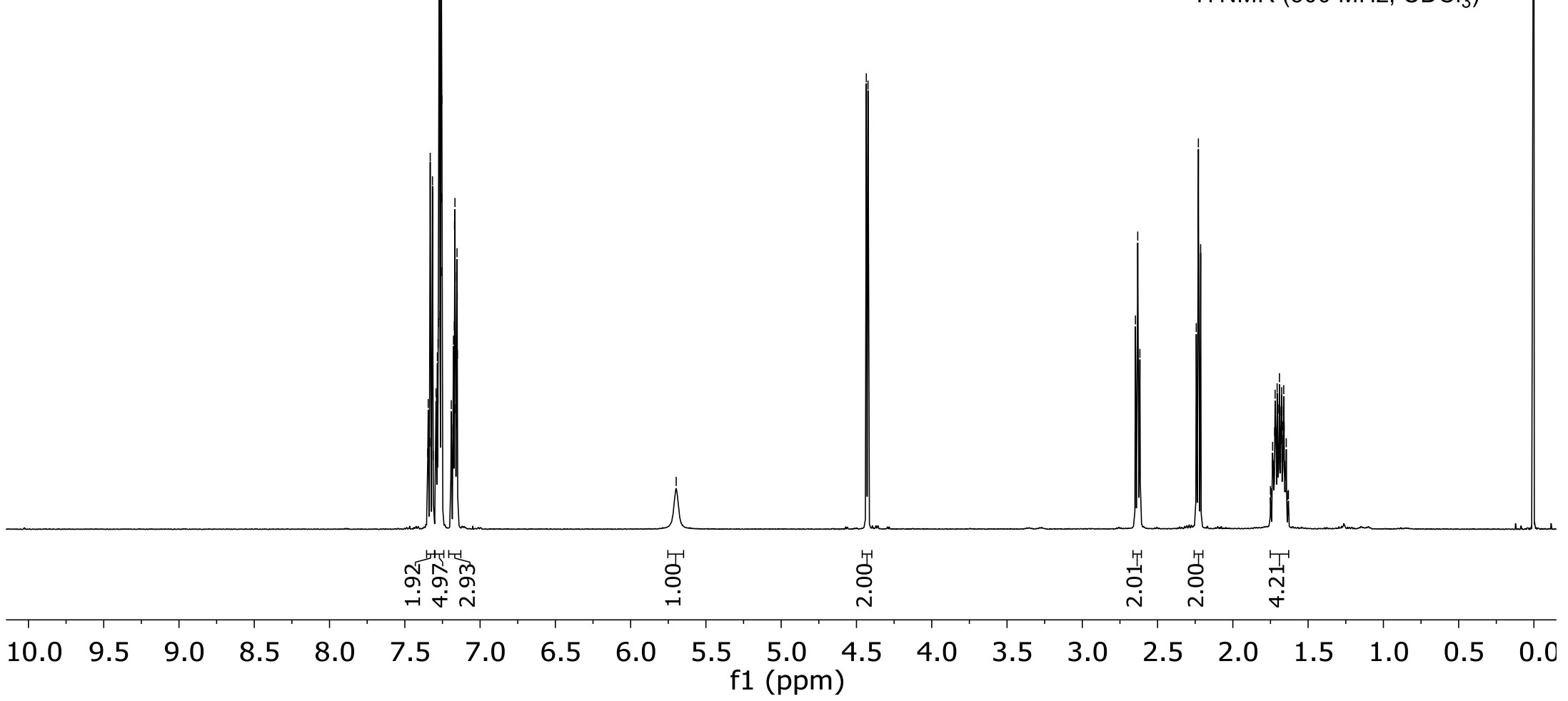

SI-59 
$\frac{m}{\mathrm{u}}$



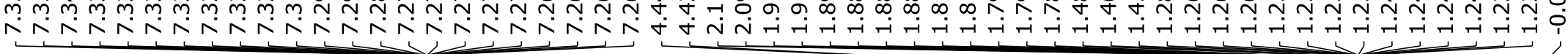

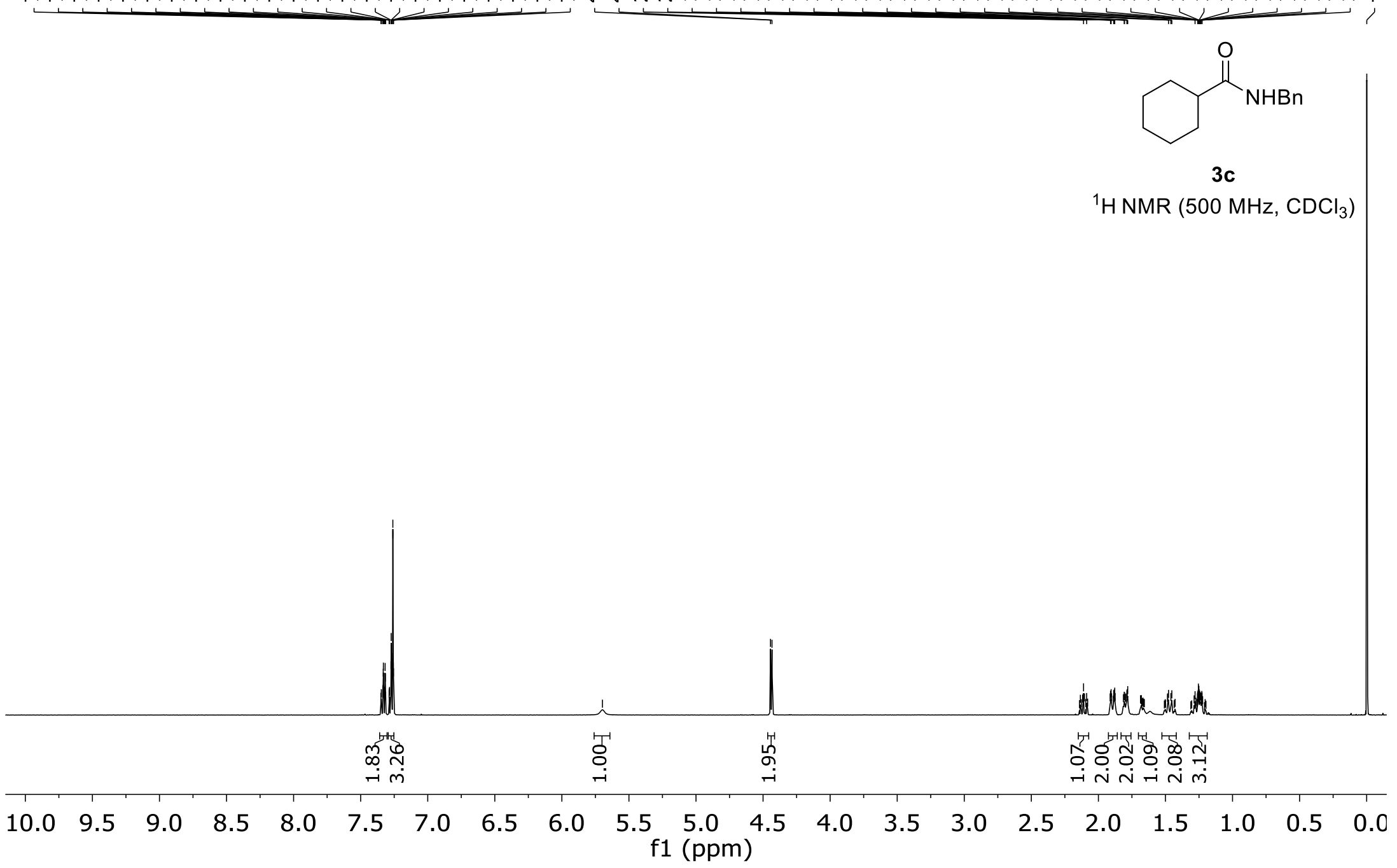




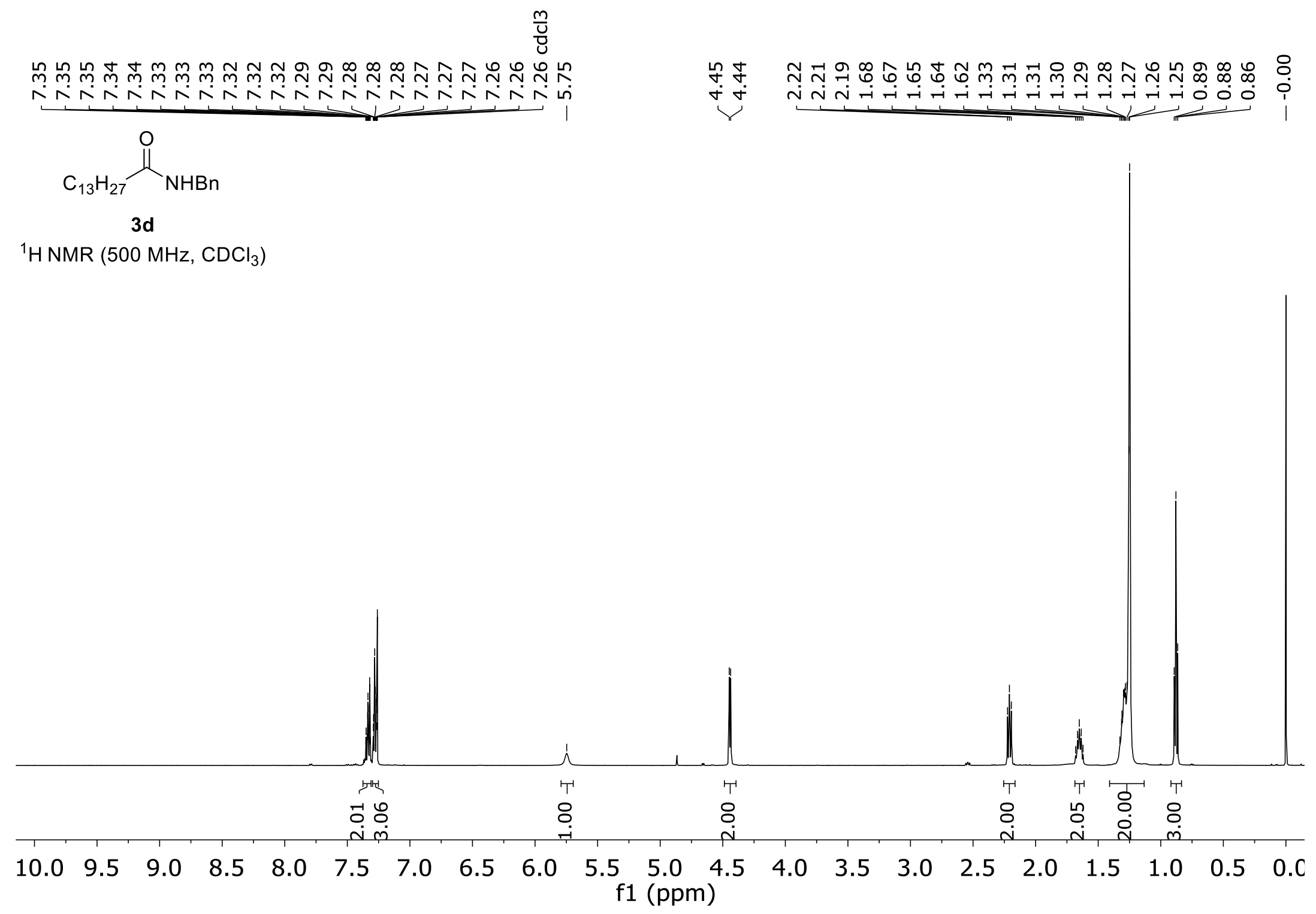


$\frac{m}{\mathrm{u}}$

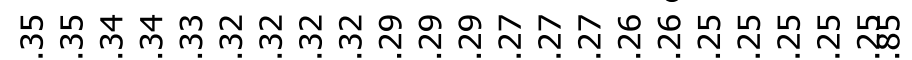

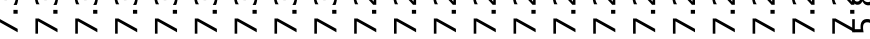

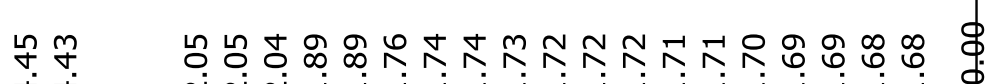

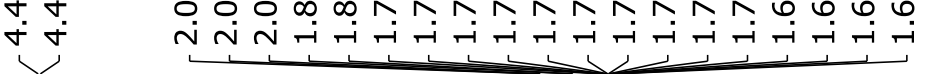

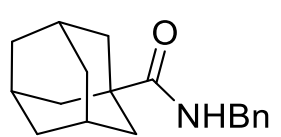

$3 e$

${ }^{1} \mathrm{H}$ NMR $\left(500 \mathrm{MHz}, \mathrm{CDCl}_{3}\right)$

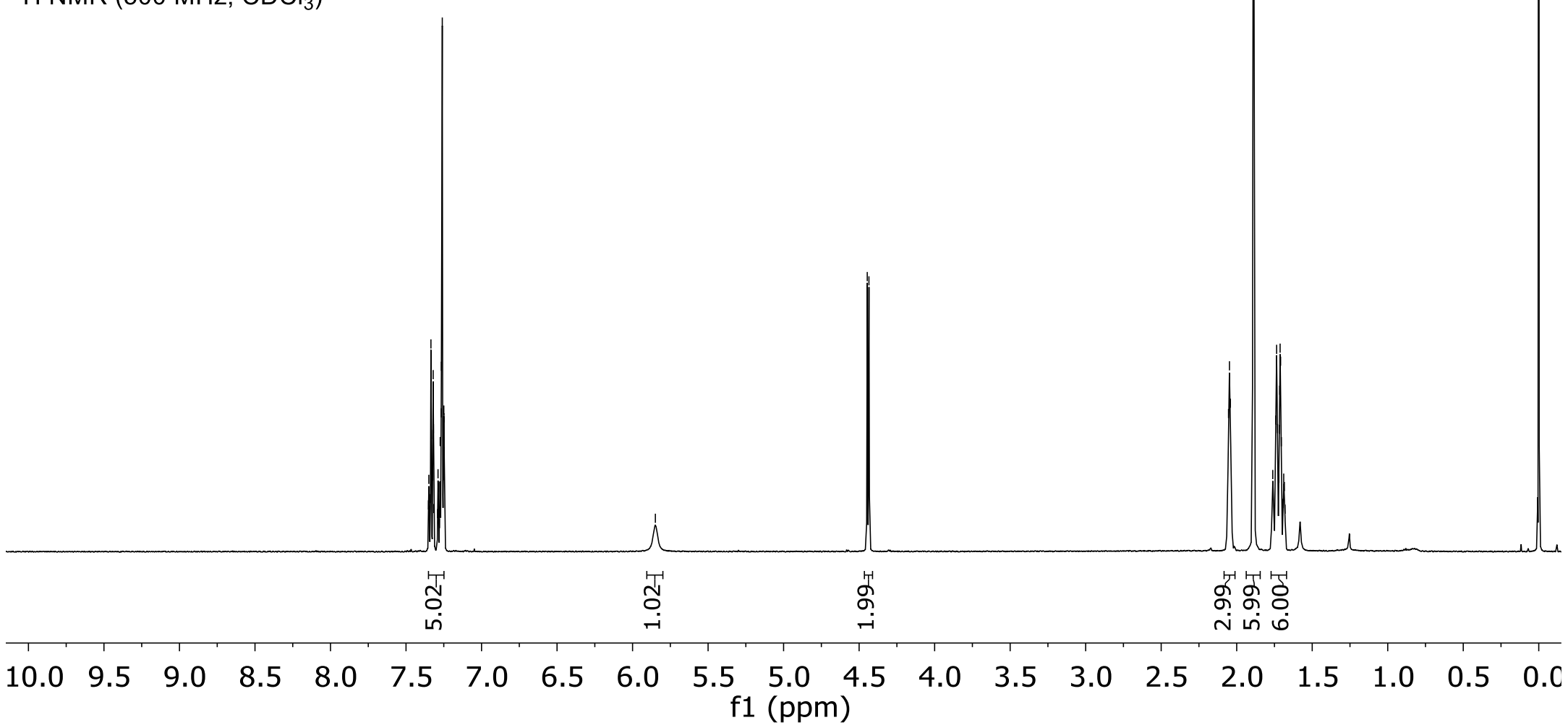


$\frac{m}{\mathrm{i}}$

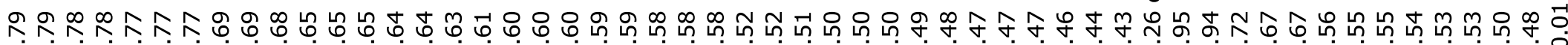

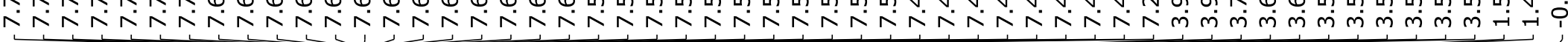

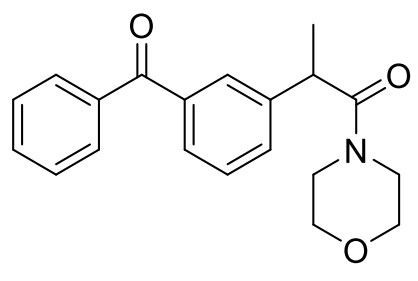

$3 f$

${ }^{1} \mathrm{H}$ NMR $\left(500 \mathrm{MHz}, \mathrm{CDCl}_{3}\right)$

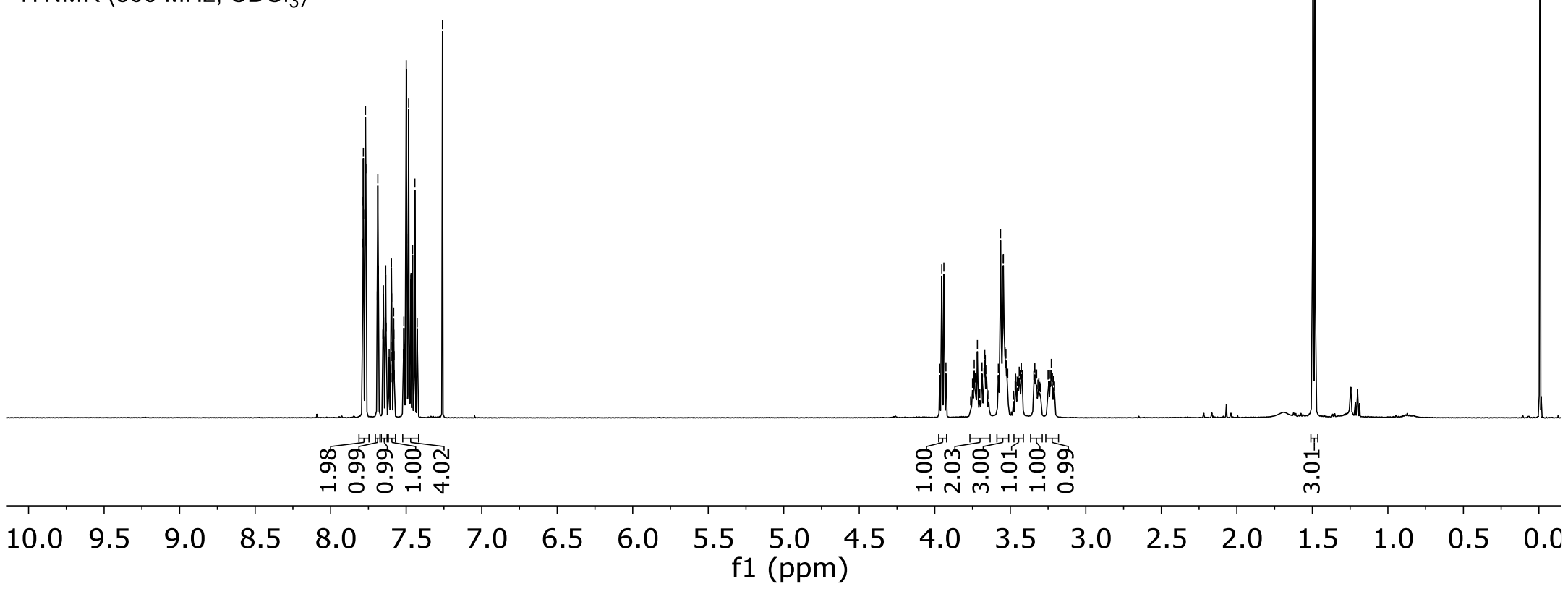


0
$\stackrel{0}{\sigma}$
$\stackrel{7}{\mid}$

$m$ ก เ $\infty$ ก

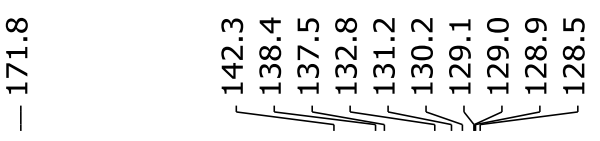

$\frac{m}{\mathrm{u}} \frac{m}{\mathrm{v}} \frac{\mathrm{m}}{\mathrm{v}} \mathrm{i}$

+.

ヘペ்

ำ

dit 2

年年

$\stackrel{\circ}{\stackrel{0}{1}}$

$\overrightarrow{0}$

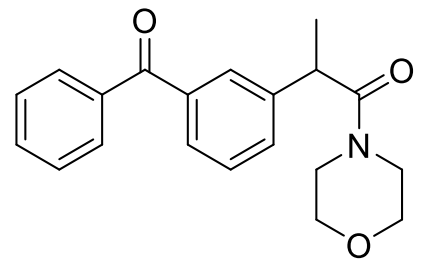

$3 f$

${ }^{13} \mathrm{C}$ NMR $\left(126 \mathrm{MHz}, \mathrm{CDCl}_{3}\right)$

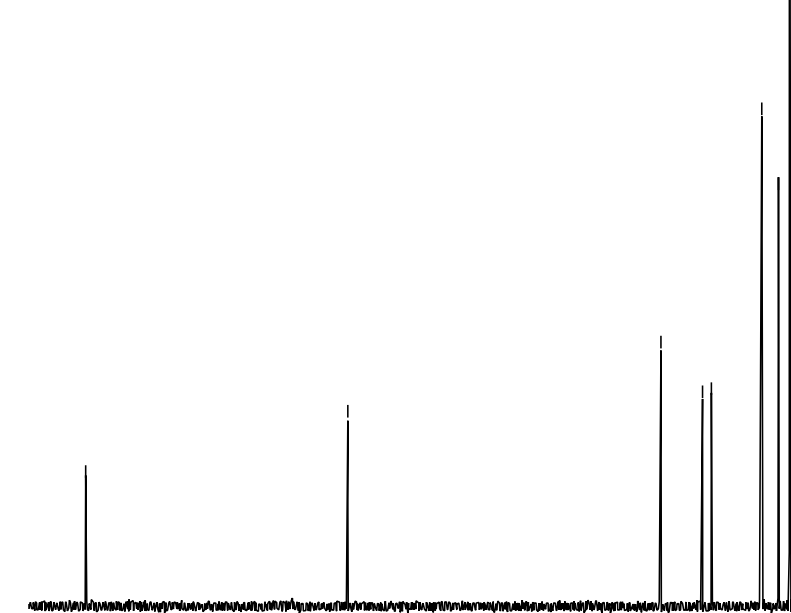

$\begin{array}{llllllll}200 & 190 & 180 & 170 & 160 & 150 & 140 & 130\end{array}$

120

$\begin{array}{lll}110 & 100 & 90\end{array}$

f1 (ppm)

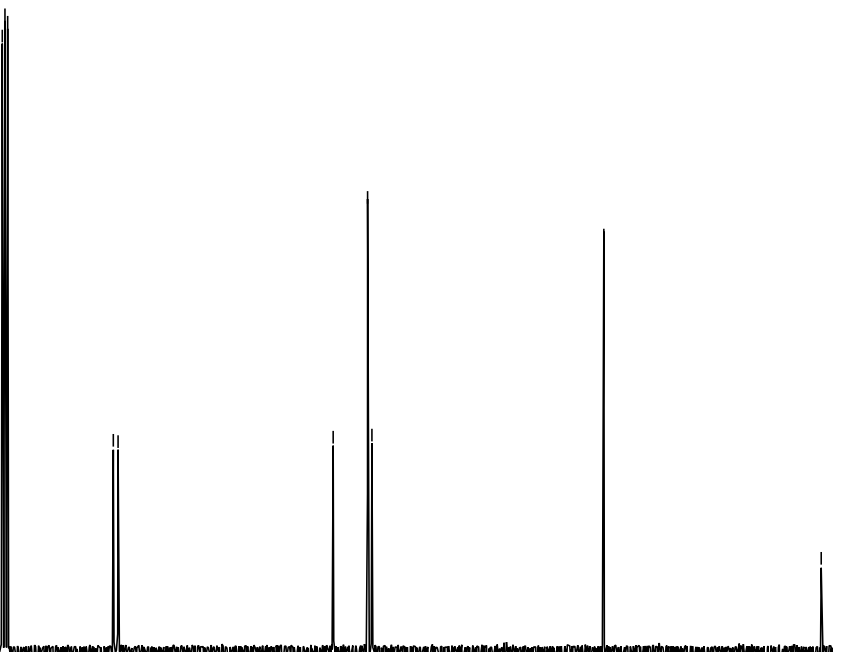

SI-64 